
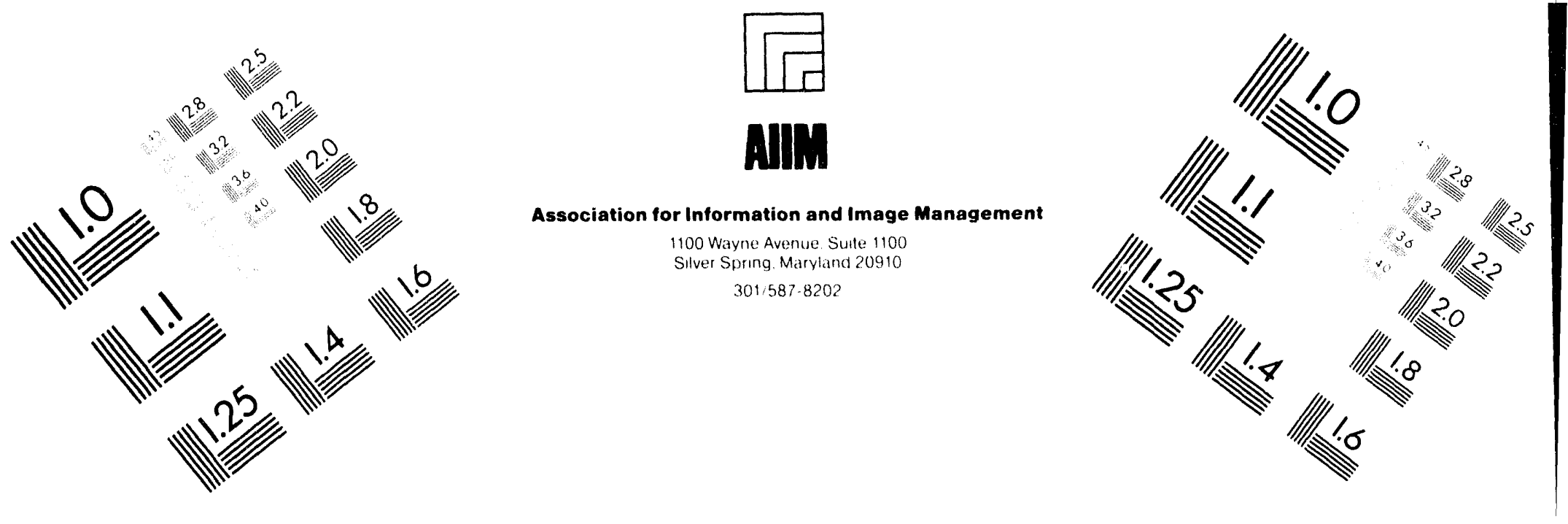

\title{
Centimeter
}

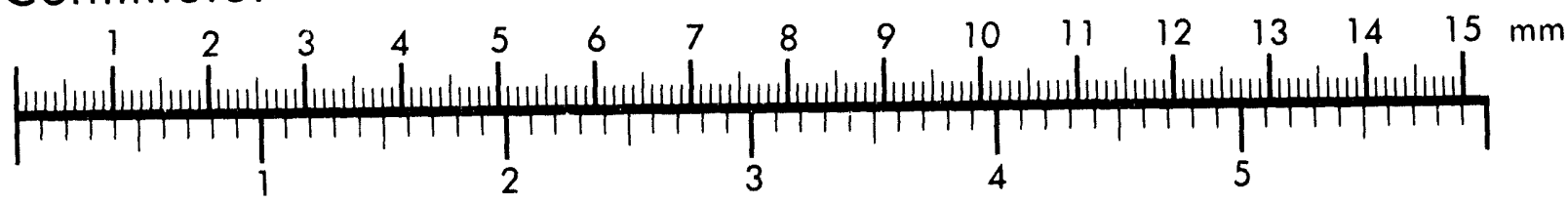

Inches
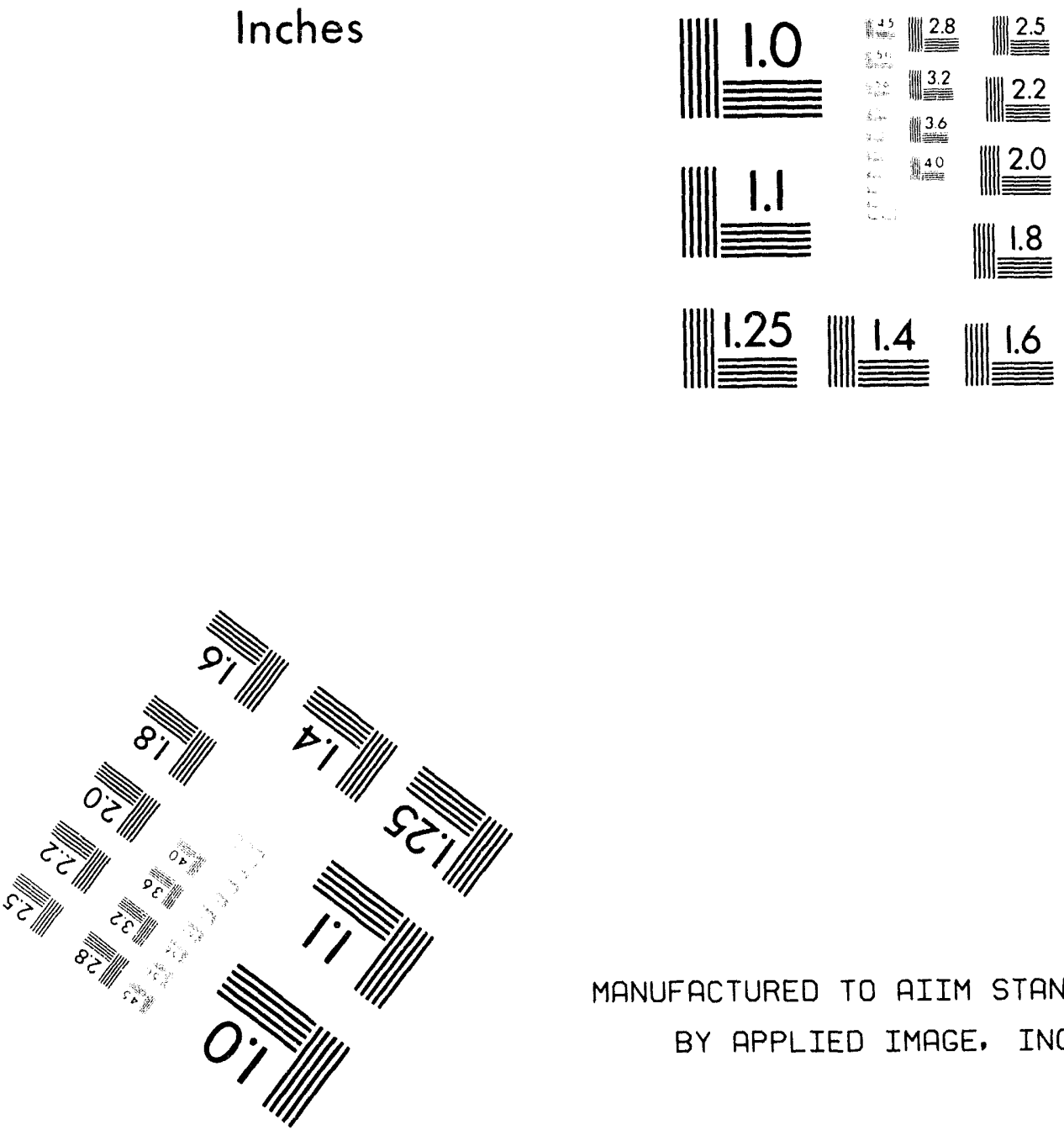

MANUFACTURED TO AIIM STANDARDS

BY APPLIED IMAGE. INC.

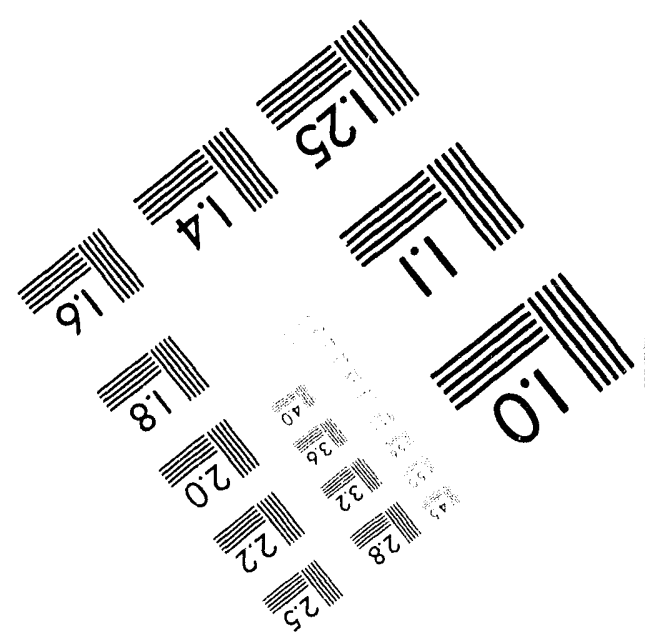



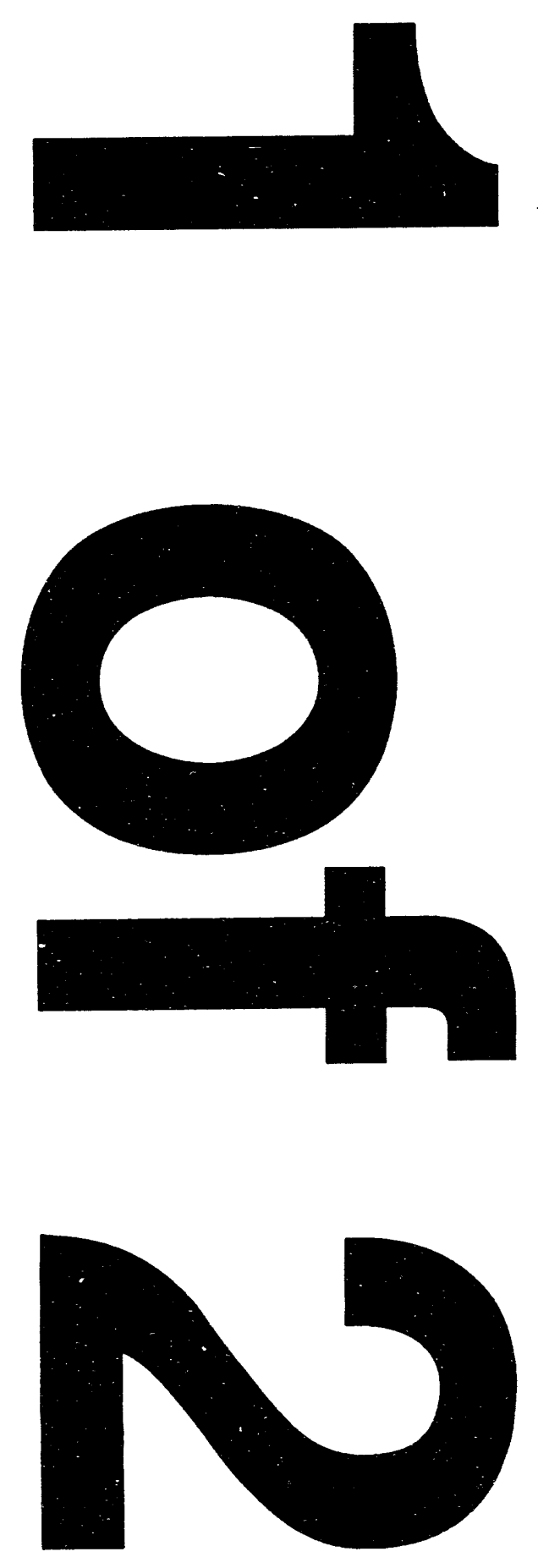


\section{Questions and Answers Based on Revised 10 CFR Part 20}

Manuscript Completed: April 1994

Date Published: May 1994

Prepared by

T. Borges, R. S. Stafford, P. Y. Lu, Oak Ridge National Laboratory

D. Carter, U.S. Nuclear Regulatory Commission

Oak Ridge National Laboratory

Operated by Martin Marietta Energy Systems, Inc.

Oak Ridge National Laboratory

Oak Ridge, TN 37831-6050

\section{Prepared for}

Division of Regulatory Applications

Office of Nuclear Regulatory Research

U.S. Nuclear Regulatory Commission

Washington, DC 20555-0001

NRC FIN L2416

Under Contract No. DE-AC05-840R21400 


\begin{abstract}
NUREG/CR-6204 is a collection of questions and answers that were originally issued in seven sets and which pertain to revised 10 CFR Part 20. The questions came from both outside and within the NRC. The answers were compiled and provided by NRC staff within the offices of Nuclear Reactor Regulation, Nuclear Material Safety and Safeguards, Nuclear Regulatory Research, the Office of State Programs, and the five regional offices. Although all of the questions and answers have been reviewed by attorneys in the NRC Office of the General Counsel, they do not constitute official legal interpretations relevant to revised 10 CFR Part 20. The questions and answers do, however, reflect NRC staff decisions and technical opinions on aspects of the revised 10 CFR Part 20 regulatory requirements. This NUREG is being made available to encourage communication among the public, industry, and NRC staff concerning the major revisions of the NRC's standards for protection against radiation.
\end{abstract}




\section{TABLE OF CONTENTS}

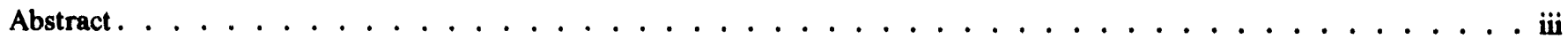

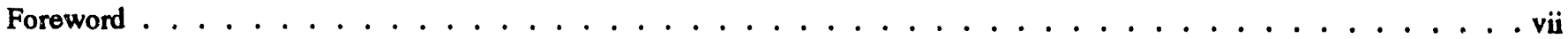

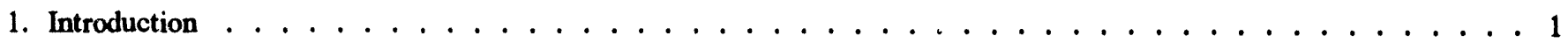

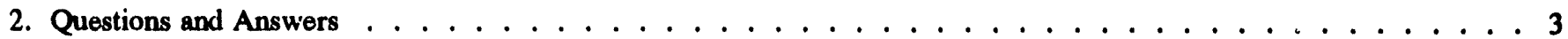

2.1 Subpart A - General Provisions .......................... 3

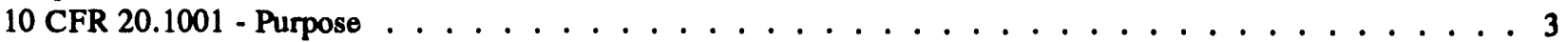

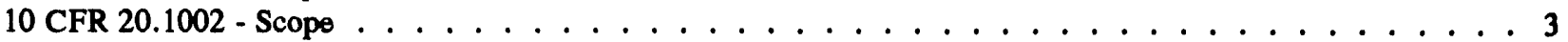

10 CFR 20.1003 - Definitions . . . . . . . . . . . . . . . . . . . . . . 3

10 CFR 20.1004 - Units of Radiation Dose . . . . . . . . . . . . . . . . . . . . . 11

10 CFR 20.1008 - Implementation . . . . . . . . . . . . . . . . . . . . . . . 11

2.2 Subpart B - Radiation Protection Programs . . . . . . . . . . . . . . . . . . . . . . . . . . . 12

10 CFR 20.1101 - Radiation Protection Programs . . . . . . . . . . . . . . . . . . . . . 12

2.3 Subpart C - Occupational Dose Limits . . . . . . . . . . . . . . . . . . . . . . . . . . . . . . 14

10 CFR 20.1201 - Occupational Dose Limits for Adults. . . . . . . . . . . . . . . . . . . . . . . . 14

10 CFR 20.1202 - Compliance with the Requirements for Summation of External and Internal Doses. . . . . . . 19

10 CFR 20.1203 - Determination of External Dose from Airborne Radioactive Material . . . . . . . . . . . . 20

10 CFR 20.1204 - Determination of Internal Exposure . . . . . . . . . . . . . . . . . . . . 20

10 CFR 20.1206 - Planned Special Exposures . . . . . . . . . . . . . . . . . . . . 22

10 CFR 20.1208 - Dose to an Embryo/Fetus. . . . . . . . . . . . . . . . . . . . . . . . . . . . 24

2.4 Subpart D - Radiation Dose Limits for Individual Members of the Public . . . . . . . . . . . . . . . . . 26

10 CFR 20.1301 - Dose Limits for Individual Members of the Public . . . . . . . . . . . . . . . . . . 26

10 CFR 20.1302 - Compliance with Dose Limits for Individual Members of the Public . . . . . . . . . . . . 29

2.5 Subpart $\mathrm{F}$ - Surveys and Monitoring . . . . . . . . . . . . . . . . . . . 32

10 CFR 20.1501 - Surveys and Monitoring-General . . . . . . . . . . . . . . . . . . . 32

10 CFR 20.1502 - Conditions Requiring Individual Monitoring of Internal and External

Occupational Dose . . . . . . . . . . . . . . . . . . . . . . 32

2.6 Subpart G - Control of Exposure from External Sources in Restricted Areas. . . . . . . . . . . . . . . . . 38

10 CFR 20.1601 - Control of Access to High Radiation Areas . . . . . . . . . . . . . . . . . . . . . . 38

10 CFR 20.1602 - Control of Access to Very High Radiation Areas . . . . . . . . . . . . . . . . . 40

10 CFR 20.1603 - Control of Access to Very High Radiation Areas-Irradiators . . . . . . . . . . . . 41

2.7 Subpart H - Respiratory Protection and Controls to Restrict Internal

Exposure in Restricted Areas . . . . . . . . . . . . . . . . . . . . . . . . 42

10 CFR 20.1701 - Use of Process or Other Engineering Controls . . . . . . . . . . . . . . . . 42

10 CFR 20.1702 - Use of Other Controls . . . . . . . . . . . . . . . . . . . . . . . 42

10 CFR 20.1703 - Use of Individual Respiratory Protection Equipment . . . . . . . . . . . . . . . . 44

2.8 Subpart I - Storage and Control of Licensed Material . . . . . . . . . . . . . . . . . . . 46

10 CFR 20.1801 - Security of Stored Material . . . . . . . . . . . . . . . . . . . . . 46

2.9 Subpart J - Precautionary Procedures . . . . . . . . . . . . . . . . . . . . . . . . . . . . . 47

10 CFR 20.1902 - Posting Requirements . . . . . . . . . . . . . . . . . . . . . . . 47

10 CFR 20.1903 - Exceptions to Posting Requirements . . . . . . . . . . . . . . . . . . . . . . 49

10 CFR 20.1904 - Labeling Containers . . . . . . . . . . . . . . . . . . . . . . . . . . . 50

10 CFR 20.1906 - Procedures for Receiving and Opening Packages . . . . . . . . . . . . . . . . 50

2.10 Subpart K - Waste Disposal . . . . . . . . . . . . . . . . . . . . . . 52

10 CFR 20.2001 - Waste Disposal - General. . . . . . . . . . . . . . . . . . . . . 52

10 CFR 20.2003 - Disposal by Release into Sanitary Sewerage . . . . . . . . . . . . . . 53 
2.11 Subpart $L-$ Records . . . . . . . . . . . . . . . . . . . . . . . . 54

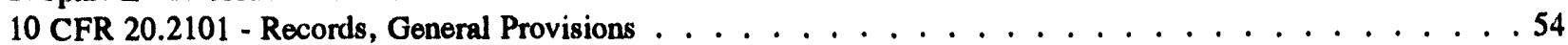

10 CFR 20.2104 - Determination of Prior Occupational Dose . . . . . . . . . . . . . . . . . 54

10 CFR 20.2105 - Records of Planned Special Exposures _ . . . . . . . . . . . . . . . 57

10 CFR 20.2106 - Records of Individual Monitoring Results . . . . . . . . . . . . . . . 57

10 CFR 20.2107 - Records of Dose to Individual Members of the Public . . . . . . . . . . . . . . 59

10 CFR 20.2110 - Form of Records . . . . . . . . . . . . . . . . . . . . 60

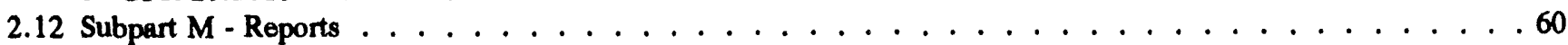

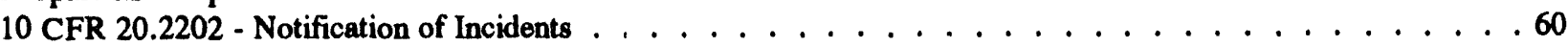

10 CFR 20.2203 - Reports of Exposures, Radiation Levels, Etc. . . . . . . . . . . . . . . . . . . . .60

10 CFR 20.2206 - Reports of Individual Monitoring . . . . . . . . . . . . . . . . . 60

2.1310 CFR 20 Appendices . . . . . . . . . . . . . . . . . . . . . . 62

10 CFR Part 20 Appendix A. . . . . . . . . . . . . . . . . . . 62

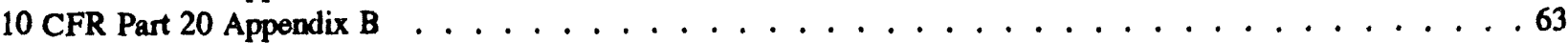

2.1410 CFR 19 - Notices, Instructions, and Reports to Workers: Inspection and lnvestigations . . . . . . . . 65

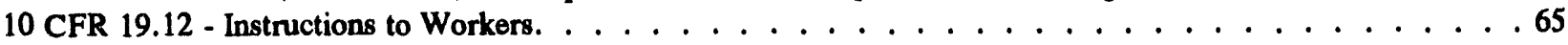

10 CFR 19.13 - Notification and Reports to Individuals . . . . . . . . . . . . . . . . 66

2.1510 CFR 50 - Domestic Licensing of Production and Utilization Facilities . . . . . . . . . . . . . . .68

10 CFR Part $50 \ldots \ldots \ldots \ldots \ldots$

2.16 Regulatory Guides . . . . . . . . . . . . . . . . . . . . . . . . . . . . . 69

Regulatory Guides - General . . . . . . . . . . . . . . . . . . . . . . . . . . 69

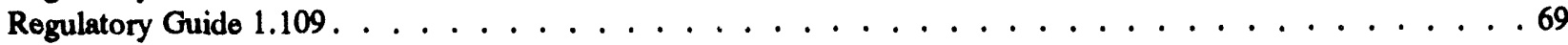

Regulatory Guide $8.25 \ldots \ldots$

Regulatory Guide $8.36 \ldots \ldots$. . . . . . . . . . . . . . . . . . . . . . . . 69

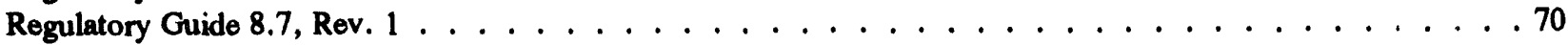

2.17 Technical Specifications. . . . . . . . . . . . . . . . . . . . . . . . 70

Reactor Technical Specifications . . . . . . . . . . . . . . . . . . . . . . . 70

Power Reactor Technical Specifications and Materials Licenses . . . . . . . . . . . . . . . . . 71

2.18 Other Questions . . . . . . . . . . . . . . . . . . . . . . . . . 72

Appendix A - Numerical List of Questions and Answers . . . . . . . . . . . . . . . . 75

Appendix B - Regulatory References Cited in Text . . . . . . . . . . . . . . . . . . . 89

Appendix C - Questions and Answers by Regulatory Reference . . . . . . . . . . . . . . . . . . 93 


\section{FOREWORD}

This report contains questions and answers concerning the major revision of 10 CFR Part 20 (10 CFR Part 20 Sections 20.1001 20.2402) and its implementation. The questions and answers in this report have been available to the public previously as seven separate consecutive sets of questions and answers in the NRC Public Document Room; however, this report makes all of the questions and answers from the seven separate documents available in a single, more convenient, form. (The NRC staff expects to prepare, and make publicly available, additional questions and answers on this subject as questions arise during the implementation of the revised 10 CFR Part 20.)

These questions and answers were compiled by the NRC headquarters radiation protection staff primarily for use in training NRC regional inspection staff members. As each set of question and answers was completed, it was made publicly available for information of interested individuals and organizations and to encourage communications between the public and the NRC staff concerning this major revision of the NRC's standards for protection against radiation.

The questions were provided by individuals and organizations outside the NRC and by NRC staff members. Answers to these questions have been prepared and reviewed by NRC staff members in the NRC Offices of Nuclear Reactor Regulation (NRR), Nuclear Material Safety and Safeguards (NMSS), Nuclear Regulatory Research (RES), Office of State Programs (OSP), and the five NRC Regional Offices. The questions and answers also have been reviewed by attomeys in the NRC Office of the General Counsel.

The questions and answers in this report are NRC staff positions on NRC regulatory requirements and guidance for radiation protection (health physics). Therefore, these questions and answers are "health physics positions" as this term is defined in NRC report number NUREG/CR-5569 Rev. 1, Health Physics Positions Database, February 1994. Because all of the questions in this report concern the new revision of 10 CFR Part 20 and related requirements, they have been compiled as a separate data base rather than combining them with other health physics positions in a single data base. Consideration will be given in the future to consolidating the two data bases. Users of these data bases are invited to comment on the desirability of this potential consolidation.

On February 3, 1994, the NRC published a notice of proposed rulemaking (59 FR 5132) that would amend 10 CFR Parts 19 and 20. This proposed rule would: (1) delete the definition of "controlled area" to make it clear that any area to which access is restricted for the purpose of radiological protection is a "restricted area" as defined in the regulation, (2) revise the definition of "occupational dose" to delete reference to the "restricted area, " (3) revise the definition of "unrestricted area" to be consistent with the deletion of the controlled area, (4) revise the provision entitled "Instructions to Workers," so that radiation protection training will be provided to all persons with the potential to be occupationally exposed and (5) restore a provision to Part 20 that whenever licensees are required to report exposures of individual members of the public to the NRC, then those individuals are to receive copies of the report. These proposed amendments, if issued in final form, would result in changes to the following (and possibly other) questions and answers:

$\begin{array}{llll}\text { Section } & \text { Question Numbers } & \text { Section } & \text { Question Numbers } \\ & & & \\ 10 \text { CFR 19.12 } & \# 95, \# 411, \# 422 & 10 \text { CFR 20.1301 } & \# 106, \# 203, \# 206, \# 384 \\ 10 \text { CFR 20.1003 } & \# 25, \# 26, \# 66, \# 67, \# 80, \# 94, & 10 \text { CFR 20.1302 } & \# 28, \# 29, \# 104, \# 417 \\ & \# 119, \# 148, \# 412, \# 413 & 10 \text { CFR 20.1502 } & \# 82, \# 126, \# 213, \# 429, \# 444 \\ 10 \text { CFR 20.1201 } & \# 31, \# 33, \# 34, \# 77 & 10 \text { CFR 20.1801 } & \# 129, \# 419, \# 450 \\ 10 \text { CFR 20.1206 } & \# 136 & 10 \text { CFR 20.1902 } & \# 27, \# 53 \\ 10 \text { CFR 20.1208 } & \# 442 & 10 \text { CFR 20.2107 } & \# 391\end{array}$


Foreword

The answers to questions in this report do not constitute official legal interpretations, which can only be provided by the General Counsel, and they do not reflect official NRC policy as approved by the Commission. The answers do reflect NRC staff decisions and technical opinions on specific aspects of regulatory requirements.

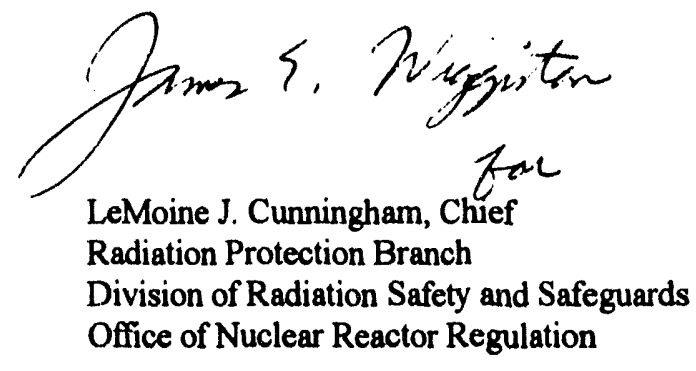




\section{INTRODUCTION}

This report contains questions asked by indivicuals outside the NRC concerning the implementation, relevance, and applicability of the revised 10 CFR Part 20 . Other questions and answers in this report were developed by the NRC to further explain the revised regulations. The answers to the questions have been provided by NRC staff members within the offices of Nuclear Reactor Regulation, Nuclear Material Safety and Safeguards, Nuclear Regulatory Research, Office of State Programs, and the five regional offices.

This report is the unedited contents of the original seven question and answers sets. These were placed in the NRC Public Document Room identified by their dates of issuance and NRC accession numbers as shown below. The accession numbers are used by NRC staff to retrieve the original documents from the NUDOCS system and by members of the public to obtain copies from the NRC Public Document Room.

$\begin{array}{lll}\text { Set } & \text { Date Issued } & \text { PDR Number } \\ \text { First } & 12 / 06 / 91 & \text { PDR-9112190258 } \\ \text { Second } & 04 / 17 / 92 & \text { PDR-9205010117 } \\ \text { Third } & 07 / 23 / 92 & \text { PDR-9207300261 } \\ \text { Fourth } & 09 / 14 / 92 & \text { PDR-9209230012 } \\ \text { Fifth } & 06 / 08 / 93 & \text { PDR-9306110303 } \\ \text { Sixth } & 09 / 28 / 93 & \text { PDR-9310070005 } \\ \text { Seven } & 10 / 29 / 93 & \text { PDR-9311050284 }\end{array}$

The NRC public document room can be contacted for copies of the individual question and answer sets at the following address and phone number:

- Write: U.S. Nuclear Regulatory Commission Public Document Room 2120 L Street, N.W.

Room LL6

Washington, DC 20013-7082

- Telephone: (202) 634-3273

- FAX: (202) 634-3343

Each question included in this report was assigned a unique number for identification purposes, but not necessarily in numerical order. It must be noted, however, that the numbers were not all inclusive. Many of the question numbers, particularly those in the range 151 - 370, were not used, whereas others were deleted prior to the release of the question and answer sets. In Appendix $A$ of this report, a numerical listing of the questions and answers, the question and answer set in which it was issued, and the most relevant section under which it appeared are given. Appendix B of this report contains a listing of the of the regulatory references cited in this report. These inchude 10 CFR Part 19, revised 10 CFR Part 20, 10 CFR Part 34, 10 CFR Part 50, NUREG documents, Regulatory Guides, and others. In Appendix C of the report, all questions and answers that pertain to a particular regulatory reference are listed.

Each question and answer appears under the section of the revised 10 CFR Part 20 to which it is most closely related. The sections of revised 10 CFR Part 20 are in turn arranged in order of their appearance in the revised code of federal regulations. Following the $10 \mathrm{CFR}$ Part 20 sections are questions and answers relating to 10 CFR Part 19, 10 CFR Part 50, regulatory guides, technical specifications, and other topics. Unless otherwise indicated, references to the Federal Register refer to a page number in the May 21, 1991 edition. This edition contained the major revision of 10 CFR Part 20 as a final rule on pages 23360-23474. The questions and answers in this compilation inchude corrections that were issued with question and answer sets 2-7, inclusive, and other corrections of typographical errors.

With issuance by the U. S. Department of Energy (DOE) of the U.S. DOE Radiological Control Manual (DOE/EH0256T) in June 1992, the committed effective dose equivalent (rather than the "annual effective dose equivalent") is used by DOE to assign internal dose received by personnel at DOE facilities. This information updates the information previously provided in the answer to Questions 76 and 83 (under 10 CFR 20.1204) and to Question 113 (under 10 CFR 20.2104).

10 CFR 20.1603, "Control of Access to Very High Radiation Areas - Irradiators," which is the subject of question 130, was deleted from Part 20 effective 7/1/93. 


\section{QUESTIONS AND ANSWERS}

\subsection{SUBPART A - GENERAL PROVISIONS}

\section{CFR 20.1001 - Purpose}

Question 407: (a) Does Part 20 apply to emergency response personnel such as city fire fighters? (b) If Part 20 does apply, would the radiation dose received by the workers be considered to be an occupational dose or a public dose?

Answer: (a) No. As stated in 10 CFR 20.1001, "Purpose, " Part 20 applies to activities conducted under licenses issued by the NRC. Emergency response activities such as fire fighting by employees of a city fire department are not conducted under a license issued by the NRC (even when the fire being fought is in a facility of an NRC licensee). Furthermore, as stated in 10 CFR 21.1001, nothing in Part 20 shall be construed as limiting actions to protect health and safety. Thus, Part 20 does not apply to emergency response activities and workers such as fire fighting by employees of a city fire department.

For NRC licensees, it is the Commission's intent that the regulations be observed to the extent practicable during emergencies, but that conformance with the regulations should not hinder any actions that are necessary to protect public health and safety such as lifesaving or maintaining confinement of radioactive materials (56 FR 23365). Also, for nuclear power reactor licensees, a different part of the regulations, 10 CFR Part 50, includes a requirement, in 10 CFR 50.47(b)(11), that the offsite emergency response plans must inchude means for controlling radiological exposure of emergency workers in an emergency. (Referenco: 10 CFR 20.1001)

\section{CFR 20.1002 - Scope}

Question 5: Who is responsible for regulating radium - the State or NRC?

Answer: The NRC regulates radium when it is in NRC. licensed uranium or thorium ores (source material, as defined in Part 20) or in tailings or wastes from processing these ores (byproduct material, as defined in Part 20). The control of radium that may be incidental to NRC-licensed operations is evaluated by NRC as required by NEPA. Releases of radium from a site, other than from NRClicensed material (ores or tailings), may be required to meet State release limits. Also, an NRC licensee may be required to get a State license for the radium in naturally-occurring radioactive material (NORM) if the State requires a license for the use and possession of this material. (References: 10 CFR $20.1001,10$ CFR 20.1002, 10 CFR 20.1003)

\section{CFR 20.1003 - Definitions}

Question 1: If a licensee decides to implement Part 20 in mid-year, how does the licensee treat the annual dose limits? Prorated? Add contributions from beginning of year before the revised Part 20 was adopted?

Answer: The licensee must define the "year" consistent with the definition in 10 CFR 20.1003. If a licensee intends to implement the revised Part 20 at any time other than the beginning of the year, the licensee must subtract the dose received for the current year prior to the revised Part 20 dose being adopted from the revised Part 20 dose limit. The difference need not be prorated. For example, assume a licensee adopts the revised Part 20 on July 1, 1992, and defines its dose year as January 1 - December 31 . If the worker had received 1.5 rems between January 1 and June 30,1992 , he or she would have $(5-1.5)=3.5$ rems available for the remainder of the year. If the worker already has more than 5 rem (e.g., two 3-rem quarters), the licensee must shift the worker to tasks in which the worker will receive no occupational radiation exposure. (Reference: 10 CFR 20.1003)

Question 4: How is the dose from radon considered? What about technologically enhanced radon at a licensed facility? [Note: Technologically enhanced natural radiation sources have been defined as "truly natural sources of radiation ... which would not occur without (or would be increased by) some technological activity not expressly designed to produce radiation." Reference: T.F. Gesell and H.M. Prichard, Health Physics 28, 361-366, April 1975.]

Answer: How the dose from radon is treated depends upon the source of the radon. If the source is NRC-licensed material such as mill tailings or ores, then the dose from 
radon and its particulate daughters should be included in estimates of doses to workers or to members of the general public (except for 40 CFR Part 190 evaluations which exclude radon). If the source of the radon is from radium that is not licensed or controlled by any agency, then the dose from radon and its daughters is considered background radiation and may bo excluded from occupational or public dose estimates, whether there is any technological enhancement of the concentrations or not. Many states are working toward licensing cortain materials containing radium and these sources will need to be known to licensees even if they are not the persons licensed by the States. (See definitions of "background radiation," "source material," and "byproduct material" in $10 \mathrm{CFR}$ 20.1003). (References: $10 \mathrm{CFR}$ 20.1001, 10 CFR 20.1002, 10 CFR 20.1003)

Question 25: Does the definition of a "member of the public" mean "all" individuals? If so why is the exception statement added to the definition?

Answer: No. A particular individual can be a "member of the public" at some times and not at others. For example, an indivicual who works at a nuclear power plant and receives an "occupational dose" is not a member of the public while at work, but is a "member of the public" during offhours at home. (Reforence: 10 CFR 20.1003)

Question 26(a): There has been some confusion about the revised Part 20 requirements with respect to controlled areas and when individuals are recoiving a public or an occupational dose. Before asking questions involving specific exposure scenarios (in parts b, $c$, and d of this question), does the NRC staff have any general guidance on these topics?

Answer: Anyone attempting to answer questions about which dose limits apply in a particular situation should be familiar with the requirements of 10 CFR 20.1201, 10 CFR 20.1207, 10 CFR 20.1208, and 10 CFR 20.1301, and with the definitions of the following terms in 10 CFR 20.1003: occupational dose, public dose, member of the public, restricted area, controlled area, and unrestricted area.

\section{Qccupationn Doseres. Public.Dose}

By definition, and with the exceptions given in the definitions of "occupational dose", any dose received by any individual in a "restricted area" is an "occupational dose." No one in a restricted area is a "member of the public." Outside "restricted areas" (i.e., in "controlled areas" or in "unrestricted areas"), whether the dose to an indivichual is an "occupational dose" or a "public dose" depends on whether the dose recoived by the indivictual is (as specified in the definition of "occupational dose") a dose received "in the course of employment in which the individual's assigned duties involve exposure to radiation and to radioactive material from licensed and unlicensed sources of radiation, whether in the possession of the licensee or other person." In other words, outside "restricted areas", whether the dose to an individual is an "occupational dose" or a "public dose" (and whether the occupational dose limits or the public dose limits apply to the individual) depends on what the individual is doing and not on what area (controlled or unrestricted area) the individual is in when the dose is received.

Different understandings of the meaning of the second part of the definition of "occupational dose" (which begins ". . or in the course of employment ... .") has been a source of much of the confusion with respect to applicable dose limits. Generally, this part of the definition does not mean that any dose received by an individual while working, regardless of the type of work, is an "occupational dose." Doses received by an individual while working outside a restricted area (in a controlled or unrestricted area) usually would be categorized as public dose when the dose received is within the public dose limit (and is not likely to exceed that limit) and the work being done is not closely connected (i.e., is only casually connected) to the licensed activity.

\section{Licensee Discretion}

The regulations (revised Part 20) allow licensees a certain amount of discretion in developing a radiation protection program that is suitable and practical to implement at the licensee's location and for the licensee's particular set of working conditions. For example, licensees are permitted by the regulations to select the boundaries for restricted areas and controlled areas. (Because licensees are not required by 10 CFR Part 20 to have controlled areas they may choose whether or not to have controlled areas.) When an individual is to work in a controlled area or an unrestricted area, the licensee should evaluate the individual's assigned duties and determine whether a dose would be categorized as a public dose or an occupational dose in accordance with the definitions of these terms in 10 CFR 20.1003.

The following criteria that include both regulatory requirements and basic radiation protection philosophy will be used in the NRC inspection program.

\section{Restricted Area}

- When an area satisfies both the definition of a restricted area in Part 20 and the definition of a protected area in Part 73, it is considered to be a restricted area for purposes of compliance with 10 CFR Part ?0. 
- Boundaries of stétricted areas may be selected by licensees but being selected, they should be documented (recorded) (good practice).

- Access to restricted areas must be controlled, e.g., by barriers, signs, or guards (\$20.1003). Note: Areas that can have personnel access controlled but that are not being cortrolled (0.8., because the radiation source has been removed) are not restricted areas.

- Posting of a restricted area as a restricted area is not required although other posting may be required within the area (820.1902).

- Doses recoived by all individuals in restricted areas are occupational doses (\$20.1003).

- Individuals working in or frequenting a restricted area must be provided training, as appropriate (\$19.12).

- Individuals ontering a restricted area must be informed that thoy are subject to occupational dose limits.

- Bffort must be mado to maintain all doses ALARA (820.1101).

- A decision must be made as to whether monitoring is required (\$20.1502).

\section{Contmlled Amen}

- Controlled areas are not required (\$20.1003).

- As indicated in tho preceding section, an area that satiofies both the definition of a restricted area and the definition of a controlled area is considered to be a restricted area for purposes of compliance with 10 CFR Part 20.

- Boundaries of controlled areas may bo selected by licensees but should be documented (recorded) (good practice).

- Posting of a controlled area as a controlled area is not required (\$20.1902).

- Doses received in controlled areas may be occupational doses or public doses. Generally doses will be public doses except when the licensee determines that an individual receives exposure to radiation "in the course of employment . . . ." [\$20.1003, 8820.1301(b)].
- Doses are to be categorized as public doses (i.e., public dose limits apply) whenever reasonable and practical (good practice) (except for occupational doses).

- In determining whether an individual in a controlled area is to be categorized as an individual who receives an occupational dose or as a member of the general public, the more difficult decisions concern individuals who may be occasionally exposed or whose assigned duties are not closely connected to the licensed activity. Such individuals inchude messengers, delivery men and women, custodial workers, secretaries, clerical workers, hospital volunteers, etc. Usually, such individuals are considered to be members of the public and the doses they receive are well within the limits for members of the public. However, if the assigned duties of these individuals are closely and frequently connected to the licensed activity, and their doses may approach or exceed the limits for members of the public, the doses such individuals receive are better treated as occupational doses.

- Only wher doses are to be categorized as occupational doses (i.e., occupational dose limits apply) do the following conditions apply:

- A decision must be made as to whether monitoring is required (\$20.1502).

- The licensee should have the ability to exercise positive control over the indivicual's activities in the controlled area.

- The licensee should provide appropriate instructions.

- The licensee should inform the individual that he/she is subject to occupational dose limits rather than public dose limits ( 819.12 -this is an implied requirement).

\section{Individual Members of the Public}

- Individuals in controlled areas and unrestricted areas are members of the public unless they are receiving an occupational dose (\$20.1003 \& \$20.1301).

- Licensees should apply lower dose limits (public dose limits) to non-workers whenever possible and reasonable (good practice).

- An individual is not a member of the public when they enter a restricted area (\$20.1003). 
- Effort must be made to achieve doses that are ALARA (820.1101).

Question 26 (b): Do occupational dose limits or public dose limits apply to the doses received by the individuals described in the following scenarios for nuclear power plants?

1. Assume an indivichual employed by a licenseo working at a two-unit site (one nuclear plant and one fossil plant) is permanently employed at the fossil plant, which is inside the nuclear plant's controlled area. The individual does not enter any restricted areas. What dose limits apply to that indivicual while working at the fossil plant?

2. What dose limits apply to a pregnant taxi driver while she is picking up and discharging passengers within the controlled area (outside the restricted arenj of nuclear power plant?

3. What dose limits apply (a) to construction $w$ irkers who are building a second nuclear power plant within the controlled aren (outside the restricted area) of the first nuclear power plant at that site and (b) to secretaries in the administrative building within the controlled area (outside the restricted area)?

Answer: For scenarios $\# 1,2$, and 3, the dose limits for members of the public apply. However, if turbine shine from the nuclear plant is such that the individuals in scenarios \#1 (fossil plant workers) and \#3 (construction workers and secretaries) are likely to exceed the dose limits for members of the public, the licensee should consider the individual doses to be occupational doses and meet the requirements for individuals who receive occupational doses.

Question 26(c): Do occupational dose limits or public dose limits apply to the doses received by the individuals described in the following scenarios for a hospital?

A hospital has defined a controlled area as all areas within the main building. These areas can only be accessed by doors which open to the outside environment. In addition, they have designated the hot lab as a restricted area. The hot lab can only be accessed through the nuclear medicine department.

1. Individual $A$ is a maintenance worker. He is employed by the hospital and has been assigned to repair ventilation ducts in the nuclear medicine (NM) department. The job must be performed during normal work hours; patient procectures will not be rescheduled. The ducts are not used to ventilate the hot lab.

2. Individual B is an emergency room nurse employed by the hospital. On frequent occasions she accompanies patients to the nuclear medicine department for emergency lung scans.

3. Indivichual $\mathbf{C}$ is not employed by the hospital but visits the hospital on a weekly basis for the purpose of performing preventive maintenance on the gamma cameras. He froquently observes the nuclear medicine technologist during patient studies to verify equipment operation.

4. Indivicual D is employed by the hospital as a caretaker. During the summer he routinely cuts the grass outside the hospital. Note: The hot lab has at least one outside wall.

Answer: Occupational dose limits apply to individuals B (emergency room nurse) and C (who maintains gamma cameras). The assigned duties of individuals $B$ and $C$ are closely and frequently connected to the licensed activities. Limits for members of the public apply to Individuals $A$ (who repairs a ventilation duct) and D (caretaker who cuts grass). The assigned duties of Individuals A and D are only remotely (and, in the case of Indivichual A, infrequently), connected to the licensed activity and it is reasonable and practical to apply the public dose limits.

Question 26 (d): Do occupational doses limits or public dose limits apply to the doses received by the individuals described in the following scenarios for a radiography company?

A large radiography company performs radiography both in the field and in a hot cell within its plant. The hot cell is located in the delivery bay. The company shares its physical plant with an affiliated company. UPS deliveries for both companies come to the same bay area. The radiography company has defined its restricted area to be the hot cell and its controlled area to be the delivery bay.

1. Individual $\mathrm{E}$ is a secretary employed by the radiography company. Her desk, where she performs all administrative assignments, is located in the delivery bay, adjacent to the hot cell.

2. Individual $F$ is a data entry clerk at the affiliated company. He is employed by a temporary agency on a 12month assignment. He is responsible for picking up all UPS shipments (within the controlled area).

3. Individual $\mathbf{G}$ is a co-worker of Individual E. He frequently enters Individual E's office to use the telephone to 
make personal calls during the course of a normal work day.

Answer: Individual E (secretary): Assuming that the secretary's location near a hot cell is essential, the occupational dose limits apply.

Individual F (clerk): Limits for the general public apply. There is only a casual connection between the individual's assigned dutios and the licensed activity that results in the individual's exposure.

Individual G (co-worker): This individual is subject to the duse limits for a member of the general public. He has not entered a restricted area and his cussigned duties do not involve exposure to radiation and to radionctive material from licensed and unlicensed sources of radiation.

(Reference: 10 CFR 20.1003)

Question 40: Assume a licensee has defined its compliance year as January 1, 1993 to December 31, 1993. What is the mechanism to change its definition of year? For example, the licensee wants to monitor from Jamuary 31, 1994 to Jamuary 30, 1995, how should it account for the lost days Jamuary $1-30,1994$ ? Is it acceptable to prorate the doses?

Answer: No. The question refers to the definition of "year" in 10 CFR 20.1003. The licensee is not allowed to make the one-step change as postulated in the example in the question because that change involves omitting certain days. Omitting days, even with dose proration, is not allowed. However, the license could accomplish the desired change in two steps, one step in each of two consecutive years, that would give a "year" beginning 1/31 of one calendar year and ending 1/30 of the following year. The first step, using the example, would be a change, at the beginning of 1993, to a "year" of 1/1/93 to $1 / 30 / 94$ (13 months). The second step would be a change, at the beginning of 1994 , to a "year" of $1 / 31 / 94$ to $1 / 30 / 95$. This two-step change meets the requirement of "years" that begin in Jamuary with no day omitted or duplicated in consecutive years. (Reference: 10 CFR 20.1003)

Question 57: The definition of a very high radiation area (10 CFR 20.1003) and the requirement for control of access to very high radiation areas specify an absorbed dose of 500 rads in an hour. Is this a deep dose, a shallow dose, or an eye dose?

Answer: The 500-rad dose is intended to be a deep dose, evaluated at a tissue depth of $1 \mathrm{~cm}\left(1000 \mathrm{mg} / \mathrm{cm}^{2}\right)$.

(References: 10 CFR 20.1003, 10 CFR 20.1602)
Question 66: This question concerns restricted area limitations. At some sites for nuclear power plants the restricted area has been defined as the site boundary. In some areas routine public access was available with the understanding that, should the need arise, public use of these areas could be prohibited. Examples of this type of access include fishing, visitor centers, and farming. This type of use now appears to fall within the intent of the definition of controlled area and therefore, a new restricted area boundary located somewhat nearer the plant must be defined, in places where such uses exist.

The next physical boundary is a single fenced area, roughly corresponding to the security definition of owner controlled area. Station parking is routinely within this area and access is provided through openings in the single fence which are not continuously guarded. These openings are posted, "No Trespassing." The direct questions involved are:

a. Can this area (single fenced area) qualify as the restricted area boundary?

b. If so, are postings sufficient or would guands be required?

c. If posting is sufficient, what is the acceptable wording?

Answer:

a. Yes, access to this area could be limited so as to meet the definition of a restricted area. However, it should be recognized that the dose received by an individual in a restricted area is an occupational dose that is subject to the occupational dose limits in Subpart $\mathbf{C}$ of the revised Part 20 (or to the occupational dose limits of 10 CFR 20.101 in the old Part 20) and the requirements in 10 CFR 19.12 on instructions to workers. (See definitions of "restricted area" and "occupational dose.")

b. Although neither posting nor guards aro required specifically, access to a restricted area must, by definition, be controlled. In the situation described in the question, access control could be accomplished by posting or use of guards

c. Since posting is not specifically required (see b. above), the wording is left to the discretion of the licensee.

NOTR. This answer also applies to research and test reactors, fuel fabrication plants, and major radioactive materials processors insofar as the conditions described in the question for nuclear power plants apply to these other facilities. (References: 10 CFR 20.1003, 10 CFR 20.1201, 10 CFR 20.1206, 10 CFR 20.1207, 10 CFR 20.1208, 10 CFR 19.12) 
Question 67: This question concerns water approaches to nuclear sites. Several sites for nuclear power plants include portions of navigable lakes or rivers within their licensed exclusion areas. Obviously, the utility does not own these areas. Would such boundaries as defined in our licenses qualify as restricted areas, controlled areas, or unrestricted areas?

Answer: The licensee cannot limit access to navigable lakes or rivers that the licensee does not own; therefore, these bodies of water cannot be part of a restricted area or controlled area and must be considered to be unrestricted areas. However, for the dose calculations for airborne offluents that are required by reactor technical specifications and that are related to 10 CFR 50 Appendix I, doses are not required to be calculated over such bodies of water.

(Reference: 10 CFR 20.1003)

Question 74: Dose rates aro used to establish posting requirements for radiation areas, high radiation areas, and very high radiation areas. 10 CFR 20.1601(a)(1), "Control of Access to High Radiation Areas," refers to a "deep-dose equivalent" in describing when a control device should be provided to rechuce radiation doses below 0.1 rem in one hour, thus implying that the "dose equivalent" in the definition of a "high radiation area" is the "deep dose equivalent" [at a tissue depth of $1 \mathrm{~cm}\left(1000 \mathrm{mg} / \mathrm{cm}^{2}\right)$ ]. Are the "dose equivalent" in the definitions of "radiation area" and "high radiation area" and the "dose" in the definition of "very high radiation area" all considered to be at a tissue depth of $1 \mathrm{~cm}\left(1000 \mathrm{mg} / \mathrm{cm}^{2}\right)$ ?

Answer: Yes. In addition see Question 57. (References: 10 CFR 20.1003, 10 CFR 20.1601)

Question 80: The revised Part 20 (\$20.1003) provides definitions of "member of the public," "public dose," and "occupational dose." These definitions are not consistent with the definition of "member(8) of the public" defined (for nuclear power plants) in Generic Letter 89-01, Supplement 1 (NUREGs 1301 and 1302).

Consider that typically, ono would expect any individual entering the "restricted aren" would be considered to be occupationally exposed and not classified as a "member of the public." All individuals, inchuding utility employees, their contractors, and delivery people outside the "restricted area," in the "controlled area," would be considered as "members of the public." The only exception is where a utility employee or its contractor doing work in a portinn of the "controlled area" where public access has been restrict- ed due to radiological exposure considerations. This concept is consistent with the revised rule.

Will the definitions of "member(s) of the public" in Generic Letter 89-01, Supplement 1 (NUREGs 1301 and 1302) be changed to be consistent with the definition of "member of the public" in the revised Part 20?

Answer: Yes. The NUREGs themselves will not be changed; however, in a forthcoming Generic Letter on model Technical Specifications that incorporate provisions of revised Part 20, the definition of "member(s) of the public" will be changed to be consistent with revised Part 20. See Question 26 and answer in the fourth set of questions and answers for clarification of the definition of "occupational dose." (References: 10 CFR 20.1003, NUREG-1301, NUREG-1302).

Question 93: In the definition of individual monitoring devices, is there any reason electronic monitoring devices are not mentioned?

Answer: No. The particular devices included in this definition are a few examples, not a comprehensive listing, of such devices. (Reference: 10 CFR 20.1003).

Question 94: Why was the "controlled area" defined?

Answer: The "controlled area," which is not defined or used in the old Part 20, was defined and used in the revised Part 20 to provide regulatory recognition of the existence of such areas and to clarify their regulatory status within the context of 10 CFR Part 20. In a related change, in revised Part 20, occupational dose limits no longer apply only in restricted areas, and lower (public) dose limits no longer apply to everyone outside a restricted area. Thus, under the old Part 20, an individual who receives an occupational dose in a controlled area is subject to the same (low) dose limit as a member of the public in that same area. Under the revised Part 20, an individual who receives an occupational dose in a controlled area is subject to the occupational dose limits, but a member of the public in the same controlled aren is subject to the (lower) dose limits for members of the public. (Reference: 10 CFR 20.1003).

Question 96: (a) The roentgen (R) is not defined or used in revised Part 20; however, many survey instruments and computer records show dose rates in terms of " $\mathrm{mR} / \mathrm{h}$ " or "R/h." Will these survey instrument face pieces and computer forms have to be changed when revised Part 20 is implemented? (b) Most rediation instrumentation is currently 
calibrated in units of roentgens rather than rads. A roentgen of $x$ - or gamma-radiation in the energy range of 0.1 - 3 $\mathrm{MeV}$ produces $0.96 \mathrm{rad}$ in tissue. Will these instruments need to be recalibrated to account for this difference.

Answer: (a) No. The survey instruments will not need to be changed. See Question 428 for additional information concerning the use of the unit "roentgen" and its subunits.

(b) No. It may be assumed that one roentgen equals one rem or a more accurate conversion factor may be used. (References: 10 CFR 20.1003, 10 CFR 20.2101).

Question 119: Is it permissible under 10 CFR Part 20 for a licensee to have a controlled area that is controlled for purposes of radiation protection but that is not a restricted area?

Answer: No. By definition, in Part 20, "reatricted area means an area, access to which is limited by the licensee for the purpose of protecting individuals against unctue risks from exposure to radiation and radioactive materials." As stated in the answer to Question 26(a) under the heading "Controlled Area": ". . an area that satisfies both the definition of a restricted area and the definition of a controlled are is considered to be a restricted area for purposes of compliance with Part 20." (Reference: 10 CFR 20.1003)

Question 144: When will licensees be permitted to use weighting factors other than one to determine and record external whole body dose (effective dose equivalent from external sources) as the occupational dose of recond?

Answer: After the NRC has received and approved an application for the use of weighting factors (W) other than one for obtaining the effective dose equivalent. See the discussion of the comment on the use of effective dose equivalent for external exposure in the Statement of Considerations (56 FR 23368, thind column and 23369, first cohumn). The response to the comment concludes with the statement that "The use of other weighting factors for external exposure may be approved on a case-by-case basis upon request to the NRC." (Reference: 10 CFR 20.1003).

Question 148: What is the dose limit for a member of the public in a restricted area?

Answer: By definition (10 CFR 20.1003), the dose received by an individual in a restricted aren is an occupational dose. Also, by definition, "member of the public" means an individual in a controlled or unrestricted area (not an indivichal in a restricted area). Therefore, the occupational dose limits (and not the dose limits for individual members of the public) apply to the dose received by any individual in a restricted area. See related Question 26. (Reference: 10 CFR 20.100 3 ).

Question 149: 10 CFR 20.1003 defines the shallow-dose equivalent as the dose equivalent at a tissue depth of 0.007 cm. (a) Does this mean that the dose to the skin of the whole body is the sum of the non-penetrating dose equivalent (beta and low energy photons) and the deep dose equivalent? (b) Is it proper to calculate the extremity dose by oumming the dose equivalent mieasured on an extremity dosimeter (which may only be worn for part of the monitoring period) with the deep dose equivalent?

Answer: General response: 10 CFR 20.1502 requires monitoring of external dose for individuals who are likely to receive, in a year, a dose in excess of $10 \%$ of the applicable limits. Requirements to measure/assess the dose equivalent at depths of $0.007,0.3$, and $1 \mathrm{~cm}$ exist under old Part 20 as well as revised Part 20. In old Part 20, these requirements are inchuded in the instructions for Item 5 of NRC Form 5. In the revised Part 20, these requirements are in Part 20 iteelf, togetber with new dose limits and special names in the definitions for the dose equivalents at these three depths. The only explicit requirements concerning the precision and accuracy of personnel dosimetry are the NVLAP accreditation requirements, which are the same in old Part 20 [10 CFR 20.202(c)] and revised Part 20 [10 CFR 20.1501(c)]. Methods that have been acceptable for menauring/assessing dose equivalent at these three depths in the past should continue to be acceptable in the future.

Answers to the specific questions are as follows:

(a) No. The "dose to the skin of the whole body" is the shallow dose equivalent. The shallow-dose equivalent is the dose equivalent at a depth of $0.007 \mathrm{~cm}\left(7 \mathrm{mg} / \mathrm{cm}^{2}\right)$ from all types of radiation, whether "penetrating" (such as gamma rays and neutrons) or "non-penetrating" (such as weak beta radiation and lower energy $x$-rays).

(b) No, not in general. The question does not make it clear whether or not the dose summing is for dose during the same time period. It is never proper to calculate an extremity dose (shallow-dose equivalent) for a particular time period by adding a deep dose equivalent to the shallow-dose equivalent. If the question refers to a monitoring period during which an extremity dosimeter (measuring shallowdose equivalent) was used only part of the time, but during which a whole-body dosimeter was used all of the time, the 
answer depends on the circumstances of the individual's exposure. It would be acceptable to assume, for the times during which the extremity dosimeter is not used, that the extremity dose (shallow-dose equivalent) is equal to the shallow-dose equivalent measured by the whole-body dosimeter. If only the deep-dose equivalent is measured by the whole-body dosimeter, it would be acceptable to assume, for tines during which the extremity dosimeter is not used, that the extremity dose is equal to the deep-dose equivalent (measured by the whole-body dosimeter) if it can be shown that types and levels of radiation to which the extremity was exposed would not have resulted in a significantly higher shallow-dose equivalent to the extremity than the deep dose equivalent to the whole body. (Reference: 10 CFR 20.1003)

Question 150: 10 CFR 20.1003 defines tissue monitoring depths of $0.007,0.3$, and $1 \mathrm{~cm}$ for shallow, eye, and deepdose, respectively; (a) Is it important to measure at (or extrapolate the measurements to) these exact depths? (b) could the eye and deep-dose both be determined at $0.3 \mathrm{~cm}$ ?

Answer: See the "general response" in the answer to Question 149.

(a) As under the old Part 20, it is important to measure (or to extrapolate measurements to, or otherwise assess the dose equivalent) at a reasonable approximation of these depths.

(b) No. The deep-dose equivalent is, by definition, the dose equivalent at a depth of $1 \mathrm{~cm}$, not $0.3 \mathrm{~cm}$. However, the dose at $0.3 \mathrm{~cm}$ (eye dose) would usually be a conservative approximation (overestimate) of the dose at 1 cm (deep-dose). (References: 10 CFR 20.1003)

Question 412: This question refers to the answer to Question 26(b) under \$20.1003. What is the basis for using a dose threshold to decide whether a person is categorized as a member of the public or as occupationally exposed? The definitions do not specify a dose threshold.

Answer: Question 26(b) asked whether occupational or public dose limits apply to individuals, described in three different scenarios, who are exposed within controlled areas (outside any restricted areas) at a nuclear power plant. These scenarios described (1) a fossil plant worker, (2) a pregnant taxi driver, and (3) construction workers building a second nuclear power plant and secretaries in the administrative building. The answer to Question 26(a) states that the public dose limits apply to the individuals in all three scenarios, but the answer also states that if turbine shine from the nuclear plant is such that fossil plant workers, con- struction workers, or secretaries (but not the pregnant taxi driver) ". . . are likely to exceed the dose limits for members of the public, the licensee should consider the indivicual doses to be occupational doses and meet the requirements for individuals who receive occupational doses." The basis for this answer is the NRC staff's understanding of the intent of the definition of "occupational dose", specifically, that portion which states that "occupational dose means the dose received by an individual . . . in the course of employment in which the individual's assigned duties involve exposure to radiation ...." This understanding of the definition is also expressed in more general terms in the answer to Question 26(a). (Reference: 10 CFR 20.1003)

Question 413: This question refers to the answers to Questions 66 and 31 under \$20.1003 and \$20.1201, respectively, and to Question 26(d) under \$20.1003. Simply designating an area as a restricted area so you can control everyone at occupational dose limits is a perversion of every radiation protection principle published. Of course, this is just my opinion. I hope NRC will revise its interpretation of this definition.

For example, a secretary in a nuclear medicine clinic without any direct person-to-person contuct with patients should not be subject to occupational limits just because she is in a restricted area. Many other examples could be cited, and some that are more in the gray area should be examined carefully. Clearly, there is a significant population of exposed persons that are not being held to the proper standard. The following statement refers to the answer to Question 26(d) concerning "individual E." In spite of the definition of occupational dose, mere geography is not justification for classifying a person as a radiation worker.

Answer: The questioner appears to object to the definition of "occupational dose" that states that "occupational dose means the dose received by an individual in a restricted area or ...." The NRC cannot change this definition by revising its "interpretation of this definition." The definition can only be changed by rulemaking.

While there may have been a lack of clarity in the referenced answers, our intention is that licensees should not engage in a practice of "simply designating an area as a restricted area so you can control everyone at occupational dose limits." Question 66 asks if a simple fenced area can qualify as a restricted area and the answer is yes, provided it is the licensee's purpose to limit access for the purpose of controlling radiation exposures. Question 31 asks if students and volunteers (such as nuclear medicine students and "candy stripers" who transport nuclear medicine patients or perform volunteer work in a nuclear medicine department) 
are subject to occupational dose limits. The answer to this question is that these individuals are subject to the occupational dose limits because, and provided that (as the question implies), the type of work they are assigned involves exposure to radiation; it does not matter where (in which area) they are working Question 26(d) asks if the occupational dose limits or public dose limits apply to "Individual E," a secretary for a radiography company, who works in a "controlled area" next to a "restricted area" containing a hot cell. The answer is that the occupational dose limits apply), again because the type of work assigned presumably involves exposure to radiation since it must be performed near the hot cell. (References: 10 CFR 20.1003, 10 CFR 20.1201).

Question 434: How are occupational dose limits applied in regard to the revised Part 20 definition of "year"? The purpose of this question is to obtain additional clarification of the intent and application of the "year" as it is defined in the revised Part 20 and discussed previously in Question 40. Apparently, licensees may establish a year that is other than January 1 through December 31 (e.g., Question 40 addresses a year that is from January 31 of one year through January 30 of the following year). In responding to the question, consider the following example. A worker receives dose sequentially at facilities of two different licensees, the first licensee using a year of January 1 December 31, and the second licensee using a year of January 31 - January 30. The worker receives 4 rems total effective dose equivalent (TEDE) at the facility of the first licensee during the period January 1 - January 30, and then transfers to the second licensee's facility, arriving for work on February 1. For work performed at the second licensee's facility, is the individual's remaining available TEDE 1 rem or 5 rems?

Answer: Five rems. For a particular licensee, the relevant time period for determining compliance with an annual dose limit is the year beginning and ending on the dates specified by that licensee, providing that the time period chosen by the licensee is consistent with the definition of "year" in 10 CFR 20.1003. In the example provided, the worker started work at the facility of the second licensee at the beginning of that licensee's "year" and, therefore, the worker had no prior occupational dose during that licensee's "year." (Reference: 10 CFR 20.1003).

\section{CFR 20.1004 - Units of Radiation Dose}

Question 73: Table 1004(b). 2 does not inchude entries for "cold" noutrons, (e.g., 7 × 10-9 $\mathrm{MeV}$ neutrons) which are used in experiments at some research reactor facilities. What vahues of the quality factor, $Q$, and the fluence per unit dose equivalent should be used for "cold" neutrons?

Answer: The values for "thermal neutrons" should be used until the use of other values is approved by the NRC.

(Reforence: 10 CFR 20.1004 Table 1004(b).2)

\section{CFR 20.1008 - Implementation}

Question 30: If a license condition ties the licensee to a section in the old Part 20 and there is no corresponding section in the revised Part 20, does the requirement in the old Part 20 stay in effect after implementation of the revised Part 20.

Answer: Yes. See 10 CFR 20.1008(e). The license condition that ties the licensee to a section in the old Part 20 "remains in force until there is a technical specification change, license amendment, or a license renewal that modifies or removes this condition." (Reference: 10 CFR 20.1008(e))

Question 58: Before implementing all of the provisions of the revised Part 20, would a licensee be in violation of 10 CFR 20.1008(a) if the licensee voluntarily adopted the provisions of 10 CFR 20.1208 for protection of the embryo/ fetus?

Answer: No, licensees can voluntarily provide protection for the embryo/fetus in accordance with the provisions of 10 CFR 20.1208 before implementing all of the provisions of revised Part 20. However, licensees would have to be clear that they are not "adopting Part 20" because that would require it to be adopted in full. (References: 10 CFR 20.1008(a), 10 CFR 20.1208)

Question 65: The following question concerns OMB approval of the information collection requirements of the revised Part 20. Section 20.1008 indicates that licensees shall implement the provisions of all sections of revised Part 20 on or before January 1, 1993 and that if a licensee chooses to implement revised Part 20 before then, the licensee shall implement all provisions of revised Part 20 not otherwise exempted by subsection 20.1008 (d). However, section 20.1009 says that the information collection requirements of the revised Part 20 will not become effective until OMB approves them. Does this mean that before OMB approval is obtained, a licensee can implement all of 
the provisions of the revised Part 20 except the information collection requirements?

Answer: OMB approval of the information collection requirements of revised Part 20 was obtained on January 24, 1992, with the exception of NRC Forms 4 and 5. OMB approval for these forms is expected in the future.

(References: 10 CFR 20.1008, 10 CFR 20.1009)

\subsection{SUBPART B - RADIATION PROTECTION PROGRAMS}

\section{CFR 20.1101 - Radiation Protection Programs}

Question 7: Relative to 10 CFR 20.1101, radiation protection programs, what would a typical radiography licensee have to do beyond what that licensee is doing now?

Answer: Ensure that the program was documented and review the program's content and implementation periodically (at least annually). (See Regulatory Guide 10.6 for additional information). If the licensee does not have a radiation protection program, then such a program must be developed. (Reference: 10 CFR 20.1101)

Question 11: Should the Radiation Protection Program be a stand-alone document or can it be the sum of many documents or manuals (e.g., a requirement for HP audits inchuded as part of a QA audit program document)?

Answer: Section 20.1101 requires a documented radiation protection program. This documentation does not have to be a stand-alone document but it must be reviewed annually. (Reference: 10 CFR 20.1101)

Question 62: With 10 CFR 20.1101(b) making ALARA a requirement ("shall" instead of a "should"), does the NRC staff plan or anticipate any significant change in inspection program focus or in enforcement activity with respect to ALARA for occupational exposure at nuclear power plants?

Answer: No. In general, the recent performance of the nuclear power reactor industry has been good with respect to offorts to achieve occupational doses that are ALARA. Collective doses (person-rem) for both PWRs and BWRs have been declining since the early 1980s. The NRC staff is not planning any significant change in the depth or scope of inspections with respect to ALARA and, therefore, no significant change in the inspection program and procedures. NRC headquarters does plan to review all draft notices of violation of 10 CFR 20.1101(b) in order to monitor proposed enforcement actions in this area to ensure that a reasonably consistent approach is established. Consistent with current and past policy, the NRC Regional Offices will continue to allocate increased inspection resources (e.g., ALARA team inspections) to inspections of poor ALARA performers. (References: $10 \mathrm{CFR}$ 20.1101(b))

Question 99: The following questions concern the relationship of emergency plans for nuclear power plants to 10 CFR 20.1001 ("Purpose") and 10 CFR 20.1101) "Radiation Protection Programs"). (a) To what extent do radiation protection programs need to be established such that during emergency conditions, the revised Part 20 can be complied with? (b) For example, in order to comply with the new BPA "Manual of Protective Actions For Nuclear Incidents" October 15, 1991, do germanium counting systems need to be established to analyze air samples for iodines and particulates, and computer programs to calculate CEDE, so that CEDE can be added to external dose to get TEDE? (c) Do emergency survey/phume chase teams need to wear breathing zone air samplers?

Answer: (a) In general, the revised Part 20 contains no new requirements that would make changes necessary in existing radiation protection programs as they relate to emergency conditions. 10 CFR 20.1001 includes the sentence, "However nothing in this part shall be construed as limiting actions that may be necessary to protect public health and safety," and the intent of this sentence is discussed in the statement of considerations (56 FR 23365, first column). NRC requirements concerning emergencies at NRC-licensed facilities (i.e., nuclear power plants and fuelcycle licensees) are contained in 10 CFR Parts 30, 40, 50, and 70, and no conforming changes to these requirements were needed as a result of the revised Part 20. (b) and (c) See answer to (a). With regard to the offsite emergency workers such as fire fighters, law enforcement officers, civil defense workers and environmental field team members, the EPA manual provides guidanco given in Tablo 2-2 titled "Guidance on Dose Limits for Workers Performing Emergency Services." In addition to the refinements in the dose limits, the revised EPA Manual uses the CEDE and the TEDE concept. There are no changes necessary with respect to the monitoring of the external exposure levels of these workers in the early phase of an accident except as noted in the referenced table. The question is, therefore, how to account for the inhalation dose of offsite emergency workers to prevent them from exceeding their limits. Due 
to the urgency of offsite response in the early phase of an accident, it will not be practical to set up air samplers at numerous locations and analyze those samples in a timely mannor. Air samples and radiation measurements taken by the field monitoring teams will be valuable to determine the dose to emergency workers after the fact, but will be of little value during the actual performance of emergency tasks, since some form of real time exposure rate indication is needed. To create this real time indication, a correction factor can be developed that when multiplied by the emergency worker's dosimeter reading can provide a conservative estimate of the inhalation dose. The NRC and FEMA are currently investigating this issue. After appropriate review the NRC and FEMA will provide guidance for offsite agencies to use. (References: 10 CFR 20.1001, 10 CFR 20.1101, 10 CFR 50.47)

Question 118: 10 CFR 20.1101(c) requires that each licensee "periodically (at least annually) soviow the radiation program content and implementation." A nuclear power plant has many reviews and audits (including quality assurance audits) of various aspects of their radiation protection programs during a year and reviews are on a schechule that covers all phases of the program on a 2-3-year review cycle. Is this acceptable to the NRC?

Answer: Yes, provided that the combination of these reviews and audits covers program content and implementation. Reviews and audits at nuclear power plents should incorporate the following features to assess procedural compliance, technical performance, implementation, and effectiveness of the facility radiation protection program.

- Radiation protection supervisory reviews

Onsite radiation protection supervisors should periodically perform and document reviews of the effectiveness of the radiation protection staff in such areas as radiological work practices, work monitoring, procedural compliance, and survey adequacy.

- Quality assurance audits

Quality assurance audits should be performed by the onsite auditing group. Personnel in the auditing group should have sufficient radiation protection training or experience 80 they can determine whether radiation protection functions are being performed as required. The quality assurance program audits should meet the requirements of Appendix B to 10 CFR Part 50.

- Corporate or contract audits
Offsite (corporate or contract) audits and evaluations should be performed to determine whether the radiation protection program complies with the regulations and other requirements and whether plant-wide objectives are being met as well as to identify needed program improvements. (Reference: 10 CFR 20.1101)

Question 133: 10 CFR 20.1101(b) requires licensees to use, to the extent "practicable," procectures and engineering controls based upon sound radiation protection principles to achieve doses that are ALARA. The ALARA concept emphasizes dose-recuction techniques that are reasonabio considering costs.

However, "practicable" may imply something that has been proposed and seems feasible but has not been actually tested in use. "Practical" is more consistent with the ALARA concept because "practical" implies "sensible", "involving good judgement" and "proven success in meeting the demands made by actual living or use." In making decisions about ALARA procedures and engineering controls, will licensees be permitted to interpret "practicable" as "practical"?

Answer: In the context of this regulation, the word "practicable does not have the connotations attributed to it in the question. 10 CFR 20.1003 states that "ALARA . . means making every reasonable effort to maintain exposures to radiation as far below the dose limits in this part as is practical ..." (emphasis added). The discussion of 10 CFR 20.1101(b) in the preamble to revised Part 20 (56 FR 23367) includes the following statement: "Compliance with this requirement [10 CFR 20.1101(b)] will be judged on whether the licensee has incorporated measures to track and, if necessary, to rectuce exposures and not whether exposures and doses represent an absolute minimum or whether the licensee has used all possible methods to reduce exposures." Thus the use of the word "practicable" in 10 CFR 20.1101(b) does not imply procedures and engineering cuntrols that are unproven. (Reference: 10 CFR 20.1101)

Question 134: 10 CFR 20.1101(c) requires a periodic (at least annual) reviow of the radiation protection program as defined in 20.1101(a). 10 CFR 20.1101(a) refers to 10 CFR 20.2102 for recordkeeping requirements. (a) Does the use of the word "audit" in 10 CFR 20.2102(a) require records for all audits that are performed in addition to the periodic review? (b) Are the reviews required by 10 CFR 20.1101(c) also considered to be audits that are subject to the quality assurance criteria specified in 10 CFR Part 50, Appondix B, XVIII? 
Answer: (a) No. The recordkceping requirements of 10 CFR 20.2102(a)(2) apply only to audits and reviews performed by the licenseo to comply with 10 CFR 20.1101. If the review is performed annually, then only the records of that roviow are required.

(b) No. The requirements of Parts 20 and 50 are separate requirements. However, quality assurance audits of aspects of the radiation protection program at nuclear power plants pursuant to the requirements of 10 CFR Part 50, Appendix B, XVIII, may partially satisfy the requirements of 10 CFR 20.1101(c). (Reference: 10 CFR 20.1101, 10 CFR 20.2102).

Question 380: Nuclear power plant licensees are required to moet the quality assurance criteria in 10 CFR Part 50 Appendix B. Regulatory Guide 1.33 describes a program acceptable to the NRC staff to demonstrate compliance with 10 CFR 50 Appendix B requirements and includes guidance regarding the documentation, use of procechures and periodic review of radiation protection programs. Does commitment to and conformance with 10 CFR Part 50 Appendix B and Regulatory Guide 1.33 fully meet the requirements of 10 CFR 20.1101(a) and (c)? Note: The answer to Question 118 provided previously did not clarify if additional requirements are imposed on nuclear power plants by $10 \mathrm{CFR}$ 20.1101(a) and (c) that are new or different from the previously applicable requirements.

Answer: No. See related question 134 and answer. 10 CFR Part 50 Appendix B and 10 CFR 20.1101(a) and (c) are different requirements. 10 CFR Part 50 Appendix B establishes quality assurance requirements for the operations of nuclear power plant safety-related structures systems and components. 10 CFR 20.1101(a) requires each license to develop, document, and implement a radiation protection program commensurate with the scope and extent of licensed activities and sufficient to ensure compliance with the provisions of Part 20. 10 CFR 20.1101(c) requires periodic reviews of that radiation protection program. Although for nuclear power plants, there is some overlap between the requirements of 10 CFR 50 Appendix B and the requirements of 10 CFR $20.1101(\mathrm{a})$ and (c), they clearly are different requirements. For example, some aspects of the radiation protection program established pursuant to 10 CFR 20.1101 (a) may not be considered "safety related" within the meaning of this term in 10 CFR 50 Appendix B. The reference to 10 CFR Part 50 Appendix B in the answer to Question 118 was provided in the context of a discussion of quality assurance audits and was not an indication that "commitment to and conformance with Appendix B and Regulatory Guide 1.33 fully meet the requirements of 820.1101(a) and (c)." (References: 10 CFR 20.1101).
Question 381: (a) For nuclear power facilities does conformance with Regulatory Guides 8.8 and 8.10 fully meet the requirements of 20.1101(b) regarding ALARA programs? (b) If not, does the NRC plan to update these Regulatory guides to conform to new requirements?

Answer: No, to both questions. (a) Regulatory Guide 8.8 Rev. 3 is now (in 1993) 15 years old, the second proposed revision to this guide is now 11 years old, and Regulatory Guide 8.10 is 16 years old. These guides do not adequately cover all the means that the nuclear power industry has developed and shown to be practical and cost-effective for maintaining occupational doses ALARA. For example, these guides do not recognize the importance of water chemistry controls and radiation source and field controls for maintaining doses that are ALARA.

(b) The NRC staff has not yet established a schedule for updating these guides. The staff did issue Draft Regulatory Guide DG-8004, "Radiation Protection Programs for Nuclear Power Plants," to provide guidance on compliance with 10 CFR 20.1101, "Radiation Protection Programs," inchuding guidance on the ALARA requirements of 10 CFR 20.1101(b). However, representatives of the nuclear power inchustry stated that this guide was not needed and it has been withdrawn. (Reference: 10 CFR 20.1101).

\subsection{SUBPART C - OCCUPATIONAL DOSE LIMITS}

\section{CFR 20.1201 - Occupational Dose Limits for Adults}

Question 2: What are the requirements for including dose from non-NRC-licensed sources (x-rays, accelerators, NORM) as part of occupational dose?

Answer: The combined total of the doses from licensed and unlicensed sources (other than background and medical radiation) must be below the Part 20 occupational dose limits. The requirement for inclusion of doses from nonlicensed sources is intended to account for occupational doses received while working for activities or with materials that are licensed or controlled by organizations other than the NRC, e.g., states, DOE, etc.. Thus licensees must record and add the doses from non-licensed sources to the doses from licensed sources to obtain the total dose for comparison with the occupational limit. (References: 10 CFR 20.1001, 10 CFR 20.1002, 10 CFR 20.1003, 10 CFR 20.1201) 
Question 3: What do you do about hot particles?

Answer: Until changed by rulemaking, the dose limits in Part 20 (10 CFR 20.1201(a)(2)) apply. Special rulemaking on "hot particles" is still pending. Until rulemaking is accomplished the NRC will continue handling hot particle enforcement issues in accordance with the stated Enforcement Policy published in the Federal Register (55 FR $31113,7 / 31 / 90$ ) and transmitted to nuclear reactor licensees as Attachment 2 to NRC Information Notice 90-48 (8/2/90). (References: 10 CFR 20.1201, U.S. NRC Enforcement Policy)

Question 6: What if an NRC licenseo hires a DOE employee who earlier in the year received an internal exposure of less then 5 rems annual effective dose equivalent, but greater than 5 rems committed effective dose equivalent?

Answer: Previous occupational exposures, even those received at an unlicensed DOE facility, count against the limit. The worker could not be allowed further radiation exposure for the year (except a planned special exposure). Note: There are also licensed DOE facilities. (References: 10 CFR 20.1201, 10 CFR 20.2104)

Question 31: Are students and volunteers subject to the occupational dose limits? For example, nuclear medicine students, or "candy stripers" that transport nuclear medicine patients or perform volunteer work in a nuclear medicine departnient.

Answer: Occupational dose is defined in revised Part 20 as "the dose received by an individual in a restricted area or in the course of employment in which the individual's assigned duties involve exposure to radiation ..." In the question above, the individual's assigned duties do involve exposure to radiation as a necessary feature of those duties; therefore, the students and volunteer are subject to the occupational dose limits. (Reference: 10 CFR 20.1003, 10 CFR 20.1201)

Question 33: What is the dose limit for visitors entering a restricted area (e.g., visitors to a bospital, patients' rolatives, escorted tourists)?

Answer: Occupational dose limits apply to all individuals who enter a "restricted area." This is also the case under the old Part 20. "Visitors to a hospital, patients' relatives, escorted tourists" who do not enter a restricted area are not subject to the occupational dose limits. Therefore, there is a need to clearly designate the particular areas in a hospital that are "restricted areas." (Reference: 10 CFR 20.1201)

Question 34: What are the applicable radiation limits in a controlled area if the licensee does not allow members of the public to enter the area?

Answer: Occupational dose limits apply to individuals who receive an "occupational dose" in a "controlled area." (See definitions of "occupational dose" and "controlled area" in 10 CFR 20.1003.) (References: 10 CFR 20.1003, 10 CFR 20.1201)

Question 41: Licensee A questions a new employee about outside employment. The employee states that he is only working at that facility. After 3 months, the employee starts working, in the evenings, at another licensed facility (Licensee B). The employee does not tell A about B; therefore, Licensee A does not take the exposure received by the employee at facility B into account when he calculates the employees annual total effective dose equivalent (TEDE). Will Licensee $A$ be in noncompliance for not knowing about the dose received by the employee at Licensee B? If licensee A was made aware of the exposure at Licensee B after-the-fact, must Licensee A go back and account for this exposure when calculating TEDE? If Licensee A finds out about the worker's exposure at Licen800 B after the year's end, and if the sum of the exposures exceeded the annual limit, is Licensee A obligated to record and report the overexposure and deduct it from the 25 rem lifetimo PSE limit?

Answer: In order to meet the requirements of $10 \mathrm{CFR}$ 20.1201(f), the licensee must establish some means to have each employee inform the licensee when that employee is receiving occupational dose from sources outside the licen$8 e{ }^{\prime} s$ control. It is not sufficient merely to ask each employee once (as in the example), with no continuing provision for employee notification. Assuming that Licensee A made no provision for learning of the new employees subsequent concurrent employment in other jobs that resulted in occupational dose, Licensee A would be in noncompliance for not determining the dose received on the job at Licensee B. If Licensee $A$ was made aware of the exposure at Licensee B after-the-fact, Licensee A must go back and account for this exposure when calculating TEDE. If Licensee A finds out about the worker's exposure at Licensee B after year's end, and if the sum of the exposures exceeded the annual limit, Licensee $A$ is obligated to record and report the overexposure and to dechuct it from the 25 rem lifetime PSE limit. Although the question and preceding answer are provided in terms of Licensee A's responsibilities with 
respect to doses received at Licensee B's facility, Licenseo $B$ has the same responsibilities with respect to doses received at licensee A's facility. (Reference: 10 CFR 20.1201)

Question 45: In determining the "eye dose equivalent," can credit be taken for shielding provided by eyeglasses/safety glusses?

Answer: Yes. (Reference: 10 CFR 20.1201(a)(i))

Question 46: Will determination of the "eye dose equivalent," at a tissue depth of $300 \mathrm{mg} / \mathrm{cm}^{2}$, be inchuded in the NVLAP personnel dosimetry accreditation program?

Answer: Not until ANSI N13.11, which defines the testing program used in the NVLAP accreditation program, is revised to include tests for the $300 \mathrm{mg} / \mathrm{cm}^{2}$ depth and this revised standard is adopted by the NVLAP program. (Note: Requirements under the old Part 20 inchude the determination of the dose to the eye at a tissue depth of $300 \mathrm{mg} / \mathrm{cm}^{2}$. See Instructions for Preparation of NRC Form 5, Item 5. (Reference: 10 CFR 20.1201(a)(2)(i))

Question 77: Representatives of the nuclear power industry are concerned that the additional terms provided in the revised rule to describe the "real estate" in and around commercial power plants seems to be overlapping. This could lead to confusion. Access to these various areas may also affect the category to which individuals working within these areas are assigned. At nuclear power plants, either the "protected area" or "radiation controlled area" may serve as the "restricted area." Although workers granted unescorted access entering the "protected area" may not be directly monitored for radiation exposure, they must be considered as "occupationally exposed." At least minimal "radiation worker" training is required for these workers consistent with the regulations. "Controlled areas" would typically extend to the "site boundary" or "owner controlled area." Does the NRC staff have any comments on this matter?

Answer: Each licensee should carefully document how the licensees local "aren" terms correspond to the aren terms in 10 CFR Part 20 (restricted, controlled, and unrestricted areas). Under both old and revised Part 20, anyone who enters a restricted area is subject to the occupational dose limits and must receive appropriate instructions in accordance with 10 CFR 19.12. Workers can also be occupationally exposed (and, therefore, subject to the occupational dose limits) in controlled and unrestricted areas (i.e., areas outside reetricted areas) depending (in accordance with the definition of "occupational dose") on the nature of the work they are doing and regardless of the area they are in outside a "restricted area." (References: 10 CFR 20.1003, 10 CFR 20.1201).

Question 97: 10 CFR 20.1201(b) refers to "doses received during accidents, emergencies, and ...." Is there any difference between an "accident" and an "emergency"?

Answer: Yes. An accident is an unexpected and undesirable event. An emergency is a situation or occurrence of a serious nature, developing suddenly and unexpectedly, and demanding immediate action. Thus an accident usually results in an emergency, but it is possible to have an emergency without an accident (e.g., action taken in an emergency may prevent an accident). In either case, licensees must account for doses received in excess of the annual limits in either an accident or an emergency, or both, in accordance with 10 CFR 20.1201(b). (Reference: 10 CFR 20.1201(b))

Question 100: (a) Is uny special TLD monitoring of eye dose equivalent required? (b) Do TLDs for eye dose measurement need to be physically located near the eye?

Answer: (a) Individual monitoring of the dose equivalent to the lens of the eye is required if the eye dose is likely to exceed, in year, $1.5 \mathrm{rem}$ (10\% of $15 \mathrm{rem})$ for an adult or $0.15 \mathrm{rem}(10 \%$ of $1.5 \mathrm{rem})$ for a minor. Licensees may use any form of monitoring that is capable of measuring these doses.

(b) The answer to this question depends on the conditions of exposure. In most cases a licensee will not have to physically place a TLD near the eye. However, there may be unusual exposure situations (such as exposure of the eye to a narrow beam of radiation) that would make it necessary to place a dosimeter near the eye. [Note: See Questions 45 and 46.) (References: 10 CFR 20.1003, 10 CFR 20.1201, 10 CFR 20.1502).

Question 123: In 10 CFR 20.1201(a)(1) does "annual limit" for dose(s) mean the limit on doses received in a "year" as defined in 10 CFR 20.1003?

Answer: Yes, (References: 10 CFR 20.1201, 10 CFR 20.1003) 
Question 172: (a) If the annual limit to the head is five rem deep dose equivalent, what is the purpose of the 15 rem eye dose equivalent? (b) How can a person receive 15 rem eye dose equivalent without exceeding the annual TEDE limit?

Answer: (a) The purpose of the 15 rem non-stochastic limit to the lens of the eye is to prevent lens opscities (cataracts). The dose limit to the head (a stochastic limit) and the dose limit to the eye (non-stochastic limit) are measured at different depths in tissue, $1 \mathrm{~cm}$ tissue equivalent depth for deep dose and $0.3 \mathrm{~cm}$ for eye dose; and for low penetrating radiation (such as beta or low-energy $x$ rays), doses at different tissue depths can be significantly different.

(b) The 15 rem eye dose equivalent applies to the exposure to the lens of the eye and is measured at a tissue depth of $0.3 \mathrm{~cm}$. The $5 \mathrm{rem}$ TEDE limit is the sum of the deep dose equivalent at a tissue depth of $1 \mathrm{~cm}$ and the committed effective dose equivalent. In general, a person can receive $15 \mathrm{rem}$ to the eye (measured at $0.3 \mathrm{~cm}$ ) without exceeding the 5 rem limit on deep dose equivalent when the head is exposed to beta or low-energy photon radiation, although it would be rare. for an individual to receive 15 rem oye dose equivalent without exceeding a deep dose equivalent of 5 rem. (Reference: 10 CFR 20.1201)

Question 175: A health care worker serves in a dual nuclear medicine and radiology position. The worker wears a dosimeter on the waist and a dosimeter at the collar. During fluoroscopy procedures, which is the primary source of exposure, the worker wears a lead apron that covers the waist dosimeter, but not the collar dosimeter. Over the course of a year, the worker receives a dose of $5.2 \mathrm{rem}$ as measured by the collar dosimeter and 1.7 rem as measured by the waist dosimeter. (a) Has the individual been overexposed? (b) Can licensees take credit for shielding while monitoring the external dose component of the TEDE?

Answer: (a) Yes, the individual has received a dose in excess of 10 CFR 20.1201 limits. The head and neck constitute part of the "whole body", and in this case, received the highest exposure. The collar dosimeter measured a dose of 5.2 rem over the course of a year. If the head and neck were not shiekled, and if the collar dosimeter was a measurement of the dose to the head and neck, then the dose exceeded the limit of 5 rem TEDE.

(b) The licensee can only "take credit" for shielding if it can be shown that the dose monitored behind the shielding is an accurate measurement of the maximum deep dose equivalent to the individual. Many shields used for radiation protection do not cover all of the upper legs, upper arms, and/or neck, and fow if any shields protect the head from external radiation. Therefore, few shields would satisfy the conditions for credit. However, licensees should use shielding as necessary to minimize the area of exposure and koep doses ALARA. (Reference: 10 CFR 20.1201)

Question 176: 10 CFR 20.1201 (a)(2)(ii) states a limit of "A shallow-dose equivalent of $50 \mathrm{rem}(0.50 \mathrm{~Sv})$ to the skin or to any extremity." (a) Can a person receive $50 \mathrm{rem}$ shallow dose equivalent to the skin of the lower arm (extremity) and 50 rem shallow dose equivalent to the upper arm (non-extremity), without having an overexposure? (b) Can a person receive 50 rem shallow dose equivalent to the left upper arm, then the same dose to the right upper arm, without having an overexposure? (c) Can a person receive 50 rem shallow dose equivalent to each extremity during one year?

Answer: (a) Yes, as long as the total shallow dose equivalent does not exceed 50 rem in either position. The skin of the extremity is not considered in the shallow-dose equivalent limit to the skin of the whole body. The annual limits are a shallow-dose equivalent of $50 \mathrm{rem}(0.50 \mathrm{~Sv})$ to the skin or to any extremity.

(b) Again, as long as it can be shown that the total shallow dose equivalent does not exceed 50 rem at any one location on the skin of the whole body, there is no violation. If the two different areas of the skin of the whole body each receives $\mathbf{5 0}$ rem total shallow dose equivalent during the year, then the limit has not been exceeded.

(c) Yes. The regulation states "... or to any extremity;" therefore, a worker may receive a shallow-dose equivalent of $50 \mathrm{rem}$ to each of the four extremities. (Reference: 10 CFR 20.1201, 10 CFR 20.1003, Regulatory Guide 8.34)

Question 177: (a) If a worker is exposed to an external source such that his head is the maximally exposed area of the body, are the doses to the head limiting, since the head is not inchuded under the definition of "extremity?" (b) What is the annual dose limit to the head, assuming no other internul or external dose?

Answer: (a) Yes. The annual limit for the dose to the head is the same as the annual limit to the trunk and other portions of the whole body, which in the absence of internal dose, is equivalent to 5 rem deep dose equivalent.

(b) The limit is 5 rem TEDE. (Reference: 10 CFR 20.1201) 
Question 217: How will licensees handle cases where occupationally exposed workers inform the licensee that they are concurrently being exposed (and/or monitored) at another facility, but refuse to name the other facility? (Note that if the worker is under contract, the other facilities may be competitors of the licensee).

Answer: Without knowing the occupational dose received by the worker at the other facility, the licensee cannot demonstrate compliance with the occupational dose limits for the worker if it permits the worker to receive concurrently an occupational dose. The licensee cannot allow the worker to receive any occupational exposure after the license becomes aware the worker is also receiving an occupational exposure at another facility which the worker refuses to name. See 56 FR 23383, thind column, and Question 41 for additional information concerning concurrent employment. (Reference: 10 CFR 20.1201, 10 CFR 20.2106)

Question 414: This question refers to the answer to Question 6 \$20.1201. This answer does not directly answer the implied question, which is, "if a person is assessed a history of 5 rem or more for the current year, is that person permitted to receive any occupational dose?"

Implied in the answer is that if monitoring is not required, that person can receive an occupational dose, presumably up to 500 mrem for an actult. Conceptually, this is not consistent with normal protection standards, i.e., "if you don't measure it, it is not there" is not a normally accepted practice. The Commission allowance for an explicit 100 mrem (SECY-90-387, November 26, 1990) would seem a much more reasonable approach. Both of these positions appear to conflict with the answer to Question 113 in the third set. Hopefully, a position similar to that taken for the declared pregnant woman with a pre-existing dose history will be taken. That is, an additional small increment of exposure is not biologically significant.

Answer: "If a person is assessed a history of 5 rem or more for the current year", that individual is not permitted to receive any additional occupational dose during that year (except a planned special exposure). The answer to Question $\mathbf{6}$ does not imply that the individual can receive any additional occupational dose (except in a planned special exposure). As noted in the preamble to revised Part 20 (56 FR 23369, second column), "the allowance of an additional 1 rem per quarter following an exposure in excess of the limits has been deleted" from the final rule published on May 21, 1991. The answer to Question 6 is consistent with the rule and the answer to Question 113, which states that "... if the 5 rem CEDE was received auring the current year, this individual would not be allowed any further exposure for the balance of the year." (Reference: 10 CFR 20.1201, 10 CFR 20.2104).

Question 415: This question refers to the answer to Question 41 under 820.1201. This answer leaves open what is an acceptable frequency for querying monitored workers. This is only an issue of monitored workers, isn't it? In the intorest of workload minimization, I suggest that an annual query/reminder along with the required annual 10 CFR 19 dosimetry report is adequate.

Answer: The requirements of 10 CFR 20.1201(f) and the answer to Question 41 apply to any individual who will receive an occupational dose, not just those individuals for whom individual monitoring is required. The frequency for querying/reminding workers should be determined by the licensee; however, given that the dose limit is annual, the frequency should be no less than annually. (Reference: 10 CFR 20.1201).

Question 435: The rule requires that "the assigned deepdose equivalent... must be for the part of the body receiving the highest exposure. [The dose] may be assessed from surveys or other radiation measurements for the purpose of demonstrating compliance with the occupational dose limits, if the individual monitoring device was not in the region of highest potential exposure." In the event of a hot particle exposure to a portion of the whole body, it is unlikely that tho associated deep dose equivalent (DDE) resulting from the hot particle gamma radiation would be appropriately measured by an individual monitoring device due to the localized nature of the exposure. Is it required that the DDE associated with a hot particle exposure be assessed and added to the monitored DDE for the purpose of demonstrating compliance with the occupational dose limits?

Answer: Yes. Although, for a hot particle on the skin, the deep dose equivalent is generally a small fraction of the shallow dose equivalent, it does need to be assessed.

(Reference: 10 CFR 20.1201).

Question 436: Licensees are required to "reduce the dose that an individual may be allowed to receive in the current year by the amount of occupational dose received while employed by any other person." How should this provision be applied to dose categories required to be monitored by the current licensee, for which the individual's dose report (0.g., NRC Form 5) from previous employment during the current year at another licensee's facility indicates "NR" (not required), "ND" (not detectable), or is left blank? May 
the dose in categories denoted on the dose record as "NR", "ND", or left blank be assumed to be zero, and therefore no reduction be made to the dose that the individual may be allowed to receive in the current year?

Answer: Yes, for cases in which "NR" or "ND" have been recorded. However, if there is no recorded dose for a dose category and no reason for this omission has been provided (i.e., "NR" or "ND" have not been entered), the licensee should determine if the dose value has been omitted erroneously before assuming it to be zero (e.g., by checking with the licensee that provided the Form 5 with a dose category left blank). If the licensee cannot determine why there is no recorded dose for a dose category, the licensee has been unable to obtain a complete record of the individual's dose history for that dose category and the individual's exposure must be limited in accordance with 10 CFR 20.2104(e)(1). (Reference: 10 CFR 20.1201, 10 CFR 20.2104, Regulatory Guide 8.7, Rev. 1).

\section{CFR 20.1202 - Compliance with the Requirements for Summation of External and Internal Doses}

Question 9: A license monitors a worker for both external and internal exposure under $\$ 20.1502$, but the internal exposure for the year is less than $10 \%$ of the dose limit. Does the licensee add it to the external exposure?

Answer: If both internal and external doses were required to be monitored (see 10 CFR 20.1502 for thess requirements), then they must be summed. If only the internal or external dose required monitoring, then they don't have to be summed. (References: 10 CFR 20.1202, 10 CFR 20.1502)

Question 38: Can the results of bioassays alone be used to determine if the licensee must sum internal and external doses under Part 20?

Answer: No. Summation is required if the licensee is required to monitor for both external and internal doses. The results of bioassays alone cannot be used to determine if the licensee must monitor internal exposures or sum internal and external dose under 10 CFR Part 20. Monitoring for internal is required for adults "likely to receive" in a year an intake greater than $10 \%$ of the limit. Determination of what an individual is likely to receive is a prospective assessment of intake. Bioassay is a retrospective assessment of intake. Future intakes are not necessarily the same as past intakes. However, bioassay data may be used together with other information as a basis for the prospective intake assessment. For example, if the uses of radioactive materials in a facility are not going to change significantly and bioassays of individuals employed in the facility have shown that no one has ever received an intake greater than $10 \%$, then one might reasonably conclude that no one is "likely to receive" an intake in excess of $10 \%$ of the limit.

(Reference: 10 CFR 20.1202)

Question 86: Does the term "per unit intake" in Footnote 1 to $\$ 20.1202$ refer to one event or to the entire monitoring poriod?

Answer: The term "per unit intake" does not refer to any particular time period. However, \$20.1202, to which Footnote 1 refers, provides a comparison to an annual limit. Thus, the time period of concern in this footnote is the "year" as defined in 10 CFR 20.1003. (Reference: 10 CFR 20.1202 Footnote 1)

Question 101: 10 CFR 20.1202(d) requires licensees to evahuate and, to the extent practical, account for intakes through wounds or skin absorption. What type of "evaluation" is appropriate for determining absorption through the skin from skin contamination, and at what "practical level" should it be accounted for? For what nuclides, using what criteria can absorption be neglected under a certain threshold, such as less than 10K, 100K of skin contamination?

Answer: The requirement to evaluate and account for intakes through wounds or skin absorption is not new. The old Part 20 has similar requirements [10 CFR 20.103(a)(1)]. Therefore, the "type of evaluation" that has been used bofore, if adequate, can continue to be used. The statement in the old Part 20 (10 CFR 20.103, Footnote 4) that such intakes should "be ovaluated and accounted for by techniques and procedures as may be appropriate to the circumstances " continues to be appropriate guidance for the revised Part 20. (Reference: 10 CFR 20.1202(d)).

Question 179: If a licensee implements the revised Part 20 in July, 1993, is the licensee required to go back and ovaluate internal dose for the purpose of determining total effective dose equivalent for the year?

Answer: No. The footnote to 10 CFR 20.2104(d), as amended in 57 FR 57877, 12/8/92, states, "Licensees are not required to partition historical dose between the external dose equivalent(s) and the internal committed dose equivalent(s)." As long as all of the licensee's worker's doses are below the old limits and/or the workers will not participate 
in planned special exposures, the licensee need not reevahuate prior doses before implementing the revised Part 20. However, the licensee must subtract the dose already received during the year from the new annual dose limits to find the limits for the remainder of the year, as explained in Question 1, Set 1. (Reference: 20.1202, 10 CFR 20.2104)

Question 180: Does the word "also" as used in 20.1202(c) mean intake by oral ingestion and inhalation, or oral ingestion and external exposure?

Answer: In 10 CFR 20.1202(c), the words ". . . also receives an intake by oral ingestion ..." mean in addition to the ingestion associated with inhalation, as discussed in 10 CFR 20.1202(b). All intakes by oral ingestion in excess of 10 percent of the applicable ALI must be accounted for, whether the dose from oral ingestion is in conjunction with intakes by inhalation, external doses, or both. (Reference: 10 CFR 20.1202, Regulatory Guide 8.34)

Question 438: In general, the nuclear power industry has conchuded that workers are not likely to exceed $10 \%$ of the annual limit on intake, and therefore intermal dose monitoring would not be required. However, some nuclear power plant licensees plan to continue internal dose monitoring and record and report monitoring results on a voluntary basis. (a) If the results of both voluntary monitoring of the committed effective dose equivalent (CEDE) and required monitoring of the deep dose equivalent (DDE) are reported on an individual's NRC Form 5, with appropriate comments indicating that the CEDE monitoring results are not required (i.e., are voluntary), are the CEDE and the DDE required to be summed as the total effective dose equivalent on the NRC Form 5? (b) If so, is the remaining available TEDE for the current year in which the results were obtained determined as 5 rems minus the year-to-date DDE phe CEDE, or as 5 rems minus the year-to-date DDE only? Note: the question assumes that the doses described are the only doses received by the individual in the current year.)

Answer: (a) No. If monitoring for DDE is required and monitoring for CEDE is not required, there is no requirement to sum the DDE and CEDE.

(b) No answer to this question is needed because the answer to (a) is "no".] Note: This question and answer apply to all licensees, not just nuclear power plants. (Reforence: 10 CFR 20.1202).

\section{CFR 20.1203 - Determination of External Dose from Airborne Radioactive Material}

Question 50: Does the footnote to 10 CFR 20.1203 mean that DAC-hours, and not measurements of external dose (using personal dosimeters), should be used for determining worker exposures to noble gases?

Answer: No, as clarified in draft Regulatory Guide 8.N8, the preferred method of determining worker exposure to noble gases is by radiation dose measurements using personnel dosimeters. However, such dosimeters may not be capable of measuring the skin dose resulting from certain noble gas radionuclides that emit weak beta radiation (e.g., $X e-133$ and $X e-133 m$ ). In such cases it is necessary to calculate the skin dose using measurements of the concentrations of these noble gases to which the workers were exposed. (Reference: 10 CFR 20.1203 Footnote)

\section{CFR 20.1204 - Determination of Internal Exposure}

Question 47: Will the NRC provide guidance on preparation of applications pursuant to 10 CFR 20.1204(c)(2) for approval to adjust DAC or ALI values to reflect the actual physical and chemical characteristics of airborne radioactive materials (e.g., aorosol size distribution or density)?

Answer: The NRC staff is considering developing such guidance. Some limited guidance on "adjusting DAC's for particle size" is included in donft Regulatory Guide 8.25, Rev. 1, Section 3.7; however, the staff recognizes that more extensive guidance, inchuding considerations of other physical and chemical characteristics of particles, may be needed. (Reference: 10 CFR 20.1204(c)(2))

Question 76: The Department of Energy (DOE) does not assign a 50-year dose commitment in the year of intake for its workers exposed to intermally deposited radioactive material. The internal dose is assigned on an annual basis. Will commercial nuclear power plant licensees be required to assess internal 50-year dose commitment for workers coming from DOE facilities? Some radionuclides encountered at DOE facilities may be beyond the normal assessment methods of commercial nuclear power plants.

Answer: The statement that DOE does not assign a 50year dose commitment in the year of intake is not correct. Although the DOE dose limits are applied to the dose actually received in a year, DOE facilities are required by 
DOE Order 5480.11 to generate and maintain individual occupational dose records that inchude "committed effective dose equivalent from intakes occurring during the year" and "committed dose equivalent to organ and tissue of concern from intakes occurring during the year." DOE Order 5480.11 also requires that reconds of exposure be made available to the worker upon request of the worker. See related Question 6. (References: 10 CFR 20.1204, DOE Order DOE 5480.11).

Question 83: If a worker who has been exposed to internal sources under Department of Energy Order 5480.11 comes to work at an NRC-licensed facility, will the worker's committed and committed effective dose equivalents need to be calculated for a fifty-year period by the licensee? DOE Order 5480.11 only requires a one-year dose commitment calculation.

Answer: See answer to Question 76. DOE Order 5480.11 requires DOE facilities to generate and maintain records of occupational dose inchuding (a) committed effective dose equivalent and (b) committed dose equivalent to organ or tissues of concern, in addition to records of (c) annual effective dose equivalent and (d) annual dose equivalent to organ or tissue of concern. (Reference: 10 CFR 20.1204, 10 CFR 20.2104, DOE Order 5480.11)

Question 121: 10 CFR 20.1204(g) provides that when a mixture of radionuclides in air exists, licensees may disregand certain radionuclides in the mixture if the licensee uses the total activity of the mixture in demonstrating compliance with the dose limits in section 20.1201 and if certain other conditions are met. How can a licensee both disregard certain radionuclides and use the tolal activity?

Answer: The term "total activity" in this section refers to "gross activity" measurements that are correlated with other measurements of individual radionuclides. For example, "gross beta" measurements of air samples might be used for determining intakes of a mixture of beta-emitting radionuclides when (a) gamma-ray spectrometry of representative air samples has identified radionuclides that account for more than $70 \%$ of the activity in the air samples (i.e., the percentage of radionuclides disregarded does not exceed $30 \%$ ) and (b) the concentration of any radionuclide disregarded is less than $10 \%$ of its DAC. (Reference: 10 CFR 20.1204)

Question 183: If an individual receives an intake of Class $Y$ material in September and, pursuant to 10 CFR 20.1204(d), the licensee waits 7 months to record the dose (March), what year should the dose be recorded?

Answer: The committed effective dose equivalent should be reconded in the year the intake was received. If the dose exceeded the limits, then it is considered an overexposure at the time when the intake occurred, and should be reported immediately. (Reference: 10 CFR 20.1204)

Question 372: When monitoring of internal exposure is required by 10 CFR 20.1502, 10 CFR 20.1204(a) requires the licensee to take "suitable and timely" measurements. Will NRC define what is suitable and timely to avoid differences of opinion among inspectors?

Answer: No. Some general guidance on what is suitable and timely will be included in Regulatory Guide 8.9, Rev. 1, "Acceptable Concepts, Models, Equations, and Assumptions for a Bioassay Program." Other than this general guidance, the NRC staff has no plans to provide a definition of what is "suitable and timely." That definition depends on the circumstances of the particular exposure. What is "suitable and timely" under revised Part 20 is (as before, under old Part 20) a matter of professional judgement in a good radiation protection program. NRC management will resolve any "differences of opinion among inspectors" that are called to its attention. (References: 10 CFR 20.1204, 10 CFR 20.1502)

Question 437: The rule provides for disregarding certain radionuclides in a mixture of radionuclides in air if three conditions are met. The conditions are:

a. The licensee uses the total activity of the mixture in demonstrating compliance with occupational dose limits and monitoring requirements;

b. The concentration of any radionuclide disregarded is less than $10 \%$ of its derived air concentration (DAC); and

c. The sum of the percentages for all radionuclides disregarded in the mixture does not exceed $30 \%$.

As used in this provision, what is the intent of the phrase "total activity of the mixture" and how is it to be applied? Please provide an example that illustrates how this provision may be properly used.

Answer: See the answer to Question 121 under the heading 10 CFR 20.1204. That answer states that the term "total activity" in 10 CFR 20.1204 refers to "gross activity" measurements that are correlated with other measurements 
of individual radionuclides; an example of the use of this provision is provided in that answer. (Reference: 10 CFR 20.1204).

\section{CFR 20.1206 - Planned Special Exposures}

Question 8: Under what circumstances are planned special exposures permitted?

Answer: The statement of considerations indicates that the intent of the planned special exposure was that it be used infrequently in circumstarces where the elimination of the $5(\mathrm{~N}-18)$ lifetime cumulative limit might create a severe handicap to the licensee's operation. See Regulatory Guide 8.N6, for further diailed guidance. (Reference: 10 CFR 20.1206)

Question 24: Will consultants or vendors be able to routinely come on site to do jobs under the Planned Special Exposure section of the revised Part 20 if their anmul exposure becomes limiting?

Answer: No. Planned Special Exposures are not to be used "routinely." See definition of Planned Special Exposure in 10 CFR 20.1003 and requirements for Planned Special Exposures in 10 CFR 20.1206. (References: 10 CFR 20.1003, 10 CFR 20.1206)

Question 63: Must doses received in excess of the limits that were in effect before implementation of the revised Part 20 be subtracted from the 25 -rem lifetime allowance for planned special exposures to obtain the total remaining dose available for planned special exposures?

Answer: Yes. See 10 CFR 20.1206(e), which limits the dose from all planned special exposures and all doses in excess of the limits to five times the annual dose limits in $\$ 20.1201$ (a) during the individual's lifetime.

The following discussion applies to individuals who worked at facilities of NRC licensees. It does not necessarily apply to individuals who worked at other facilities.

The "25-rem lifetime allowance" in the question is five times the annual limit (5 rem) for the total effective dose equivalent (TEDE), which is the sum of the deep dose equivalent (for external exposures) and the committed effective dose equivalent (for internal exposures). Before implementation of the revised Part 20 there were separate limits for internal and external exposure. For purposes of complying with "the 25 rem lifetime allowance," a previous intake, in units of MPC-hours, in excess of the old Part 20 limit may be converted to a committed effective dose equivalent, in units of rems, by multiplying by a factor of (1.25 rem/520 MPC-h). Provious whole-body exposures, in units of rem, in excess of the old Part 20 limit may be assumed to be equal to the deep dose equivalent component of the TEDE (in units of rem). For example, if, under the old Part 20 , a worker had received a whole-body dose that was 4 rem greater than the applicable limit and had also received an intake that was $100 \mathrm{MPC}$-hours greater than the applicable limit, the TEDE available for planned special exposures of that worker under the revised Part 20 would be [25 - 4 $(100)(1.25 / 520)]$ rem, or 20.8 rem.

Although the question refers only to "the 25-rem lifetime allowance" on the TEDE, the 10 CFR 20.1206(e)(2) lifetime limit (five times the annual limit) also applies to previous over-exposures involving the lens of the eye, the skin, and the extremities. For purposes of complying with 10 CFR $20.1206(\theta)(2)$, previous exposures to the lens of the eye in excess of the old Part 20 limits may be assumed to be equal to the previous overexposures to the whole body (because the limit for the whole body applied to the lens of the eye) and a previous overexposure to the skin of the whole body or to an extremity may be assumed to be equal to a corresponding overexposure to the skin of the whole body or to a hand, forearm, foot or ankle, respectively, except that overexposures resulting from beta radiation from hot particles on or near the skin need not be inchuded in the overexposures to the skin or extremities.

Note: For all future planned special exposures, the lifetime limit is applicable to each annual limit listed in 10 CFR 20.1201(a). (References: 10 CFR 20.1201, 10 CFR 20.1206, 10 CFR 20.2104, Technical Specifications)

Question 109: (a) Can a cardiologist who performs both nuclear candiology and cardiac catheterization use a planned special exposure (PSE) to perform an emergency cardiac catheterization on the last day of the licensee's monitoring year if his annual exposure as of December 30 is 4.9 rem? It is expected that he will receive greater than 100 mrem during the procedure. (b) Could the same cardiologist perform multiple cardiac catheterization as PSEs routinely during November and December if his annual exposure as of October 31 is 4.9 rem?

Answer: (a) Yes, provided all administrative requirements of 10 CFR 20.1206 are met. (Note, although NRC is not regulating non-byproduct material, NRC still has regulatory authority since the occupational dose has been defined 
to inchude exposure from "licensed and unlicensed sources of radiation.") (Reference: 20.1003 and 20.1206)

(b) No. 10 CFR 20.1206(a) requires that a PSE be authorized ". . . only in an exceptional situation when alternatives that might avoid the higher exposure are unavailable or impractical." Performing routine occupational tasks for two months is not an exceptional situation, 80 the condition in 10 CFR 20.1206(a) is not met. In short, PSEs cannot be used as a general mechanism to increase the annual dose limit from 5 rem to 10 rem TEDE, for normal situations. Note: The regulations do not prohibit the cardiologist from performing the procedures. If the cardiologist's exposure exceeds the annual limit, it shoukd be treated as an overexposure rather than a PSE. (Reference: 10 CFR 20.1003 and 20.1206)

Question 110: Can a radiography licensee consider an individual's exposure, received during a source retrieval, as a planned special exposure if an approved generic procecture for source retrieval is on file? Assume that this procedure addresses all the administrative and recordkeeping requirements of 10 CFR 20.1206.

Answer: Yes, provided it is an exceptional situation when alternatives that might avoid higher exposures are unavailable or are impractical. (Reference 10 CFR 20.1206)

Question 135: 10 CFR 20.1206 permits a planned special exposure (PSE) only if the alternatives that might avoid the higher exposure are unavailable or impractical. Under certain conditions, the collective dose for a task could be reduced if it could be performed by ono worker receiving a PSE, rather than by a series of several workers each receiving a dose less than the limit. Under these conditions would the NRC consider the alternative of using the series of workers to be unavailable or impractical?

Answer: No. Reductions in collective dose should be accomplished while keeping workers within the dose limits. Planned special exposures cannot be justified solely on the basis that they will reduce collective dose; however, reduction in collective dose may be part of the justification. (Reference: 10 CFR 20.1206).

Question 136: 10 CFR 20.1206 states that workers who will receive a planned special exposure (PSE) must be informed reganding the risk from the radiation exposure that is expected to be received. Radiation risk coefficients presently available are applicable to large populations and are not recommended for risk assessment for a small number of people. The coefficients are not applicable to individual doses as small as PSEs. How are nuclear power plant licensees expected to comply with this rule?

Answer: The requirement in 10 CFR 20.1206(c)(2) to inform the individual, who is to receive the PSE, of the estimated doses and associated potential risks is not a requirement to inform that worker of a precise probability that the worker may suffer some particular deleterious offect(8) from the estimated radiation dose(s). This requirement consists of a brief refresher of the instruction required by 10 CFR 19.12 with respect to instruction concerning the risks associated with radiation exposures. Regulatory Guide 8.29 , which is being updated, provides guidance on this subject that is acceptable for meeting the requirement of 10 CFR 20.1206(c)(2) as well as 10 CFR 19.12. That guide inchudes information concerning the differences between the risk to a particular individual and the risk coefficients applicable to large populations of exposed individuals. (Reference: 10 CFR 20.1206).

Question 137: At a nuclear power plant, the individual asked to approve a planned special exposure (PSE) will need to believe that the altematives are impractical or unavailable before doing so. But he or she must recognize that the NRC inspector who later reviews the PSE report may not agree, possibly leading to a notice of violation for an overexposure. If the individual at the nuclear power plant chooses to request it from the Region, can a decision be obtained in advance reganding the acceptability of the licensee's alternatives analysis?

Answer: Yes. Any licensee may contact the appropriate supervisor or manager (e.g., a Branch Chief in the Division of Radiation Safety and Safoguands in an NRC regional office) to determine whether or not the NRC staff agrees that the circumstances in an actual situation meot the requirement for an "exceptional situation when alternatives that might avoid the higher exposure are unavailable or impractical." A written description of the circumstances of the exceptional situation should be provided to the NRC regional office when requesting NRC review in advance of a PSE. However, an NRC decision in advance of a PSE, based on the information submitted by the licensee, that the circumstances appear to meet the regulatory requirements does not prechude a subsequent NRC finding, based on additional information obtained during an inspection, that the circumstances were not as originally described and, therefore, that the PSE was not in accordance with the regulatory requirements concerning PSEs. (Reference: $10 \mathrm{CFR}$ 20.1206). 
Questions and Answers

Question 191: Is a licensee required to provide dosimeters to an individual during a planned special exposure (PSE) that would only bo worn during the PSE?

Answer: No, there is no requirement, but the licensee may do so. 10 CFR 20.1206 requires that the doses received during a PSE be accounted for separately from the doses received under the limits of 20.1201, and the use of separate dosimeters that are worn only during the PSE is a practical means to account for the PSE dose. (Reference: 10 CFR 20.1206, 10 CFR 20.2105, 10 CFR 20.2204)

Question 192: 10 CFR 20.1206(e) says that licensees may not authorize PSEs for workers whose doses from previous PSEs and all "doses in excess of the limits" exceed certain limits. (a) What and whose limits apply? (b) Does the actual limit (e.g. 3 rem/quarter, 1.25 rem/quarter, etc.) apply, or does the equivalent annual limit apply? (c) Do doses from non-licensed sources (e.g., x-ray sources) that were in excess of the facility's limits apply, especially if the facility was not a licensee? (d) It appears that overexposures will require the licensee to back-calculate the dose in excess of the limits, particularly when that dose was received from an intake of radioactive material. However the Footnote 5 of 10 CFR 20.2106 says that assessments of dose equivalent and records made using units in effect before the licensee's adoption of this Part need not be changed. Will the licensee have to, in fact, convert the old doses in excess of the limits to committed effective dose equivalent?

Answer: (a) The regulatory limits at the time and place of the overexposure apply. If the individual worked for the Department of Energy (DOE), then the DOE limits apply. If the individual worked in a foreign country, then that country's limits apply.

(b) Tho actual limit applies.

(c) Yes. It is the purpose of the regulation to control licensed material in such a manner that the total dose to an individual, from licensed and non-licensed sources, does not exceed standards prescribed in the regulations.

(d) Yes. (Reference: 10 CFR 20.1206, 10 CFR 20.2104, 10 CFR 20.1001, Regulatory Guide 8.35)

\section{CFR 20.1208 - Dose to an Embryo/Fetus}

Question 59: How does the U.S. Supreme Court docision in the case of United Auto Workers (UAW) ys Johnson
Controls affect the NRC requirement in 10 CFR 20.1208, "Dose to an embryo/fetus," and the guidance in Regulatory Guide 8.13, "Instruction Concerning Prenatal Exposure?"

Answer: That decision has no effect on either the requirement or the guide, which are consistent with that decision. Reference: Letter from Bill M. Morris, NRC/RES, to William E. Morgan, the Booing Company, August 2, 1991).

For the infornation of those not familiar with this decision, the Supreme Court in this case overturned a U.S. Court of Appeals decision. In its decision, the Supreme Court responded in the negative to the question, "May an employer exchude a fertile female employee from certain jobs because of its concern for the health of the fetus a woman might conceive?" The court held that Title VII of the Civil Rights Act of 1964, as amended, forbids sex-specific fetal-protection policies. The majority of the court concluded with a very strong statement: "It is no more appropriate for the courts than it is for individual employers to decide whether a woman's reproductive role is more important to herself and her family than her economic role. Congress has left this choice to the woman as hers to make." (References: 20.1208, Regulatory Guide 8.13)

Qucstion 84: Can a female worker legally declare pregnancy if she does not yet have documented medical proof?

Answer: Yes. The revised Part 20 does not require a woman to have "documented medical proof" of pregnancy before declaring pregnancy. (References: 10 CFR 20.1003, 10 CFR 20.1208).

Question 120: Would a licensee be found to be in noncompliance with the limit for the dose to an embryo/fetus if, at the time the woman declared her pregnancy, the dose to the embryo/fetus exceeded 0.5 rem and the embryo/fetus subsequently received more than $\mathbf{0 . 0 5}$ rem from licensed material that was in the body of the woman before she declared her pregnency.

Answer: No. The intent of 10 CFR 20.1208(d) is that the licensee should not be in violation of the limit for the embryo/fetus as a result of doses received by the embryo/ fetus before the woman declared her pregnancy or doses received as a result of intakes before that declaration was made. (Reforence: 10 CFR 20.1208)

Question 138: Although it is extremely unlikely, long-lived residual radioactive material in the body of a female worker from her previous employment could deliver a dose exceed- 
ing the limit to a subsequently conceived embryo/fetus. For example, a former DOE worker who had been involved in an accident could have a large americium or plutonium body burden. 10 CFR 20.1208 makes no special provision for this eventuality. What action would the NRC expect the licensee to take?

Answer: The answer to this question is provided in Regulatory Guide 8.36, "Radiation Dose to the Embryo/ Fetus," which indicates that if monitoring of a declared pregnant woman is required, the existing body burden must be included in determining the embryo/fetus dose. If the licensee determines that the dose to the embryo/fetus has exceeded 0.5 rem, or is within 0.05 rem of the dose limit by the time the woman declares her pregnancy, the licensee may allow the embryo/fetus to receive an additional 0.05 rem during the remainder of her pregnancy. If the prior body burden alone caused a dose to the embryo/fetus in excess of the limit, that dose should be recorded, but the NRC would not take enforcement actions for this "overexposure" provided that the licensee does not allow the embryo/fetus to receive more than 0.05 rem after the woman has declared ber pregnancy. See the answer to the related Question 120. That answer states that the intent of 10 CFR 20.1208(d) is that the licensee should not be in violation of the limit for the embryo/fetus as a result of doses received by the embryo/fetus before the woman declared ber pregnancy or doses received as a result of intakes before that deciaration was made. (Reference: 10 CFR 20.1208).

Question 382: Do NRC regulations allow a declared pregnant woman to "undeclare" her pregnancy? If so, does this withdrawal of a previous declaration of pregnancy also oblige the licensee to withdraw restrictive measures and enhanced monitoring established solely to comply with related embryo/fetus dose limits?

Answer: Yes, to both questions. Under the regulations (which are consistent with the Supreme Court decision in the case of UAW vs. Johnson Controls), a woman has the right to choose whether or not to declare her pregnancy, including the right to revoke her declaration. It is the woman's right to choose, not the declaration of pregnancy, that is irrevocable. Note: A woman's withdrawal of her declaration of pregnancy does not alter the requirement of 10 CFR 20.2106(e) that the licensee (continue to) maintain the records of dose to the embryo/fetus (that were prepared as a result of the woman's declaration of pregnancy). See Regulatory Guide 8.7, Rev. 1, Section 2.3, concerning reporting of the embryo/fetus dose on request of the monitored woman. (Reference: 10 CFR 20.1208).
Question 416: This question refers to the answer to Question 84 under 820.1208. It has also been asserted that the declared pregnant woman (DPW) declaration can be prospective. Are there any limits on how frequently or how long a duration a person can declare they are in a DPW, e.8., 10 years?

Answer: No. There is no limit in 10 CFR Part 20 "on how frequently or how long a duration a person can declare they are in a DPW status." A woman can state that she is pregnant any time she feels it is necessary for ber to do so. Howover, by definition (in Part 20) a DPW has voluntarily informed her employer, in writing, of her pregnancy and of the estimated date of conception. Furthermore, there can be no "prospective" declaration of pregnancy. In the definition of a "declared pregnant woman," the words ". . . informed hor employer of her pregnancy ... " mean that the woman has informed her employer that she is pregnant, not that she will be, or intends to become, pregnant at some time in the future. (References: 10 CFR 20.1003, 10 CFR 20.1208).

Question 439: If the employer has been informed, in writing, by a female worker that she is pregnant, and the employer is not the licensee (e.g., the employer is a contractor to the licensee), may the employer notify the licensee of the declaration of pregnancy to establish applicability of 820.1208, Dase to an Embryo/Fetus, or must the woman herself make the declaration to the licensee?

Answer: The employer may notify the licensee that the woman has declared her pregnancy in accordance with the definition of a "declared pregnant woman" in 10 CFR 20.1003. However, there is no NRC requirement to do so. (References: 10 CFR 20.1208, 10 CFR 20.1003).

Question 440: In order to terminate a declaration of pregnancy, i.e., due to termination of the pregnancy or otherwise, must the female worker inform the licensee or employer in writing?

Answer: No. There is no requirement in the regulation specifying how to terminate a declaration. However, since the declaration of pregnancy is required to be in writing, it would be a good practice to terminate the declaration in the same manner. (References: 10 CFR 20.1208, 10 CFR 20.1003).

Question 441: If the declared pregnant woman's estimated date of conception encompasses a previous period of employment at another licensee's facility, what assumptions 
should be made by the current licensee for compliance purposes under each of the following conditions?

a. Until records are received from the previous licensee;

b. If previous monitoring reconds are incomplete or otherwise unavailable; and

c. If monitoring by the previous licensee of the woman's deep dose equivalent and/or the committed effective dose equivalent was not required, and therefore dose reconds were not maintained, but the woman is likely to have received dose due to the nature of her employment at the provious licensee's facility.

Answer: See the answer to the related Question 406 under the heading for Regulatory Guide 8.36.

(a) As provided in 10 CFR 20.2104(c), the licensee may accept, as a record of the prior dose to the embryo/fetus, a signed statement from the declared pregnant woman.

("Records from the previous licensee" are not required; however, as indicated in the answer to Question 371, it is considered good health physics practice to verify the information on prior exposure provided by the individual.)

(b) The answer to this question is the same as the answer to part (a) of the question if the woman can provide the information on the prior dose to the embryo/fetus; that is, the licensee may accept, as a record of the prior dose to the embryo/fetus, a signed statement from the woman. If the woman cannot provide this information, the licensee should [as indicated in the answer to Question 406(b)] make an effort to make a reasonable estimate of the dose using other information that the woman and her previous employer have concerning her exposure.

(c) As indicated in the answer to part (b) of the question and in the answer to Question 406, the licensee should make an effort to make a reasonable estimate of the dose using other information that the woman and her previous employer have concerning her exposure. (References: 10 CFR 20.1208, 10 CFR 20.2104).

Question 442: Is the licensee required to advise personnel of the provisions for declaring pregnancy, who work in the controlled area, have been classified as "members of the public," and do not "work in or frequent" any restricted area?

Answer: No. However, it would be a good practice to do so. The provisions of 10 CFR 20.1208 , for limiting dose to the embryo/fetus, apply only to declared pregnant women who receive doses from occupational exposure. (Reference: 10 CFR 20.1208).

Question 443: Are licensees required to advise personnol of the provisions for teclaring pregnancy, who enter a rostricted area, but do not "work in or frequent" any restricted area (๑.g., visitors on tours)?

Answer: No. (Reference: 10 CFR 20.1208).

\subsection{SUBPART D - RADIATION DOSE LIMITS FOR INDIVIDUAL MEMBERS OF THE PUBLIC}

\section{CFR 20.1301 - Dose Limits for Individual Members of the Public}

Question 42: A nuclear medicine technologist becomes contaminated with I-131 which results in an internal uptake of iodine. She continues to breast-feed her baby. Is the licensee responsible for controlling the dose to the baby as a member of the public in an unrestricted area? If so, what are the dose limits?

Answer: The licensee is responsible for the licensed material that has internally contaminated the technologist. The limit for a member of the public applies to the baby. (References: 10 CFR 20.1201 and 20.1301)

The licensee is responsible for performing a "survey" to assess the magnitude of the dose to the baby [10 CFR 20.1501(a)],

With respect to the continued breast-feeding of the baby, there are important legal, moral, and ethical considerations (including the rights of the technologist) that are outside the limited scope of 10 CFR Part 20. Both NRC and the licensee would have to address these considerations if such a situation were actually to arise. (References: 10 CFR 20.1201 and 20.1301)

Question 48: In 10 CFR 20.1301(a)(2), does " . . 0.002 rem $(0.02 \mathrm{mSv})$ in any one hour" apply to the dose in any single hour or can it apply to the average over a discrete period of time. 
Answer: The phrase " 0.002 rem in any one hour" means a cumulative dose of 0.002 rem in any period of 60 consecutive minutes regardless of the dose rates within that $60-\mathrm{min}$. poriod. It does not mean a dose rate, in units of rems per hour, obtained by averaging over a time period greater then, or less than, one hour. (Reference: 10 CFR 20.1301(a)(2))

Question 105: How should demonstration be mado of compliance with the 2 mrem in an hour limit [10 CFR 20.1301(a)(2)]? Is it adequate, for a nucloar power plant, to demonstrate compliance by having effluent control (trip) systems that provent effluent releases from excoeding the limits on the instantaneous rolease rates, and by performing periodic surveys during radioactive material storage and movements?

Answer: The 2 mrem in an hour limit is not now; it appears in the old Part 20 in 10 CFR 20.105(b)(1). Therefore, mothods for complying with this limit that havo been accoptable in the past will continue to bo acceptable under the now Part 20. The 2 mrem in an hour limit applies to doses in an unrestricted area from radiation sources located oither inside or outside of that unrestricted area. Therefore, compliance can be achieved by a reasonable combination of appropriate controls, surveys, and monitoring of sources, and potential sources. Such controls, survoys and monitoring aro not necessarily limited to the "effluent control trip system" and "periodic surveys during radioactive material storage and movements" that are stated in the question. For example, controls and surveys rolated to increased turbine shino at BWRs as a result of hydrogen water chemistry must bo inchuded. (Reference: 10 CFR 20.1301)

Question 106: (a) Are there no limits on airborne radioactivity concentrations in the controlled area, other than de facto limits for public dose to keep dose ratos loss then 2 mrem in an hour? (b) Would stack effluents creating temporary airborne radionctivity concentrations greater than DAC lovels in the controlled areas be allowed, as long as the public dose criteria of 10 CFR 20.1301 are mat? (c) It appean that these areas would not need to be "posted" or controlled, since there are not any 10 CFR Part 20 airborne radioactivity concentration limits for controlled areas. Is this correct?

Answer: (a) There are no limits on concentrations of airborne radioactive materials in controlled areas that are expressed in terms of concentrations. However, both the occupational dose limits (for individuals who receive an occupational dose in a controlled area) and the dose limits for an individual member of the public (when in a controlled area) indirectly limit the concentrations of radionctive material in controlled areas. Note that for members of the public the 100 mrem in a year limit applies. The $2 \mathrm{mrem}$ in an hour limit does not apply in a controlled area. This limit applies only in en unrestricted area.

(b) Yes.

(c) There may bo "airborno radioactivity areas" within controlled areas that noed to be posted. Seo the answer to Quection 27. (Roference: 10 CFR 20.1301, 10 CFR 20.1201)

Question 111: Section 20.105(a) of 10 CFR Part 20 provides for Commission authorization of radiation levels in unrestricted areas based on a criterion of 500 millirems in ono year to an individual in such areas. Does such an authorization for radiation lovols in an unreotricted aren that could reoult in a dose to a momber of the public in excess of 100 millirems in a year continue under 10 CFR 20.1301(c)? In othor words is this considered an "oxemption" as covered in 10 CFR 20.1008(d)?

Answer: No and No. The nature of the information roqueeted under 20.1301(c) is different from that requeeted under 20.105(a) in that 20.1301(c) requires a demonstration of need for tho proposed dase limit and procedures for maintaining doses ALARA. It may be appropriato for an applicant to refor to information submitted under 20.105(a) as part of an application submitted under 10.1301(c). (Reforences: 10 CFR 20.1301(c), 10 CFR 20.1008(d), and 20.105(a))

Question 125: 10 CFR 20.1301(a)(2) requires that the "dose" in any unreatrictod aren from external sources not exceed 2 mrem in any one hour. Which of the many "doses" in now Part 20 is "the dose" in 820.1301(a)(2).

Answer: The "dose" from extornal sources in 10 CFR $20.1301(a)(2)$ moans the deep dose equivalent or the eyo dose equivalent or the shallow dose equivalent. See definitions of these dose terms in 10 CFR 20.1003. (References: 10 CFR 20.1301, 10 CFR 20.1003).

Question 201: Why is it that releases to sanitary sowers are not inctuded in tho dose limit for members of the public while other effluent releases are?

Answer: The practice of having soparate limits for discharge to sowers is a practice that has been in place since 10 CFR Part 20 was proposed in 1955. If the dose limit for individual members of the public included the dose contribu- 
tion of licensed material into sanitary sewerage, thore woukd be no practical way for the licenseo to determine the magnitude of that dose contribution for the purpose of demonstrat. ing compliance with the limit because of the remoteness of tho indivichal being exposed from the point of discharge. Water roloused into tho sanitary sower is considered unavailable until it passes through the sowage treatmont plant. Bffluent concentration limits ( $\boldsymbol{\omega}$ in Tablo 2 of Appendix B) have always been calculated under the premise that a member of the public lives at the licensee's site boundary and utilizes the air and water available at that point. Relesse limits are set in Tablo 3 so that if the rolenses from the sewage treatment facility were the only source of ingestible water, the dose to the individual would be a committed offective dose equivalent of 0.5 rem por year. (Reference: 10 CFR 20.1301)

Question 203: Can you have radiation lovels in excess of 2 millirem in one hour or 100 millirem per year in a controlled area if the public is not allowed to ontor the area?

Answer: If the public is not allowed to enter for reasons other than limiting radiation exposure, the answer is yes. If the public is not allowed to enter in order to limit radiation exposure and for other reasons, the anwwer is no. As indicated in the answer to Queation 26(a), under the discussion of "controlled area", when an area moet both the dofinition of a controlled area and the definition of a restricted area, the area is considered a restricted area for purposes of compliance with Part 20. (Roforence: 10 CFR 20.1301)

Question 204: (a) Licensees may apply under 10 CFR 20.1301 (c) to operate at a higher anmual dose limit of 500 millirem to individual mombers of the public. How long will this $\mathbf{5 0 0}$ millirem limit apply to the licensee? (b) Can a licenseo apply for an authorization to operate at this bighor limit indofinitely?

Answer: (a) The 0.5 rem por year limit is intended to be applied primarily to temporary situations where operation of the facility, or public exposure to radiation, is not expected to recult in doses above 0.1 rem over long poriods of time. 20.1301 (c)(1) requires that the licenses specify the expected duration of operation in excess of the limit. Tho Commission will only approve such application if the licenseo provides all of the information specified in 10 CFR $20.1301(c)$, and if the information is acceptable.

(b) It is unlikely that the Commission will approve a roquest to opernte at the higher limit indefinitoly. (Reforence: 10 CFR 20.1301)
Question 205: (a) 10 CFR 20.1301(a)(2) requires that the dose in any unrestricted area from external sources does not oxceed 2 millirem "in any one hour." Since this is not an intantaneous limit, can the licensee operate at lovels much higher than 2 millirem per hour for a very short poriod of time (0.8., 90 millirem $\mathrm{hr}$ for 1 minute, then no dose for the rest of the hour)? (b) If so, how is the 2 mrem in any one bour inopectable?

Answer: Genoral response: This requirement in 10 CFR $20.1301(a)(2)$ is not now. It is essentially the same as the requirement in 10 CFR 20.105(b)(1). Specific response: (a) Yes.

(b) The licensee must be able to demonstrate compliance with the dose limits of 10 CFR 20.1301 and the survey requirements of 10 CFR 20.1501. If an inspector identifies areas whore the radiation levels may bo in excess of 2 mrem in any one bour and tho licensee is unable to demonstrato compliance with the dose limits for an unreatricted area and with tho survey requiroments, the licenses may be cited. (Reforence: 10 CFR 20.1301, 10 CFR 20.1501)

Queation 206: Can a licensee allow radiation lovel of 5 $m R$ or more in one bour in an area without limiting access to the araa?

Answer: If the phrase ". . . without limiting access to the area" is intended to moan an unreatricted area, the answer is no. Seo Queation 205, this Set. (Reforence: 10 CFR 20.1301, 10 CFR 20.1003)

Question 384: Nuclear powor plant licensees are required to med the criterin in 10 CFR 50 Appendix I and 40 CFR 190 with regards to maintaining doses to individual mombers of the public ALARA. Related Regulatory Guides $(0.8 ., 1.21,1.109$, and 4.1) describo programs which are acceptable to the NRC staff to demonstrate compliance with 10 CFR 50 Appendix I and 40 CFR 190 criteria. Specific requirements for monitoring, sumpling, dose calculation and reporting are inchuded in each plant's Technical Specifications and related Offito Dose Calculation Mamual. Doss complinnce with plant Technical Specification, applicable Regulatory Guidea, and the radiation standard in 40 CFR 190 fully meat the requirements of 20.1301 The purpose in aking this question is to obtain clarification that, although the revised 10 CFR 20 introduces now dose limits for individual mombers of the public and now offluer concentration values in 10 CFR 20 Appendix B, the scope of monitoring, sampling, dose calculation and reporting are not changed for muclear power plants by the revised 10 CFR 20 from the proviously applicable requirements and guidance. 
Answer: Not necessarily. See the queutions and answers in sections 10 CFR 20.1301 and 10 CFR 20.1302. Generally, for nuclear power plants, no major changes are noeded in "the scope of monitoring, eampling, dose calculation, and reporting" that has been adequate for compliance with plant Tochnical Specifications and 40 CFR 190, and for conformance with applicable regulatory guides. However, some rolatively minor changes may bo neoded. For oxample, at some plants, changes may bo noeded for domonatrating compliance with the requiroments of 10 CFR 20.1301 as they apply in members of the public in controlled areas. (Seo the answer to Question 104.) (Reforences: 10 CFR 20.1301, 10 CFR 20.1302).

\section{CFR 20.1302 - Compliance with Dose Limits for Individual Members of the Public}

Question 28: How are annual average concentrations (AAC) to bo calculated, and is it acceptablo for nuclear power plants to use this AAC in lieu of instenteneous limits (as currently required by tho operating license) which are derived from NURBG-0133?

Answer: AACs are calculated by multiplying the annueal offthont rolonse of individual radiomuclides by the anmual average atmosphoric dispersion factor for the most prevalent downwind sector at the controlled/unrestricted area boundary. The instantaneous limits, on the other hand, are based on a whole body dose limit of 500 mrem/y and a thyroid dose limit of 1500 mrem/y for gaseous roloases and Appendix B concentration values for liquid reloseses. In both cases, the dose rate or concentration values are applied on an instantaneous maximum basis at the boundary of tho unrestricted area. Annuul average dispersion eatimates are used to relate the concentration or dose rato to a reloase rato, and, ultimately, to an effluont monitor alarm set point. For purposes of maintaining offluont releases ALARA pursuant to 10 CFR Part 50, Appondix I, power reactor licensoes are restricted by Technical Specifications to the intantaneous limits. To permit offluent relowses at lovele corresponding to the AAC deacribed above would not onable a licenseo to moet the Appendix I dosign objectives. (Reference: 10 CFR 20.1302(b)(2))

Question 29: If a licensee controls exposure to members of the public using the new Part 20.1302(b)(2) at the boundary of the unrestricted area, how does a licenseo onsure that members of the public inside the controlled area do not excoed this limit?
Anower: Principally by the control of accese and, thereby, exponure timo, since the licenece can require mombers of tho public to exit tho controlled aren at any timo. (10 CFR 20.1301(b) provides that if a liceneces permits mombers of the public to have access to controlled areas, the limits for members of the public continus to apply to those individ. unls.) (Reforence: 10 CFR 20.1302)

Quedton 65: This quection concerne demonatration of compliance with the dose limits for individual members of the public. Section 20.1302(b), in the revised 10 CFR Part 20, permits the licenece to demonatrate complinece by:

1 "Demonetrating by measurement or calculation that the total effective done equivaleat to the individual likely to receive the higheat doese from the liceneed oporation doen not exceed the annual dow limit; or

2 Demonetrating that:

(i) the anmual average conceatrations of radionctive matorial reloased in gascous and liquid offineats at the boundary of the unreatrioted area do not exceed the values upecified in Tablo 2 of Appeadix B to \$820.1001 -20.2401 ; and

(ii) if an individual wore continually preseat in an unreatricted area, the dose from external cources would not excoed $0.002 \mathrm{rem}(0.02 \mathrm{mSv})$ in an hour and 0.05 rem $(0.5 \mathrm{mSv})$ in a year."

Option (1) above would require tho utility to demonatrate compliance with the 100 mrem in a year upecified in Section 20.1301 and tho limits to a momber of the public apecified in 40 CFR 190. This option allows for the use of occupancy factors. However, tho 10 CFR Part 2 Appondix C. Genoral Statement of Polioy and Procedure for NRC Bnforcement Actions Conforming Amoendmonts, provides an example of a Severity IV violation based on option '2' above which does not account for occupanoy factors.

It can bo interpreted that the eaforcemeat exemples have been written more conservatively then the rulo revision. This unneceseary restriction could soveroly limit availability of power, particularly at BWRs operating with hydrogen wator chemintry, without a corresponding rectuction in ectual dose to the public. It is requested that those exemples of violations be clarified to enoure consintency with the regulation.

Answer: The enforcement oxamples in quention are consistent with the corrouponding regulations. "Option 2" [10 CFR 20.1301(b)(2)] does not allow for use of occupancy factors other then unity. 10 CFR 20.1302(b)(2)(i) concorns 
efthent concentration, which do not involve occupancy, and 10 CFR 20.1302(b)(2)(ii) involves the anumption that an individual is continually prosent in the area or, in other, words, 10 CFR 20.1302(b)(2)(ii) requires the sacumption of an occupancy factor of 1.0. (Reforenco: 10 CFR 20.1302)

Question 69: This quention concerne redionctive efflued concentrations. 10 CFR 20.1302(b)(2) addresces the anmual average concentration, and limits on thew concentration, as they apply to members of the public. The changes pub. lished as conforming amendenoule to Part 2 uniformly addreas violations to these ofitueat limits as instantaneous values. While it is clear that significant inatantaneoun concentrations of these limits conatitute a concern to public safety, the deacription that any release in concestrations above the limits of Appendix B, Table 2 conatiustes a Soverity Lovel IV Violation and en inatantanoous rolease exceeding twice the limit of this table constimuting a Soverity Lovel III Violation are not consisted with the intede of the rule. If is requented that the descriptions of violation be clarified with reupect to the clear inteat of the rulo thet the limits of Appondix B, Table 2 apply to anoual average limits.

Answer: The exumples in the enforcement policy concerning rolease of radionctive materials to an unreatricted area at concentrations in excess of the limits for members of the public should be understood to refor to the anual average concentrations and not the inntantanocus concentrations. There is no requirement in 10 CFR Purt 20 based on the instantaneous concentrations (although tochnical specifications for power resctors do contain wch requiremente); thus there can be no violation of a Part 20 requirement involving inatantaneous concentrations and, therefore, the queation of the severity lovel of the violation, and the examples used for these soverity lovels, are not rolevant. Nevertbolese, the subject examples will be clarified in a future revivion of the enforcement policy to make it clear that the subject examples refor to the statement concerning anmual average concentrations in 10 CFR 20.1302(b)(2)(i). Reforence: 10 CFR 20.1302(b))

Question 72: Will certain mutorials licenseces (much as telethorapy and brachythorapy licensees) be required to conduct environmental monitoring in unreatricted areas to domonstrate compliance with the now dose limit for individual members of the public?

Answer: Yes. The licensee must demonstrate compliance with 10 CFR 20.1301. Licensees must perform radiation surveys in areas adjacent to locations whore redioactive materials are used or stored. It is unlikely, however, that a licenese will need to perform effluent or eavironmental monitoring if it is only licened for toletherapy and/or brechythorapy. (Roforencen: 10 CFR 20.1302, Byproduct Material liceanes (modical))

Qucution 102: Undor 10 CFR 20.1302(b)(2)(ii), (a) do the words, "If an individual were continually present in an unreatricted area," mean that under these provisions it should be ascumed a hypothatical individual is thore, or (b) abould ccoupancy studies be made in applyine this section?

Answer: (a) Yos. (b) No. Supplamentel meapone: Albough thin quation cams from a msolear power plant, it come unlikely that a miclear power plant would choose to we this option [10 CFR 20.1302(b)(2)], with its consorvative angumptions, to demonatrite compliance with the annual dowe limit in 10 CFR 20.1301(a)(1). It seems more likely that a molear power plant would prefor to use the option of 10 CFR 20.1302(b)(1) which does not involve the conservative asaumption (offhuent concentration "at the boundary of tho unreatricted area" and an "individual...continuously preacent in an unreatricted area"). Nuclear power plants and other uranium fivol cycle facilition muat moet the more restrictive publio dose limits of $40 \mathrm{CFR} 190$. As noted in the statement of consideration (56 FR 23374, thind columen), demonstration of complinnce with the limits of 40 CFR 190 will be considered to demonutrate complinnce with the 0.1 -rean anmul limit of 10 CFR 20.1301(a)(1) for moat facilities. This demonetration of compliance would be consistent with the option of 10 CFR 20.1302(b)(1). See the answer to the related Queation 68. (Reforenco: 10 CFR 20.1302).

Quection 103: 10 CRR 20.1302(b)(2)(ii) refors to "the dose from external sources." (a) What are "external sources"? (b) Aro both (1) shine from the facility or from stored contaminated materials and sources, as woll as (2) cloud shine from effluents to bo inchuded?

Answer: (a) "Extornal sources" are radiation sources outuide tho body.

(b) Yes. (Reforenco: 10 CFR 20.1302).

Question 104: 10 CFR 20.1302 provides two options for demonatrating compliance with the annual dose limit, in 10 CFR 20.1301, for members of the public. How does 10 CFR 20.1302(b)(2), the second option, provide demonstration of compliance with the annual dose limit for members of the public who are in a controlled area? 
Answer: It doesn't. This second option applies to mombers of the public in unrentricted areas and a controlled area is not an unreatricted area. Howover, it would bo accoptable to demonatrate compliance with the annual dose limit for members of the public in a controlled area [10 CFR 20.1301 (a) and (b)] by applying the effluent concentration critoria of 10 CFR 20.1302(b)(2)(i) and the oxtornal dose critorion of 10 CFR 20.1302(b)(2)(ii) to the contralled area, rether then to the unrestricted area. (Roforencea: 10 CFR 20.1003, 10 CFR 20.1302).

Question 207: The dose limits for an individual momber of the public as specified in 10 CFR 20.1301 aro specified in torms of rem. Since rem is an absorbed dose, must an individual bo prosent for the dose limit to apply?

Anower: No. If using 10 CFR 20.1302(b)(1) to show complience with dose limits, occupancy times (timo an individual is prowent) may bo taken into account. If using tho method in 10 CFR 20.1302(b)(2)(ii) to demonotrate compliance, dose is calculated as if an individual were contimuously presont, regardless of whother an individual is contimuously present. See rolated Queations 68, Sot 2, and 102 Set 3. (Reforenco: 10 CFR 20.1302, 10 CFR 20.1301)

Queation 208: Is the licenseo required to use the most accurate mothod for determining compliance with dose limits or is it allowable to use any one of the acceptable mothods (assuming the accoptablo method yiolds tho lower doso)?

Answer: The licensee may use any one of the acceptable methods for determining compliance with the dose limit (10 CFR 20.1301(b)(1) or (2)). Soe related Queation and Anower 102 (Reforence: 10 CFR 20.1302)

Question 417: This question refors to the answer to Queation 29 under 820.1302 . The statement that a licenseo can require members of the public to exit a controllod aron at any timo is not obvious, based on the publishod rule. A controlled area is one to which access can be limited, but that condition might oxist only at certain times or under cortain conditions or the accoss limits might be of a nature other than strict prohibition. For instanco, it might be a control that specifically limits the stay timo. Does NRC expect procedures to reflect the changing nature of such an area, i.e., controlled at one timo but unrestricted at othor times, or is an aroa that moots the requiroments to bo designated a controlled area for somo portion of time simply a controlled area all tho time? (The latter, 1 hope).
Answer: The words ". . access to which can be limited . . " in the definition of "controlled aren " mean that access can ba limited at any and all times, regardless of whether or not access in limited at any particular timo. An area dosignated by a licenses as a controlled area continues to be a controlled area until that dosignation is changed; it doos not change from boing a controlled area, and becomo an unrestricted area, simply becauso accoss is not boing limited at somo particular timo. [See discussions of "Licensee Discretion" and "Controlled Areas" in the anawer to Question 26(a).] (Roforences: 10 CFR 20.1003, 10 CFR 20.1302).

Question 427: The word "oxtornal" in 10 CFR 20.1302(b)(2)(ii) rofors to any radiation source which could irradiate an individual from outside the body. Since sources inchude both airborno radioactive matorials and contained cources, tho dose from airborno radionctive matorials could bo doublo-counted -- as a concentration purnuant to 10 CFR 20.1302(b)(2)(i) and as direct radiation pursuant to 10 CFR 20.1302(b)(2)(ii). In a situation whore the licensece was approaching the $50 \mathrm{mrem} / \mathrm{yr}$ limit from direct radiation from contained sources, the additional direct radiation component from airborno relonses may cause this limit to be exceeded. Clearly, this sinution could bo addressed through use of 10 CFR 20.1302(b)(1); however, the intent of the revised Part 20 appean to provide viablo altornatives to complying with the regulation whonover feasible. Must a licenseo who olects to use the method of 10 CFR 20.1302(b)(2) for domonutrating compliance with the public dose limits "doublecount" the dose from airbome radioactivo matorials?

Answer: No. External sources ondinarily inchude all radiation sources outside of tho body, such as direct radiation from contained sources and direct radiation from airborno radioactive materials. To the extent that doses from airborno radionctive matorials (0.8., noble gasos) are accounted for as concentration values purauant to 10 CFR 20.1302(b)(2)(i), thoy noed not be accounted for as external sources under 10 CFR 20.1302(b)(2)(ii) in detormining compliance with the $50 \mathrm{mrem} / \mathrm{yr}$ limit. (Howevor, nirborne radionctive material does need to be accounted for in detormining compliance with the limit of 2 mrem in any one hour). (References: 10 CFR 20.1302, 10 CFR 20.1301). 


\subsection{SUBPART F - SURVEYS AND MONITORING}

\section{CFR 20.1501 - Surveys and Monitoring- General}

Question 147: 10 CFR 20.1501(b) requires the licenses to enoure that inatrumoate and equipmont used for quantitative nadiation measurements are calibrated periodically;

however, thore is no corrouponding requirement in old Part 20. Does this now requiroment mean that the accuracy and frequency of ach calibrations that have been found acceptable by the NRC in the past will not be accoptable under the revised Pan 20?

Answer: No. The acceptability of calibration frequency and eccurncy is not changed by the inclusion of 8820.1501(b) in the revised Part 20. (Reforence: 10 CFR 20.1501(b)).

Question 209: (a) Does the revised Part 20 require that motors be calibrated? (b) If 20 , is the calibration frequency epecified?

Answer: (a) Yos, 10 CFR 20.1501(b) requires that the licensee insure that inatruments and equipment used for quantitative radiation moasurements are calibrated poriodically for the radiation moasured.

(b) Part 20 regulations do not dofino "periodically." Howover, apecific NRC license conditions and othor Parts of Titlo 10 (i.o., Parts 34 and 35) may specify tho periodicity for calibration. (Reforence: 10 CFR 20.1501)

Question 210: 10 CFR 20.1501(c) requires a dosimetry procousor to bo NVLAP accredited. DOE also hes an accreditation program. Do DOELAP-accredited processors moek the requirements of 10 CFR 20.1501(c)?

Answer: No. (Reforence: 10 CFR 20.1501)

Question 458: Somo Part 50 power reactor licensees have doveloped "woighted" or "offective" dorived air concentration (DAC) values for airtorno mixtures of radionuclides, on the besis that the mixtures are well known and relatively atable, as demonstrated through periodic analysis of primary sources (0.8., reactor coolant and other procoss fluids), airborne and removable contamination samples, and waste atreams (i.e., 10 CFR 61 analysis). These weighted DACs utilize a known ratio of the readily detectable radionuclides in a mixture to the more-difficult-to-detect radionuclides, to infor the total activity and the DAC fraction of a mixture from gross counting mothods (i.e., without having to do isotopic analysis of each and overy sample). Given adequsto quality control mensures, is the use of such "woighted" or "offective" DACs acceptable for posting, survey and monitoring purposes?

Answer: Yos, in general, the "woighted" or "effective" DACs can be used for inforring the total activity and the DAC fraction of a mixture from gross counting mothods provided that the mothod(s) for calculating the "weighted" or "offective" DACs (which are not described in the question) are appropriate, have been validated, and that tho uses of these weiphted/offective values are not inconsistent with other regulatory requirements, such as 10 CFR 20.1203, 10 CFR 20.1204, 10 CFR 20.1502, 10 CFR 20.1902, and the Footnotes and Note to Appendix B. The DAC values used in the calculation of the "woighted" or "offective" values (and the DAC values used for any other purpose) must be the values listed in Appendix B to Part 20 unloss tho licen800 has obtained approval, under the proviaions of 10 CFR 20.1204(c)(2) or 20.2301, to use other values. (References: 10 CFR 20.1501, 10 CFR 20.1203, 10 CFR 20.1204, 10 CFR 20.1502, 10 CFR 20.1902, Appondix B).

\section{CFR 20.1502 - Conditions Requiring Indi- vidual Monitoring of Internal and External Occupational Dose}

Question 43: The licenseo initially was required to monitor internal dose. The results indicate that monitoring is not required, i.o., levels are positive but less than $10 \%$ of the allowable limits. Can the moasured internal dose values be ignored? If yos, will the licenseo be in noncompliance if it sums internal and external doses?

Answer: The licensee was required to monitor internal dose [because the licensee had made a prospective determination that the individual(s) was (were) "likely to recoive" an intake in excess of $10 \%$ of the limits]. The internal dose valuos cannot be ignored regardless of the fact that they are less than $10 \%$ of the limits. If the licensee was not required to monitor internal dose because the licenseo had made a prospective determination that the duses likely would bo less then $10 \%$ of the limits but elected to monitor internal dose anyway, the licenseo could choose to "ignore" the measured values that are less than $10 \%$ or to add those values to the external doses to obtain the sum of the internal and external doses. Nothing in Part 20 prohibits the licensee from 
monitoring or summing intornal doses at less than $10 \%$ of the limits; therefore, a licensee can never be in noncompliance for summing the internal and external doses.

(Reforence: 10 CFR 20.1502)

Queation 44: During 1993, the liceneeo performed a prospective dose ovaluation, and decided not to moasure internal doso. In 1994, the licensece again ovaluates the internal dose and finds that the throehold for monitoring is exceoded and begins monitoring. Nothing in the facility (engineering controls or productivity lovels) has changed. The licenseo account for the internal dose contribution when calculating TEDB for 1994. Must the licensee go back and adjust TEDB for 1993 ?

Answer: Yes, the licenseo must go back and adjust the TEDE for 1993, based on tho beat available data. The information included in the question indicates that the 1993 prospective ovahuation was in orror and that internal dose should have been measured; therefore, this error needs to be corrected. (Reference: 10 CFR 20.1502)

Question 54: Must bionssay be performed for a worker who, without respiratory protection, is likely to receive an intake in excess of the applicable ALI(s) but who is not likely to receive such an intake with respiratory protection?

Answer: A "Note" in the statement of considerations (56 FR 23377, column 2) says that ". . . the concentrations to be used for evaluating monitoring thresholds are those of the ambient atmosphere before credit is taken for respiratory protective factors." That note is a conservative assumption that is appropriate if there will be no "further verification" that the assigned respiratory protection factors actually will be achioved.

At nuclear power plants, if the "surveys and bionssays, as appropriate," required by 10 CFR 20.1703(a)(3)(ii), include reasonable measures to verify that the expected degree of respiratory protection will be achieved, "the concentrations to be used for evaluating monitoring threoholds" may be those that include credit for the protection factors when respirators are to be used. Measures to verify that the expected degree of respiratory protection has been achieved may inchude (but are not limited to) measurements of nasal smears from workers who have used respirators and whole body counting, relatively soon after a job, of one or more representative workers among a group of workers who wore respiratory protective equipment while working on the job, and poriodic whole-body counting (0.8., annually) of all workers who wear respiratory protective equipment.
At fuel cycle and materials facilities using large quantities of unsealed radionctive materials, the nature of the operations is such that bioassays are required for workers who are likely to receive an intake in excess of ten percent of the applicable ALIs without respiratory protection. Because of the types and quantities of radioactive airborne particulates at fuel cyclo and matorials licensees, it is advisable to not take credit for respiratory protection factors when determining if monitoring (0.g., bioassay) is required. NRC will consider licenseo proposals to allow using respiratory protoction factors whon determining if internal dose monitoring is required, if the licensee demonstrates a verification method that the respiratory protoction factor is actually achioved for all workers wearing respirators. Unless authorized in the license, fuel cycle and materials licensees should understand that the threshold level for monitoring in 10 CFR 20.1502(b) is ten percent of the applicable ALls without credit for respirators. (Reference: 10 CFR 20.1502(b), 10 CFR 20.1703)

Question 75: Representatives of the nuclear power industry have expressed a concern regarding 10 CFR 20.1502, which requires licensees to monitor individual internal or external doses for each individual likely to exceed $10 \%$ of the applicable annual limit. Licensees are required to maintain records of individuals for whom monitoring was required under $\$ 20.1502$ [\$20.2106(a)]. The handling of internal doses at less than $10 \%$ of the limit is of particular interest. Since a licensee cannot predict future exposures at other licensee facilities during the remainder of the year, a question arises regarding summing of doses at these small fractions of the limit if a worker transfers to another licensees during the year. The following procedures have been suggested regarding reporting of internal doses at nuclear power plants that are less than $10 \%$ of the limit.

1. At nuclear power plants, an entrance bioassay is typically performed for all incoming radiation workers. Upon departure from the facility, an exit bioassay is typically performed. If no net internal contamination is detectable in the exit bioassay, no internal dose assessment is required. If internal contamination is detected, an assessment will undoubtedly be made. Any positive result above the LLD is available for reporting.

2. Respiratory protection programs are required, under 820.1703, to monitor workers to assess intake. Air sampling results and bioassay measurements are acceptable methods to perform this monitoring, with the results used to perform an intake assessment.

3. Therefore, if a worker is monitored for potential internal exposure, data regarding the results of such monitoring 
will be available and must be recorded. Since these records are available, positive results, above LLD, should be reported to subsequent licensees, oven if there is no reason to expect the worker will exceed $10 \%$ of the annual internal committed effective dose equivalent limit.

Does the NRC have any objections to this procecture?

Answer: No. This procecture for nuclear power plants goes beyond the requirements of the revised Part 20 for monitoring, recording, and reporting internal doses to workers. See the answer to Question 114. (For example, routine entrance and exit bioassays for all workers are not required by Part 20). However, the procedure is not inconsistent with the Part 20 requirements. (References: 10 CFR 20.1502, 10 CFR 20.2106)

Question 81: (a) Aro licensees required to provide instruction on the procedures for declaring her pregnancy to an occupationally exposed woman if she does not enter a restricted area? (b) Is it necessary to monitor all (occupationally exposed) declared pregnant women?

Answer: (a) There are no provisions in the revised Part 20 , or in Part 19, to provido instruction on declarations of pregnancy to women who are occupationally exposed but do not enter a restricted area. It is suggested that the licensee, in accordance with good radiation practice, provide instruction on this topic to all occupationally exposed individuals, regardless of where they receive exposure.

(b) No. Only declared pregnant women who are likely to recoive in one year from sources external to the body a dose in excess of 0.05 rem (20.1502(a)(2)) or who are likely to receive in one year a committed effective dose equivalent in excess of 0.05 rem from occupational intakes

(20.1502(b)(2)). (Reference: 10 CFR 20.1502)

Question 82: Will workers who enter a restricted area and have been determined to require monitoring under 820.1502 (a) require monitoring in the controlled area (outside the restricted area)?

Answer: Yes, if the workers receive "occupational dose(e)" in the controlled area. (References: 10 CFR 20.1003, 10 CFR 20.1502).

Question 98: The following questions concern the requirements of 10 CFR 20.1502 as applied to nuclear power plants. (a) Since the nuclear powor inclustry has had fow intakes approaching the $10 \%$ criteria for adding intermal and external doses, is the historical record of intakes phus the establishment of a corporate (licensee) policy to limit intakes to less than $10 \%$ of an ALI sufficient to exclude a nuclear power licensee from the requirements for "monitoring" intakes (10 CFR 20.1502) and adding internal and external (except for specific intake instances)?

(b) Will the apparent now practice of minimizing TEDE and allowing some intakes invalidate this historical basis and essentially require nuclear power licensees to "monitor" intakes?

(c) In determining whether a worker is likely to exceed the $10 \%$ criteria, on what basis are projections to be made of the future intake of contract workers (for the remainder of the year after they leave our site)?

Answer: (a) Yes, assuming that the conditions of exposure are not expected to change to the extent that they are outside the bounds of that historical record and that procedures will bo put into effect to implement the policy. (However, "surveys", in accordance with 10 CFR 20.1501(a), would still be needed.)

(b) Not likely. However, the resulting potential increase in intakes will need to be considered in determining whether or not workers are likely to receive intakes in excess of $10 \%$ of an ALI. The historical record should be useful in evaluating this potential increase.

(c) Such projections are not required. As indicated in draft Regulatory Guide DG-8010 ("Criteria for Monitoring and Methods for Summation of Internal and External Occupational Doses"), each licensee makes the determination independently; doses that may have been received, or that may be received in the future, at another licensee's facility are not inchuded in the determination of the monitoring requirement. (Reference: 10 CFR 20.1502).

Question 114: A licensee is required to provide individual monitoring for each occupationally exposed individual who is likely to receive, in a year, a dose in excess of $10 \%$ of the applicable limits in 10 CFR 20.1201, 10 CFR 20.1207, or 10 CFR 20.1208. Must a licensee account for the exposure that an individual may receive at another licensee's facility, if that worker transfers to another licensed facility during the monitoring year, when determining if it is likely that the individual may exceed $10 \%$ of the limits? In addition, if a now employee already has an exposure in excess of $10 \%$ of the limits when they start work at the new 
employer, must the new employer automatically monitor the employee?

Answer: No. The licensec is only responsible for evaluating the potential for exposure at its facility. If the liconseo makes an evaluation that the dose will not exceed the $10 \%$ threshold, the licensee need not recond or monitor the dose. If the licensee opts to mensure the dose, although its proliminary evaluation shows that it is not necessary and finds that the threshold has boen oxcoeded, it must reovaluato its program and provide monitoring as required. In addition the licenseo will need to reconsider the requirements to sum internal and external doses. (Reference: 10 CFR 20.1502)

Question 126: Individuals performing assignod duties are often exposed to small amounts of radiation from plant offluents at licenseos' sites under normal operating conditions. (a) If these individuals are likely to receive, or have already received, in excess of $10 \%$ of an occupational dose limit from external sources, does the licensee have to determine, record, and report doses from the effluents to comply with the revised Part 20? (b) If 80 , what are the monitoring thresholds for the external and internal components of the dose?

Answer: (a) Yes. In this case, the licensee would have to monitor and record the external dose from the effluents, since the individuals are in excess of $10 \%$ of tho occupational dose limit from all external sources (20.1502(a)). However, the licensee is not required to monitor the offluent dose separately from other external doses.

(b) The licensee must monitor and record the internal occupational dose only if the individuals are likely to receive in excess of $10 \%$ of the applicable ALIs from all occupational intakes of radioactive material. Note: For nuclear power plants, tho preceding answer does not moan that all workers for whom monitoring of extermal dose is required must wear their personal dosimetors at all timos while on site. Such workers in controlled areas (outside restricted areas) noed not wear porsonal dosimetors to measure external doses from offluents. However, they should wear personal dosimeters in a controlled area when performing work that has the potential for significant occupational exposure such as performing a radiation survey of a vohicle loaded with a shipment of radionctive matorial. (Reference: 10 CFR 20.1502)

Question 211: 20.1502(a)(2) and (b)(2) say that monitoring is required for declared progenant women "...likely to rocoive, in 1 year,..." a dose in excess of 10 percent of the applicable limits for the embryo/fetus. (a) What year does this refer to? (b) Since the gestation period is 9 months (and since monitoring would begin after the declaration, which may be several months into a pregnancy), why does the rogulation use a year? (c) The licensee badges a declarod pregnant woman (whose estimated date of delivery is in January or February) during the current calendar year. The licensee then estimates that for the next calendar year, between the start of the year and delivery, the declared pregnant woman's external doses will be less that 10 percent of the applicable embryo/fetus dose limits, is the licensee required to badge the woman for the new year? (d) Can licensees assume that after delivery, the "year" time period is over and that monitoring the woman (to demonstrate compliance with the embryo/fetus dose limits) is no longer required?

Answer: (a) The word "year" is used to indicate a 12month period starting in January. (See definition of year in 10 CFR 20.1003).

(b) This requirement is for determining whether monitoring must be provided, and the term year is used to be consistent with other monitoring criteria as specified in 10 CFR 20.1502 .

(c) Once a determination is made to monitor the declared pregnent women, monitoring is to continue for the entire pregnancy, to determine compliance with the limit of exposure to the embryo/fetus.

(d) Yes. Once the woman is no longer a declared pregnant woman, the need to provide monitoring will be based on requirements of 10 CFR 20.1502(a)(1). (Reference: 10 CFR 20.1502, 10 CFR 20.1003)

Question 212: A licensee makes a prospective determination that adult workers in Department $W$ are not likely to receive doses in excess of $10 \%$ of the limits from extermal sources, so external dosimetry is not required by 20.1502 . The workers in Department W complain when their TLD badges are taken away, so the licensee decides to leave them badged, but not to demonstrate compliance with the accupational dose limits of the revised Part 20. (a) If an inspector finds the TLD badges being worn incorrectly or misused by Department $W$ workers, can the licensee be cited? (b) Must the doses be reported to the workers? If recording is required, must it be kept on Form 5?

Answer: (a) No citation against 10 CFR 20.1502 would be issued, provided the licensee can provide documentation that adequately supports the evaluation that monitoring of oxternal dose is not needed. An inspector may bring the issue of incorrect wearing of dosimeters to the attention of 
the licenseo, and may document this lack of good practice in the inspection report.

(b) No, reporting is not required. If the badges are not used for compliance with the regulations, the licensee is not required to record the results on NRC Form 5 or its equivalent. (Reference: 10 CFR 20.1502, 10 CFR 20.2106)

Question 213: (a) Who is responsible for monitoring a representative from a service company while the individual is on-site at a licensee's facility performing duties that may recult in an cccupational dose from sources owned/possessed by the licensee? (b) Where should the results of the monitoring be maintained?

Answer: (a) The individual/organization that is licensed to possess the material used is responsible for monitoring the representative.

(b) The recults of the monitoring must be maintained by the licensee as required by 10 CFR 20.2106. (Reference: 10 CFR 20.1502, 10 CFR 20.2106)

Question 214: (a) If the individual had not been monitored at his provious employer while recoiving an occupational dose (i.e., the dose there had been determined not likely to exceed $10 \%$ of the limito), and tho current employer, Licen$800 \mathrm{Z}$, determines in advance that the worker's annual dose for both licensees will exceed 10\% (although the dose at Licenese $\mathbf{Z}$ will not exceed 10\%), must Licensee $\mathbf{Z}$ monitor for external dose? (b) If the individual worked for several provious employers during the year, somo who badged and somo who did not, and Licenseo $\mathbf{Z}$ makes a prospective determination that its own activities will result in a dose less then 10\%, must Licenses $\mathrm{Z}$ monitor for extornal dose?

Anower: (a) No. Tho criteria to determine whether monitoring is required is independent of exposures received at any other place of employment prior to or subsequent to employment with Licenceo $\mathbf{Z}$.

(b) No. (Reference: 10 CFR 20.1502, 10 CFR 20.2104, Regulatory Guide 8.34)

Quection 215: An individual wortes concurrently at Licensees $\mathbf{W}, \mathbf{X}, \mathbf{Y}$, and $Z$. All four licensees make a prospective determination that external doses will not exceed $10 \%$ of the limits atthnir orm facility. Must any of the licensees monitor for external dose?
Answer: No. See the answer to related Question 214. (Reference: 10 CFR 20.1502)

Question 216: Will Regulatory Guide 10.8 be revised to include guidance on monitoring external dose (and demonstrating compliance with the annual occupational dose limits) for health personnel working in several hospitals simultaneously? [Note: This is a common practice for physicians in Hawaii and there is no good mechanism for licensees to track where the physicians work outside the facility.]

Answer: Appendix X to Regulatory Guide 10.8, Rev.2, was developed to provide guidance on how to implement revised Part 20 at a medical facility. This guide will be revised in its entirety in the future to address the changes in 10 CFR Part 20. (Reference: 10 CFR 20.1502)

Question 375: In supporting a conclusion that individual monitoring of internal occupational dose is not required [10 CFR 20.1502(b)] nnd, therefore, that summing of internal and external dose is not required [10 CFR 20.1202(a)], what is considered to be acceptable for bioassay frequency, DAChour administrative limit, and whole-body counting minimum testing level?

Answer: Under 10 CFR 20.1502(b), there is no required frequency for bioassay, DAC-hour administrative limit, or minimum testing level for whole-body counting either for individuals for whom monitoring is required or to support a conchusion that individual monitoring is not required. However, the answer to Question 54 provided a number of examples of measures that could be used at nuclear power plants to verify that the expected degree of respiratory protection will be achieved so that the concentrations of radionuclides in air after credit is taken for respiratory protection may be used in making the prospective assessment that individual monitoring for internal dose is not required. These messures "inchude, (but are not limited to) measurements of nasal smears from workers who have used respirators and whole body counting, relatively soon after a job, of one or more workers among a group of workers who wore respiratory protective equipment while working on the job and periodic whole-body counting (e.g., annually) of all workers who wear respiratory protective equipment."

It should be recognized that in addition to the bioassay requirements of 10 CFR 20.1502 (b), there is the bioassay requirement of 10 CFR 20.1703 (a)(3)(ii), which is related to the use of individual respiratory protection equipment. If whole body cointing is to be used to verify the effectiveness of the respiratory protection program, it must be able to 
demonstrate that estimates of intake based on exposure calculations (i.e., on air concentrations and on taking credit for protection factors) are consistent with estimates of intake based on bioassay. The licensee should take into account the fact that demonstrating effectiveness of the respiratory protection program may have to bo based on exposures over durations much shorter than a year, particularly for materials that are expected to be cleared rapidly from the body. Some general guidance on air sampling is provided in Regulatory Guide 8.25, Rev. 1, (which states that this guide does not apply to reactor facilities), and general guidance on bioassay will be provided in Regulatory Guide 8.9, Rev. 1. (References: 10 CFR 20.1502, 10 CFR 20.1202, 10 CFR 20.1703, Regulatory Guide 8.9)

Question 398: Regulatory Guide 8.7 (Section C.2.2) states that "if during the course of the year the dose to date for the year exceeds 1 rem CEDE [committed effective dose equivalent] or the individual receives an overexposure in another dose category, the CDE [committed dose equivalent] to the maximally exposed organ must be calculated, recorded and reported." If an individual arriving from work at another (previous) licensee's facility within the current year has a CEDE that exceeds 1 rem, does the guidance imply requirements for monitoring, recording or reporting of internal dose, even if the present licensee's prospective evaluation shows that the indivictual is not "likely to exceed" $10 \%$ of an annual limit on intake (ALI)?

Answer: For the situation described in the question, the quoted section of the Regulatory Guide 8.7 indicates that the previous licensee should have calculated, recorded, and should report the CDE to the maximally exposed organ. However, as indicated in Section C.1.1 of Regulatory Guide 8.7 , in performing the prospective evaluation (under 10 CFR 20.1502) to determine if monitoring is required "for individuals who received exposure at other facilities in the current year, the previous dose need not be considered in prospective evaluation. Only the dose that could be received at the facility performing the evaluation need be considered when determining the need for monitoring and, therefore, the recordkeeping and reporting requirements." (References: 10 CFR 20.1502, Regulatory Guide 8.7).

Question 429: A "Note" added to the answer to Question 126 clarifies the answer with respect to nuclear power plants. Does this clarification also apply to non-power reactor facilities?

Answer: Yes. As indicated in that "Note", workers at nuclear power plants, for whom individual monitoring is required and who are outside restricted areas need not wear personal dosimeters to measure external doses from effluents. However, they should wear personal dosimeters when performing work with or near licensed materials that are sources of external occupational exposure (e.g., when performing a radiation survey of a vehicle loaded with radioactive material ready for shipping.) (Reference: 10 CFR 20.1502).

NOTE: Questions 444, 445, and 446 relate to determining whether occupational radiation dose monitoring of an individual is required (i.e., is the individual likely to exceed $10 \%$ of an applicable limit?)

Question 444: In this example, it has been determined that an individual will receive less than 100 mrems in a year while in the controlled area, and the individual has therefore been classified as a member of the public while in the controlled area. The individual also accesses and performs work in the restricted area. In evaluating whether the individual requires monitoring in the restricted area, may the evaluation be limited to only the dose likely to be received in the restricted area, i.e., may the potential dose received in the controlled area be disregarded for the purpose of the evaluation?

Answer: The answer to the question is yes, assuming that the basis for classifying the individual as a member of the public while in the controlled aren is the type of work the individual will do in the controlled area.

As emphasized in the answer to Question 26(a), whether the dose to an individual outside a restricted area is an occupational dose or a public dose depends on what the individual is doing and not on what area (controlled or unrestricted area) the individual is in when the dose is received. Furthermore, it is possible, and acceptable (as indicated in many previous questions and answers), for the licensee to consider the dose (other than background, etc.) that individual receives in a controlled area to be an occupational dose, even though, as stated in the question, the dose the individual receives in the controlled area is less than 100 mrem per year. Regardless of the magnitude of the dose, the dose is an occupational dose if it is received (in accordance with the definition of occupational dose) ". . . in the course of employment in which the individual's assigned duties involve exposure to radiation and to radioactive material ..." For example, an individual who performs a radiation survey, in any area, of a vehicle loaded with radioactive material prepared for shipment would be receiving an occupational dose as a result of exposure to the radiation from the radioactive material on the vehicle regardless of the magnitude of the dose. However, the dose (other than background, etc.) received by a worker performing office work in a controlled area could be considered to be either 
an occupational dose or a public dose; either choice would be considered to be consistent with the definition of "occupational dose." See Question 26 and answer for additional information concerning licensee options with respect to area designations and dose categories. See Question 126 concerning the use individual monitoring of occupational doses from effluents. (References: 10 CFR 20.1502, 10 CFR 20.1003).

Question 445: In this example, it hus been determined that an individual is not likely to exceed 5 rems shallow dose equivalent from any sources with the possible exception of dose from hot particles. There is a potential that exposure to an individual from a hot particle may occur and that the dose to the individual from a hot particle, should it occur, may potentially exceed 5 rems shallow dose equivalent. In this circumstance, may the potential dose resulting from a potential exposure to a hot particle be disregarded for the purpose of the evaluation on the basis that the dose is not likely to exceed $10 \%$ of the applicable limit? Note that the scope of this question is limited to the requirements for individual monitoring (\$20.1502) and is not intended to address the general requirements for radiological surveys (820.1501).

Answer: Yes. The fact that an individual has the potential to receive a dose does not mean that the individual is likely to receive the dose. [Note: It should also be recognized that individual monitoring devices (personal dosimeters) are not appropriate for measuring doses from hot particles on or near the skin.] (Reference: 10 CFR 20.1502).

Question 446: In this example, an individual has worked at the licensee's facility earlier in the current year and was required to be monitored because the individual accessed a high radiation area. During this period, the individual's monitored dose did not exceed $10 \%$ of a limit. Now the individual is performing other work at the licensee's facility in the restricted area, but no longer has access to high radiation area. An evaluation based on the individual's new job scope shows that the individual is not likely to exceed $10 \%$ of a limit for their entire period of work during the year at the licensee's facility. (a) May the personnel dose monitoring of the individual be discontinued on the basis that the individual is not likely to exceed 10\% of a limit and the individual no longer has access to high radiation areas? (b) If so, must the individual's dose monitoring results, acquired during the period of required monitoring, still be reported in accordance with $\$ 20.2206$ "Reports of Individual Monitoring"? The purpose of these questions is to determine under what conditions required individual monitoring may be discontinued as no longer required.
Answer: (a) Yes. (b) Yes. (References: 10 CFR 20.1502, 10 CFR 20.2206).

Question 461: Does the word "applicable" in the phrase "applicable ALI(8)" in 10 CFR 20.1502(b)(1) mean that the stochsstic ALI(s) [SALI(s)] should be used?

It is noted that 10 CFR 20.1502(b) requires the licensee to monitor the occupational intake and assess the committed effective dose equivalent. We believe that the answer to this question should be yes, if a licensee is operating under the "more limiting" dose limit of 5 rem TEDE. The occupational dose limits in 10 CFR 20.1201 apply to the "more limiting" of 5 rem TEDE or 50 rem TODE. If a licensee's prospective assessment shows that the exposure conditions at their facility is most likely to be limited by the 5 rem TEDE limit, then the "applicable" ALI is the SALI. This is further shown by the wording used in 10 CFR 20.1502(b); i.e., use of the "committed effective dose equivalent" terminology.

Answer: No, not necessarily. The "applicable" ALI is the ALI for the appropriate radionuclide, the appropriate column (inhalation or ingestion), and, for inhalation ALIs, the appropriate "class" (D, W, or $Y$ ). When both a stochastic and a non-stochastic inhalation ALI are listed for a particular radionuclide (e.g., for I-131), the "applicable ALI" in 10 CFR 20.1502(b) means the more limiting ALI, which is listed first (the non-stochastic ALI), not the stochastic ALI, which is listed second and is shown in parentheses. The statements made by the questioner following the question are not relevant to the question. (Reference: 10 CFR 20.1502).

\subsection{SUBPART G - CONTROL OF EXPOSURE FROM EXTERNAL SOURCES IN RESTRICTED AREAS}

\section{CFR 20.1601 - Control of Access to High Radiation Areas}

Question 218: 10 CFR 20.1601(a)(1) says that the control devices must cause the radiation level to be reduced "upon entry." (a) Must the devices preclude authorized or unauthorized entry? (b) At what point must the control devices activate, when a person passes the final $30 \mathrm{~cm}$ before, or entry itself? 
Answer: (a) 10 CFR 20.1601(a) requires that entrance or access points to a high radiation area have "one or more" of the listed features to preclude excessive radiation exposure to an individual. The control device in subparagraph (1) stipulates only that it cause the radiation level to be reduced so that an individual, upon entry, could not receive 100 mrem in an hour within $30 \mathrm{~cm}$ of an accessible area of the source. This paragraph does not distinguish between "authorized" or "unauthorized."

(b) The control device must activate "uponentry into the area" at the "entrance or access point." (Reference: 10 CFR 20.1601)

Question 219: 10 CFR 20.1601 requires control of access to high radiation areas. It provides an exception for access to hospital areas with patients containing radioactive material, "provided that there are personnel in artendance..." who will take certain specified precautions. (a) Does a nursing station within line-of-site of a patient's room satisfy the requirement? (b) Does a nursing station controlling access to a ward, but not in the line-of-site, satisfy the requirement?

Answer: (a) Yes, provided there are personnel in attendance at all times who will take the necessary precautions to prevent the exposure of individuals to radiation or radioactive material in excess of the limits established in Part 20, and operate within the ALARA provisions of the licensee's radiation protection program.

(b) Yes, provided the room is properly posted. (Reference: 10 CFR 20.1601, Appendix X to Regulatory Guide 10.8)

Question 373: What are the minimum requirements for height and access restrictions of barriers used to prevent entry to locked high radiation areas (HRAs) and very high radiation areas (VHRAs) at nuclear power plants?

Answer: The NRC has prepared Regulatory Guide 8.38 that details control measures that should be implemented for such areas. This regulatory guide provides guidance on the following program elements as related to control of locked HRAs and VHRAs: management controls, procedural controls, training, communications and physical controls.

In general, there are no prescriptive, specific minimum height requirements for barriers preventing entry to locked HRAs and VHRAs. It is required that physical controls (such as barriers) provide assurance that individuals are not gaining unauthorized access to locked HRAs. For VHRAs, 10 CFR 20.1602 requires "additional measures to ensure that an individual is not able to gain unauthorized or inadvertent access." The NRC staff realizes that tools (wrenches, wire cutters, cutter torches) are readily available in a nuclear power plant and that it is virtually impossible to prevent determined willful circumvention of physical barriers. However, physical controls can and should be established so that any such willful acts are detectable (i.e., they result in cut locks or fencing, wall panels removed, etc). For example, the use of a fence to prevent access to a VHRA would not satisfy the requirements of 10 CFR 20.1602 if an individual could gain access to the VHRA by climbing over the fence. (References: 10 CFR 20.1601, 10 CFR 20.1602)

Question 385: Do licensees have discretion regarding the form and applicability of additional posting and barriers for individual high radiation areas (HRAs) that are located within a larger area posted and barricaded (e.g., with a locked door) as an HRA or inside a posted HRA control point? If licensees must post and barricade such individual HRAs at each area's entrance, then "double posting" results. Double posting has long been a concern due to the confusion that it might create for workers. The need to clearly identify to workers areas with high radiation levels might be accomplished through posted survey maps, "hot spot" stickers, or other means. In addition to effectively accomplishing the need for notifying workers of high radiation areas, these methods may be preferable to posting and barricading each HRA, located as described above, due to potential dose savings that could result from fewer entries into the area solely for the purpose of verifying the secondary postings and barriers. This question is intended to establish flexibility in implementation, appropriate to the circumstances, to maintain control over access and inform workers in an effective and efficient manner.

Answer: Power reactor licensee discretion and flexibility with respect to posting and barriers for high radiation areas is the same under revised Part 20 and applicable Technical Specifications as it has been under old Part 20 and applicable Technical Specifications. Existing guidance on control and posting of high radiation areas is contained in the Health Physics Positions (HPPOS) Data Base (NUREG/CR-5569, Rev. 1). The particular question of individual HRAs that are located within a larger posted and barricaded HRA or inside a posted HRA control point is addressed in the documents identified as HPPOS-014 and HPPOS-066 in NUREG/CR-5569, Rev. 1. HPPOS-066 is IE Information Notice No. 84-82, "Guidance for Posting Radiation Areas," dated November 19, 1985. Other related guidance is contained in HPPOS-036, HPPOS-234, HPPOS-242, and HPPOS-210. This guidance will continue to be applicable under the revised Part 20. Regulatory Guide 8.38 also 
contains guidance on this subject for nuclear power plants. For most material licensees, posting and access control requirements contained in 10 CFR Parts 20,34, 35, and 36 should be adequate. More detailed information and requiremonts would bo contained in individual licenses and license applications. (References: 10 CFR 20.1601, 10 CFR 20.1902).

Question 430: Question 373 concerns the minimum requirements for height and access restrictions of barriers used to prevent entry to locked high radiation areas (HRAs) and very high radiation areas (VHRAs) at nuclear power plants. Does this question and answer also apply to nonpower reactors?

Answer: No. The answer to Question 373 and Regulatory Guide 8.38 which is referred to in the answer were all written to address conditions at nucloar power plants and are not necossarily adaptable to all situations at non-power reactors, materials, or fuel cycle facilities. Furthermore, the answer to Question 373 states that, in general, there are no proscriptive, specific minimum height requirements for barriers used to prevent entry to locked HRAs and VHRAs. (Reference: 10 CFR 20.1601, 10 CFR 20.1602).

Question 431: Although Question 385 does not refor to any particular class of licensee (e.g., power reactor, non-power reactor, materials), the answer to the question mentions only power reactor licensees and material licensees. Does the answer to this question also apply to non-power reactor or fuel cycle licensees?

Answer: Yes, to the extent that the situations described in the answer apply to non-power reactors or fuel cycle licensees. However, there may be situations at non-power reactors and fuel cycle facilities that are not within the scope of the answer. (Reference: 10 CFR 20.1601).

\section{CFR 20.1602 - Control of Access to Very High Radiation Areas}

Question 49: For control of access to very high radiation areas, will physical barriers be needed to prechude unauthorized accoss?

Answer: Yes. See draft Regulatory Guide 8.N10. (Reforence: 10 CFR 20.1602)
Question 92: At power reactor facilities, when the reactor is at power, very high radiation areas (due to neutron and N-16 gamma radiation fiekds) can exist inside the primary containment. At some facilities, these areas inside containment are not readily locked, without substantial plant modifications to make them lockable. In recognition of this situation, the following controls are planned to meet the requirements of 10 CFR 20.1602 as it relates to a PWR or de-inerted BWR containment at power: When the reactor is at power and entry is not required, the primary containment access hatch (and any other access way) will be locked and posted as a very high radiation area. The key control access and special radiation work permit for entry will be in accordance with, or provide protection equivalent to, the guidance in draft Regulatory Guide DG-8006. When the reactor is at power, and entry is required, a qualified (in accordance with the applicable ANSI standard) radiation protection technician will accompany and provide continuous job coverage to each (small) group of workers assigned to perform a particular task (e.g., surveillance). Do the preceding controls moet the intent of 10 CFR 20.1602?

Answer: Yes. The controls outlined are an example of one way (but not the only way) to comply with 10 CFR 20.1602 in this situation. (References: 10 CFR 20.1003, 10 CFR 20.1602).

Question 220: 10 CFR 20.1602 gives requirements for control for access to very high radiation areas, and has no exemption clause. 10 CFR 20.1003 defines a very high rudiation area. (a) Are teletherapy rooms or fixed/field radiography facilities, with beams that can deliver in excess of 500 rad in 1 hour at 1 meter, very high radiation areas? (b) Do the requirements in 20.1602 apply to teletherapy rooms or fixed/field radiography facilities?

Answer: (a) Yes.

(b) Yes. However, this does not prohibit patients from receiving prescribed medical treatment in a teletherapy room (Reference: 10 CFR 20.1602, 10 CFR 20.1003)

Question 423: Standard Technical Specification (STS) 6.12 for nuclear power reactors provides methods for control of access to high radiation areas that are alternatives to the methods specified in a CFR Part 20. Power reactor licensees that have adopted this technical specification are required to provide additional controls for access to high radiation areas with dose rates greater than $1 \mathrm{rem} / \mathrm{h}$ in addition to the controls required for access to high radiation areas with dose rates of $1 \mathrm{rem} / \mathrm{h}$ or less. Providing the additional controls at $1 \mathrm{rem} / \mathrm{h}$ is conservative relative to providing 
additional controls for areas having dose rates of 500 rads or more in an hour as required for very high radiation aroas by 10 CFR 20.1602. Do licensees that have adopted STS 6.12 , and that are providing tho additional controls required by this STS for areas with dose rates greater than 1 rom por hour or less, have to provide additional controls for very high radiation areas in accordance with 10 CFR 20.1602?

Answer: Yes, they do. The alternative controls for high radiation aroas in STS 6.12 do not apply to the now requiroment in 10 CFR 20.1602 to provido additional controls for very high radiation areas. The compensatory measures in the STS that provide alternative methods of control for areas with dose rates greater than 100 mrem per hour but less than $1000 \mathrm{mrem}$ per hour do not constitute adequate controls over access to very high radiation areas. (Referencos: 10 CFR 20.1601, 10 CFR 20.1602, Reactor Technical Specifications)

Question 447: Is the spent fuel pool, when contrining irradiated fuel, required to be posted and controlled as a Very High Radiation Area under any of the following circumstances:

a. When there are no activities underway involving the spent fuel pool?

b. When underwater manipulation of irradiated fuel or other irradiated hardware is underway?

c. When diving operations in the spent fuel pool are underway?

d. Are there other considerations that could affect requirements for posting and controlling access to the spent fuel pool?

Answer:

(a) No.

(b) No.

(c) The answer depends on the particular circumstances of the diving operations. See discussion under (d) below.

(d) See Health Physics Position documents HPPOS-016 and HPPOS-245 (NUREG/CR-5569, Rev. 1.) for additional information concerning access controls for spent fuel pools and HPPOS-002 for additional information concerning diving operations in a spent fuel pool. These position documents refer to 10 CFR 20.203(c) of Part 20 prior to the 1991 revision with respect to posting and control of high radiation areas; bowever, these positions continue to be applicable with respect to posting and control of both high and very high radiation areas under 10 CFR 20.1601, 10 CFR 20.1602, and 20.1902(b) and (c) of the revised Part 20. These position documents emphasize that whon a diver enters the pool to perform "under pool-surface chuties" or upon movement of highly radioactive materials stored in the pool, proper bealth physics controls must bo initiated. IE Information Notice No. 90-33, dated May 9, 1990, providen suggeations for radiological control considerations that can holp minimize the possibility of unexpected exposure from radiation sources in spent fuel pools. (Reforences: 10 CFR 20.1602, 10 CFR 20.1902, 10 CFR 20.1003).

Question 448: If irradiated hardwaro, suspended (e.g., on a lanyard) in the apent fuel pool, is potentially reading greater than $\mathbf{5 0 0}$ rads/hour at ono meter (i.e., if it were removed from the pool), does access to this hardware require posting and control as a Very High Radiation Area?

Answer: No. Seo Section 4.2, "Materials," in Regulatory Guide 8.38, "Control of Access to High and Very High Rediation Areas in Nuclear Power Plants." Also see Health Physics Position document HPPOS-245 (NUREG/CR-5569, Rov. 1.). Although this position doctiment was written to address access controls for spent fuel pool storage pools under the unrevised Part 20 requirements for high radiation areas, it also applies to these access controls under the revised Part 20 requirements for both high and very high radiation areas. The essential point is that although movement of radioactive material stored in the pool has the potential to create a high, or very high, radiation area around the pool, those areas are not created until movement of the material actually results in a radiation level, in an aren that is accessible to individuals, that meets the dose critorion in the definitions of a high, or a very high, radiation area. NRC Information Notice No. 90-33, dated May 9,1990 , is also relevant. After providing reviews of a number of events in which sources of unexpected occupetional radiation exposures were encountered in activities associated with spent fuel storage pools, this notice provides suggestions (which are not regulatory requirements) for radiological control considerations that can belp minimize the possibility of unexpected exposures from radiation sources in these pools. (References: 10 CFR 20.1602, 10 CFR 20.1601, 10 CFR 20.1003).

\section{CFR 20.1603 - Control of Access to Very High Radiation Areas-Irradiators}

Question 130: 10 CFR 20.1603(a), Footnote 2, exempts a nuclear power plant from the requirements of $\$ 20.1603$ 
unless a non-eelf-shielded irradiator is used at the reactor. (a) If the source used for the calibration of high-radiation instruments is non-self-shielded, and the absorbed dose at 1 meter diatance could exceed 500 rads in 1 hour, is the source an irradiator? (b) Do the provisions of 820.1603 (a) apply?

Angwer: (a) No. An "irradiator," as tho term is used in 10 CFR 20.1603, uses gamma radiation to irradiute products to chenge thoir charactoristics in somo way (5S FR 50008, 12/4/90, Licenses and Rediation Safoty Requirements for Large Irradiators, proposed 10 CFR Part 36). A radionctive source used for calibrating radiation survey instruments is not an "irradiator."

(b) No. However, the provisions of 10 CFR 20.1602 would apply. (Reforence: 10 CFR 20.1603).

\subsection{SUBPART H - RESPIRATORY PROTECTION AND CONTROLS TO RESTRICT INTERNAL EXPOSURE IN RESTRICTED AREAS}

\section{CFR 20.1701 - Use of Process or other Engineering Controls}

Question 90: Can a licensee require its workers to routinely take potassium iodide (KI) when handling large quantities of radioiodine and take credit for the rechuction in occupational dose that results from the ise of the KI?

Answer: No. Requiring the use of KI for this purpose is neither a "process or engineering control...to control the concentration of [radioiodine] in air" (10 CFR 20.1701). Furthermore, because KI blocks uptakes (not intakea), the use of $\mathrm{KI}$ for thyroidal blocking cannot be considered to be among the "other controls" required by 10 CFR 20.1702 for limiting intekes. The following cautionary note in NRC Information Notice 88-15 (4/18/88) continues to be applicable under the Revised Part 20:

"It is important to stress that the use of potassium iodide is not a substitute for preventive measures; e.g., proper handling techniques, control measures, and emergency procedures that protect the individual from exposure to radioactive material."
A licenses should optimize design and engineering controls, as well as operating procedures, as a moans of ensuring that doses from nirborne redioiodine are ALARA. However, in situation where KI has been administored following a suspected intake, the licenses may take credit for the protection if bioassays support the effectiveness of the $\mathrm{KI}$ in blocking tho thyroid.

Finally, although licensees are not authorized to requiro thoir employees to routinoly take $\mathrm{KI}$ when working with radioiodino, nothing in NRC regulations probibits an individual from taking $\mathbf{K}$ on e purely vohntary heria; however, the NRC does not recommend the voluntary use of $\mathrm{KI}$ in this manner. (Reference $10 \mathrm{CFR} 20.1701$ )

Question 115: The words, "e.g., containment or ventilation," have been added to 10 CFR 20.1701. Does this mean that increased emphasis is boing placed on glove bags to do valve replacements, repacks, otc. at nuclear power plants?

Answer: No. These words were added simply to provide exumples of "process or other engineering controls." (Reforence: 10 CFR 20.1701)

\section{CFR 20.1702 - Use of Other Controls}

Question 145: Automated porsonnel contamination monitors ("portal monitors") are used at nuclear power plants to detect radioactive surface contamination on the skin and clothing of workers. The alarm setpoints for these monitors are maintained very low to detect low lovels of surface contamination and hot particles. Implementation of the "respirator ALARA rule," [10 CFR 20.1702 and $20.1703(b)(1)]$ may result in intakes of radioactive material by workers that will trigger the alarms on these monitors. Would the NRC object if, to facilitate compliance with the "now respirator ALARA rule", portal monitor set points were raised to a more reasonablo lovel?

Answer: Set points for automated personnel contamination monitors are established by, and can be changed by, licensees without NRC approval. NRC has no requirement that licensees use automated personnel monitors nor does it have numerical guidance on set points for these monitors (unless a licenseo has committed to using automated personnel contamination monitors, with a particular set point in a license application). However, if a licensee uses these monitors and the monitor alarms because of an intake (rather than because of external contamination), that intake should be evaluated. The question implies that the detection of small intakes of radioactive material using these monitors is 
undeeirablo and should be avoided by nining the monitor set points above their current lovels. This is not necessarily the case. At loast one nuclear power reactor licenseo has recognized that the sensitivity of theee monitors for delecting intakes can bo used to advantage in internal "passive intornal monitoring program" for workers for whom individual monitoring for intake is not required by 10 CFR 20.1502(b). That licensee plass to use these monitors with a setpoint that results in the reliable detection of internal contamination equivalent to s $1 \%$ of the ALI for mixtures of radionuclides encountered in the licenese's plant. (Reforence: 10 CFR 20.1702)

Question 385: In evaluating whether to require the use of respirators to limit intakes, it is found that woaring a respirator will likely increase the total offective dose equivalent (TEDE). However, the workere requeat that thoy bo allowed to wear respirators to limit intakes, despito the results of the ovaluation. With regard to NRC regulation, what discretion may the licenseo oxercise in this circumstanco?

Answer: 10 CFR 20.1702 provides for the use of respirators consistent with maintaining the TEDE as low as is ressonshly achiovable. Assuming that the licensee has provided appropriato training to the workere in question, the liconsee may exerciso discretion on a caso-by-case basis in determining whethor to grant approval to a worker's request for using a rospirator whon the TBDE-ALARA determination dictates that respiratory protection not be used. The NRC staff realizes that the significand "culture shif" "/paradigm shift" (i.o., changing from the traditional operational philosophy of not allowing any worker intakes to one of allowing some intakes when this is consistent with the goal of maintaining the TEDE ALARA) may not take place quickly. Purthermore, acceptence of this chenge will certainly be difficult for somo individuals. Therefore, the NRC staff realizes that during this transition poriod licensees will need reasonable flexibility to allow for individual needs and problems in making this shift. Howevor, the staff expects that over time the transition to ALARA-TEDE will be made and this worker acceptanco problem will becomo an excoptional occurrence. In the meantimo, when assigning a respirator to the requesting worker, the licensee shoukd make every reasonable effort to provide the worker with a respirator that minimizes the loss of worker officiency. Note: The NRC staff is aware of existing state OSHA regulations that reppire an employer to provide a worker with a respirator upon request; compliance with such stato regulations is accoptable to the NRC staff. See the answer to the related Question 387. (Reference: 10 CFR 20.1702, 10 CFR 20.1703).
Queation 387: In ovaluating the use of respirators to limit intukes, in addition to determining the total effective dose equivaloat (TBDE), should the ovaluation and subsequent docision on whether to use respirators also consider industrial safoty hazards associated with wearing respirators? For example, added offort increasing the probability of heat strese, limited range of vision while climbing, or difficulty of munouvering readily whilo working in confined spaces due to wearing a respirator may pose potentially greater safoty riske than doos the potential dose from uptake of aistorne radionctive matorial to which an individual might be oxposed by not wearing a respirator.

Answer: 10 CFR 20.1702 provides for the use of respiraton consistent with maintaining the TEDE as low as is renanably achievable. A reduction in the TEDE for a worker is not menonshly achiovablo if an attendart increase in the worker's industrial boulth and safoty risk would oxceed the benefit to be obtained by the recluction in the radiation risk associated with the reduction in the TEDE. Tho NRC has nover maintained that application of the ALARA principle requires ignoring factors other than radiation that may have an adverse impact on public health and safoty. (Roferences: 10 CFR 20.1702, 10 CFR 20.1703).

Question 388: In rogard to Question 91 (proviously answered in the thind set of Q\&As), cen NIOSH approved respiratory oquipment which makes use of a combination particulate filter and iodine sorbent with a protection factor for particulates be used in a mixed particulate and iodine atmosphere to limit intakes? This practice would seem valid for equipment that is NIOSH approved and has a protection factor for particulates.

Answer: Yes. However, there is no assigned protection factor for radioiodine with this equipment. [The NRC may authorize radioiodino protection factors for this equipment in accordance with 10 CFR 20.1703(b)(2) as it has previously authorized them in accordance with 10 CFR 20.103(d).] (References: 10 CFR 20.1702, 10 CFR 20.1703).

Question 449: Detectablo, minor intakes may result for somo individuals who do not wear respirators during specific radiological work activitios for the purpose of maintaining the total offective dose equivalent (TEDE) as low as is rensonably achiovablo (ALARA), as required by regulation. Such resulting intakes may involve substantial follow-up activitios in torms of bionssay, internal dose assessment, and responses to various monitor alarms (e.g., hand-held friskors and portal monitors) as the indivictual continues to perform work in the restricted area in the period following the 
intake, due to the senvitivity of the monitors and the low monitor alarm sot points, established to detect umall amounts of contamination or hot particles on individuale exiting work areas or the restricted area. In ovahuating whether or not to use respirator in a given situation, may the assesement of costs versus benefits appropriately include the resource costs associated with follow-up activition to potential intakes, and ultimately be factored into the decision making on wearing respirators?

Answer: Yes; bowever, there is no requirement that these costs be considered. (Reforence: 10 CFR 20.1702).

\section{CFR 20.1703 - Use of Individual Respira- tory Protection Equipment}

Question 60: In a respiratory protection program what reconds are needed of evaluations that demonstrate complince with the requirement for mintaining the total effective dose equivalent ALARA? For example, muat such an evahuation be made each time an individual is to wear a respirator?

Answer: Such reconds need not be made each time someone is to don a respirator. A licenses who performs and records such evaluations in accordance with the following guidance will be considered to be in compliance with the requirements for such ovaluations:

1. (a) If the licensee establishes a reasonable threshold value for prospective deep dose equivalent (rem) for en individual from a task/job balow which a recond of such an evaluntion is not needed, and

(b) the licensee establishes a threahold value for prospective colloctive deop dose equivalent (person-rem) from a tark/job balow which the record of much an ovaluation is not needed,

(c) in situations in which the licenseo plans to use respirntory protection equipment, the licensee does not need to record auch ALARA evaluations for situations in which the projected external dose to any individual is below the throsholds established undor 1(a) and 1(b) above for both the projected indivichual external dose [1(a)] and projected collective external dose [1(b)].

2. If the licensee establishes a threshold value for proupective intake of radionctive material (as a fraction of the ALI or as DAC-bours) for an individual from a task/job balaw which a record of such an ovaluation is not needed, in siturations in which respiratory protection equipment is not planned to be used, the licensee does not need to record such ALARA ovaluations when the prospective intake is bolow the throshold.

3. Irreupective of the statements in $\# 1$ and $\# 2$ above, the licensee does need to perform and record such evaluations for situations to which the ALARA provisions of $10 \mathrm{CFR}$ 20.1703 (b)(1) apply, that is to situations in which it is anticipated that protection factor for the respiratory protection equipment to be provided is less than the multiple by which the peak concentrations of airborne radioactive materials in the working area are expected to exceed the concentrations rpecified in Appondix B Table 1, Col, 3.

4. Regandleas of the magnitude of the projected external dose, the licenses does not need to perform or record such ovaluation before requiring the use of respiratory protection equipment a a precautionary measure in situations in which there is a large uncertainty in the magnitude of the projected concentrations of airborne radioactive material to which the workers will be exposed (0.8., a now job with no history of previous similar jobs), (References: 10 CFR 20.1101(b), 10 CFR 20.1703)

Question 78: Under 820.1703(d), licensees must notify the NRC Regional Director at leat $\mathbf{3 0}$ days prior to firat using respiratory protection equipment pursuant to $\$ 20.1703$ (a) or (b). All current respiratory protection programs have been documented undor the provisions of $820.103(\mathrm{~g})$ which contains equivalent language. Do licensees need to "re-notify" NRC if such notification has already taken place under the "old" Part $20 ?$

Answer: Licensees do not need to "ro-notify" NRC if such notification hes taken place under the old Part 20.

(Reforonce: 10 CFR 20.1703(d)).

Question 91: As long a no credit is taken for the protection provided by the respiratory protection equipment, the old Part 20, in 10 CFR 20.103(c), allows licensees to use this equipment without meeting the requirements of 10 CFR 20.103 (c)(1) through 20.103(c)(4), inclusive. Has this "loophole" in the old Part 20 been closed in the revised Part $20 ?$

Answer: Yes. 10 CFR 20.1703(a), which contains requirements similar to those in 10 CFR 20.103(c), imposes these reguirements "if a licenseo uses respiratory protection equipmont to limit intakes," regardless of whother the licon$s e 0$ makes "allowance for this use of respiratory protective equipment in estimating exposures of individuals . . .." (Reference: 10 CFR 20.1703) 
Question 124: Do the requirements of 10 CFR 20.1703(a) apply to respiratory protection equipment that is to be used only in emorgonciea?

Answer: Yes, if that equipment is to be ueed to limit intakes of radioactive material. (Reforence: 10 CFR 20.1703)

Question 131: 10 CFR 20.1703(a)(3)(iii) requires that respirators bo tested for operability immediately prior to aach use. How is this to be done?

Answer: This requirement is not now. It is essentially the same as the requirement in 10 CFR 20.103(c)(2). For guidance on respirator operability tonts (fit chocke), Regulatory Position C.4.C in Regulatory Guido 8.15, (2) Section 8.5.2.3 in NUREO-0041, and (3) Section 7.4 and Appendix A7 in ANSI Z88.2-1980. (Reforence: 10 CFR 20.1703).

Question 132: How are nuclear power plant licenseen to identify the "potential" hazard using air armpling techniques as spocified in 10 CFR 20.1703(a)(3)(i)? (Air sampling is only useful in hazard identification affer radionctive material becomos airborno).

Answer: 10 CFR 20.1703(a)(3)(i), which requires that a rospiratory protection program inchudo "air sampling sufficient to identify the potential hazand . . .", usee the word "potential" with renpect to the hezard because airborne radioactive matorial is only a "potential" hazard to a worker until the worker is exposed to it. Bofore workers enter an aren containing airborne radionuclides, the concentrations of those radionuclides should be ostimuted using air sampling. This is not a now requirement (see 10 CFR 20.103(c)(2). The potential hazard of radioactive material that may bocome, but that has not yet become, airborno can't be identified by air sampling. The potontial hazard must bo identified by other means (e.g., using the experience gained in previous similar activition that cause radionctive material to becomo airborno). Procedures that have been accoptable in the past for identifying potontial hazards of airbome radioactive matorial, or of radioactive material that may becomo airborne, will continue to be accoptable. (Reforence: 10 CFR 20.1703)

Question 374: In genoral, do established respirator offectiveness programs at nuclear power plants moet the intent of the rogulation in providing assurances of the offectiveness of chosen respiratory protection?
Answer: Yos. There is no explicit requirement in 10 CFR Part 20 for a "rospirator offectivenese program" other than the requirement of 10 CFR 20.1703(a)(3)(ii) for "surveys and bionsays, as appropriate, to ovaluato actual intakes." 10 CFR 20.1704 specifies that the Commission may impose additional reatrictions to ensure that the respiratory protection program is adequate and to limit the extent to which a licensee may we reepiratory protection equipment instead of process or other ongineering controls. The NRC staff does not anticipale a noed to impose further restrictions on the use of respiratory protoction equipment at nuclear power plants pursunet to 10 CFR 20.1704. Also as indicated in the (rovined) anowor to Quostion 54, information from a "respirator effectivenoses program" can be used to justify the assumption that the concontrations of radionuclides in air to be used for detormining whether or not monitoring is required [pursuent to 10 CFR 20.1502(b)] are the concentrations that include credit for the assigned protection factors when respinators are to be used, rather than the concentrations without that credit. See the answer to the related Question 376. (Reforences: 10 CFR 20. 1703, 10 CFR 20.1704, 10 CFR 20.1502)

Question 418: This question refers to the answer to Question 91 in 820.1703 . Please clarify this response, as indicated bolow.

(a) Can NRC envision any purpose by which a licenseo can use respiratory protection devices without having an approvod respiratory protection program, 0.g., meeting the provisions of $820.1703 ?$

(b) For instance, work is being conducted where the licen800 has determined there is no requirement for respiratory protection but workers prefor to use it anyway. From the workers porspective it is for protection. From the licensees viewpoint, it is simply for peace of mind, with the added benefit of boing an ALARA effort. Is this usage subject to $820.1703 ?$

Disciunion: If the answer to these questions is that 820.1703 applies to any conceivable use of respirators then this in essence is a directive for all licensees without approved equipment or an approved program to discard all respiratory protection equipment. It cannot be used even for ALARA purposes at less than DAC levels. It cannot be kept on hand for use in emergency response situations where any protection is useful in initial response conditions. (Note: As a basic presumption, assume that any use of respirators complies with the basic OSHA guidance for medical approval.) 
Anwer: (a) The requirements of 10 CFR 20.1703 must be $m$ if the respirntory protection equipment is used to limit intakes of rudionctive matorial purnuant to 10 CFR 20.1702. 10 CFR 20.1703 does not apply if the respiratory protection equipmeat is uned for other purposen (0.8., for protection againat harmful duats, foge, fumes, mists, gases, smokes, uprays, or vapore that are not radionctivo); bowever, OSHA regulations (whioh inchudo a requiremeat for a minimal ecosptablo reopiratory protection program) do apply to most of these uese.

(b) Yes, assuming that tho equipmont will be used to limit intake, this usage is subject to 10 CFR 20.1703. The use of respiratory protection equipment without moeting the respiratory protection program requirements of 10 CFR 20.1703 (0.8., respirator not properly maintained, poor fit of respirntor to wearer, untrained or improporly trained respirator user) can be hazardous to the worker, can load to a fales sease of protoction, and cannot be juatified on the basis of ALARA, worker peace of mind, or usofulnoses in an emergency. (Reforenco: 10 CFR 20.1703).

\subsection{SUBPART I - STORAGE AND CONTROL OF LICENSED MATERIAL}

\section{CFR 20.1801 - Security of Stored Material}

Question 129: 10 CFR 20.1801 and 20.1802 do not specify the quantitios of radioactive matorial bolow which unauthorized access to, unauthorized removal from, or the maintenance of constant survoillance over, aro not required in controlled aross. Will these requirements bo imposed (a) on all quantities of licensed mutorial, howover small and (b) on quentition that are exempt from laboling by 10 CFR 20.1905(a) and (b)?

Answer: (a) No. The requiremonts of 10 CFR 20.1801 and 20.1802 are not now; thoy are essentially the samo as the requirements of 10 CFR 20.207(a) and 20.207(b) except that the revised Part 20 requiremonts apply to controlled areas as well as unrestricted areas. NRC will continue to enforco these requirements as it has in the past.

(b) No. (Reforences: 10 CFR 20.1801, 10 CFR 20.1802, 10 CFR 20.1905)

Question 419: This question rofers to the answer to Queation 129 in $\$ 20.1801$. This is a very useful interpre- tution, but it cortainly is not ovident in the cited regulations. Is there reluted oupporting justification somowhero?

Answer: The answer to Question 129 is a statement as to how this requirement will be onforced by tho NRC staff (i.o., in the same way as similar requirements have been coforced in the pust). As indicated in the answer to Queation 129, the requirements of 10 CFR 20.1801 and 20.1802 are essentially the samo as the requirements of 10 CFR 20.207(a) and 20.207(b) excopt that 10 CFR 20.1801 and 20.1802 apply to controlled area as well as to restricted areas. Tho answer is based on the NRC staff's understanding of the intent of these requirements, as reflected in the staff's enforcement of the similar requirements of 10 CFR 20.207(a) and 20.207(b). (Reference: 10 CFR 20.1801).

Question 450: Licensees are required to "secure from unauthorized removal or access" licensed materials in storage, and to "control and maintain constant surveillance" of licensed matorials not in storage, in controlled or unrestricted areas. The following questions relate to the security and control of licensed materials in controlled areas anly, i.e., the questions aro not intended to address unrestricted areas:

a. Would the provisions for security and control be met if the licensed materials aro appropriately labeled or marked (0.8., in accordance with 820.1904 ) and are located within an aren to which access is controlled through the use of barrior ropes and sigas restricting access by unauthorized porsonnel?

b. Would the provisions for security and control bo met if the licensed materials were located in an aren as described in "a", above, that was located within a Part 50 licensee socurity protected area?

c. If the area described in " $a$ ", above, was posted with radiological caution signs (e.g., "Caution, Radiation Area"), would such an area actually be a restricted area, and therefore the provisions of $\$ 20.1801$ and $\$ 20.1802$ would not apply?

Answer:

(a) No. To secure the material from unauthorized removal means to make certain, to guarantee, and to ensure that there is no unauthorized removal of the material. Using nothing but ropes and signs to control access to the licensed materials does not secure stored material from unauthorized removal in accordance with 10 CFR 20.1801 and does not "maintain constant surveillance" of the material in accordance with 10 CFR 20.1802. 
(b) No. This use of barrier ropes and signs within a Part 50 licenses security protected aren does not necessarily secure the licensed metorial from unauthorized removal from that area (in accordance with 10 CFR 20.1801 for stored material) and does not provide the constant survoillance of the material (in accordance with 10 CFR 20.1802 for matorial that is not in storage). Individuals who are authorized to enter the security protected area are not necessarily authorized to remove the licensed material and, a indicated in the anewer to (a), above, this use of ropes and barriors does not secure the material from unauthorized use.

(c) No, not necessarily. Simply posting the area doscribed in part (a) of tho question with a "radiological caution sign", such as "Caution, Rediation Area," does not, in the absence of other moasures for access control, result in the creation of a "reatricted area" and, thoreby, make the provisions of 10 CFR 20.1801 and 20.1802 inapplicable. However, the provisions of 10 CFR 20.1801 and 20.1802 would not apply to the area doscribed in part (a), above, if that area is contained within a radiation area within a restricted area, access to which is adequately controlled. (References: 10 CFR 20.1801, 10 CFR 20.1802, 10 CFR 20.1003, 10 CFR 20.1904).

\subsection{SUBPART J - PRECAUTIONARY PROCEDURES}

\section{CFR 20.1902 - Posting Requirements}

Question 27: Do licensees have to post controlled areas (outside the restricted area) as airborne radioactivity areas if derived air concentrations (DAC) are oxcoeded?

Answer: Yes, if the airborne radionctivity is indoors. If the airborno radioactivity is outdoors, tho answer depends on the particular situation. In certain situations the licensee may need to identify and delineate an outdoor airborne redioactivity area. For example posting would be required in a small area, accessible to workers, in the immediate vicinity of a vent on the outside of a building, exhausting air containing concentrations of radionctive materials in excess of tho DACs apecified in Appendix B to 10 CFR Part 20. (References: 10 CFR 20.1003, 10 CFR 20.1902)

Question 53: (a) When a package is properly laboled for transport, shipping papers are still in effect, and a transporter has accepted rosponsibility for control of the package, do posting and labeling roquirements remain in effect while the package is on licensee property outside of the radiologically controlled area?

(b) Does the shipment have to be posted in the protected area?

(c) Does the shipment have to be posted within the ownercontrolled aroa?

(d) Once the transporter has taken control of a package and shipping papors are in offect, is the shipment exempt from posting?

Answer: The answer to all four questions is that the posting requirements remain in effoct until the transporter has actually taken possession of the package and is starting to transport it. Following are additional responses to three of the four specific questions:

(a) 10 CFR 20.1905(d) exempts this package from the habeling requirements of 10 CFR 20.1904(a).

(b) Whether or not the package is in a "protected area, " as defined in 10 CFR 73.2, is not relevant to any requirements in 10 CFR Part 20.

(c) Whether or not the package is in an "owner-controlled area" (or "controlled area" as defined in 10 CFR Part 20) is not rolovant to the posting requirements of 10 CFR 20.1902(o).

(References: 10 CFR 20.1902(e), 10 CFR 20.1903, 10 CFR 20.1904(a), 10 CFR 20.1905(d))

Question 85: In 820.1902, posting of areas is based upon "dose equivalent." Is this "deep, " "shallow, " "lens of eye," "total effective" or some combination of the above?

Answer: These posting requirements are based on the doep dose equivalent for "radiation areas" and "high radiation areas" and the absorbed dose at a tissue depth of $1 \mathrm{~cm}$ $\left(1000 \mathrm{mg} / \mathrm{cm}^{2}\right)$ for "very high radiation areas." See the answer to Question 74. (References: 10 CFR 20.1003, 10 CFR 20.1902)

Question 221: Since the posting requirements are all in terms of deep dose equivalent, what requirements should be followed when posting for low energy beta radiation?

Answer: Unless the beta particle can deliver a dose at a tissue depth of $1 \mathrm{~cm}$, the area does not require posting as a 
radiation area (20.1902(a)), high radiation area (20.1902 (b)), or very high radiation area (20.1902(c)); however, posting for airborne radioactivity area (20.1901(d)) and for areas or rooms in which licensed material is used or stored (20.1901(e)) needs to be considered for beta emitters. See Questions and Answers 57, 74, and 85 for more informa. tion. (Reference: 10 CFR 20.1902, 10 CFR 20.1901)

Question 379: Should radianctive noble gas concentrations bo oxchuded (a) with regard to evaluating and posting Airborne Radioactivity Areas and (b) in determining Derived Air Concentration-bours (DAC-hours)? The definition of Airborne Radionctivity Area refers to areas where airborne radionctivity concentrations exceed the DAC values or where an individual could exceed 12 DAC-hours in a week. DAC is defined as the "concentration of a specific radionuclide in air which, if breathed... results in an intake of one ALI [Annual Limit on Intake]." Tho values listed for radioactive noble gases in the DAC column in 10 CFR 20 Appendix B are identified as "submersion" values that apply to external, rather then internal, exposure. Also, there aro no ALI values listed in 10 CFR 20 Appendix B for radioactive noble gases. From this, it appears that radioactive noble gas concentrations do not apply to evaluating and posting Airborno Radioactivity Areas or to DAC-hour detorminations.

Answer: (a) Radioactive noble gas concentrations should not bo oxchuded with regard to evaluating and posting airborne radionctivity areas. See the discussion below.

(b) Radioactive noble gases of the "submersion" class (which bave no inhalation ALI) should be exchuded in determining DAC hours for use in determining the committed effective dose equivalent (CEDE). In other words, the DACs for noble gases aro based on external dose and should not be used to assess internal dose.

Discussion: The following discussion relates to the posting queation. Although the definition of DAC in 10 CFR 20.1003 does not include concentrations calculated on the basis of the external dose resulting from "submersion," Appendix B clearly states that the DAC values listed in Table 1 of Appendix B "relate to one of two modes of exposure: either external submersion or the internal committed dose equivalents resulting from inhalation of radioactive materials." The definition of "airborne radioactivity area" refers to "...concentrations - (1) In excess of the dorived air concentrations (DACs) specified in Appendix B...." Thus, the definition of "airborne radioactivity area" includes the DACs in Appendix B that are noble gases and that are based on "submersion." The preamble to revised Part 20 (56 FR 23379, second and third columns) also indicates that areas that meet the definition of "airborne radioactivity area" because of the presence of noble gases are required to be posted.) (References: 10 CFR 20.1902, 10 CFR 20.1003).

Question 459: In the answer to Question 379, the NRC addressed the issue of whether noble gases should be included in assessing the requirement to post an area as an airborno radioactivity area. This question is intended to obtain further clarification with regards to the two separate provisions that require posting of airborne radioactivity areas. The first provision requires posting of areas in which concentrations of airborne radioactive materials are "in excess of the derived air concentrations (DACs) specified in Appendix B." As pointed out previously (in the answer to Question 379), Appendix B includes DACs for noble gases, and therefore noble gas concentrations should be included in posting considerations. The second provision requires that posting be established for areas where an individual could "exceed...an intake of 0.6 percent of the annual limit on intuke (ALD) or 12 DAC-hours" in a week. The answer to Question 379 states, "radioactive noble gases ... (which have no inhalation ALD should be excluded in determining DAC hours for use in determining the committed effective dose equivalent (CEDE)." From this it appears that for the second provision regarding posting of airborne radioactivity areas, which established precautions to limit internal exposures from intakes, one should not take into account noble gas concentrations because they result in external exposures from submersion. However, noble gas radioactive daughters must be included when determining posting requirements under either provision. Is this clarification of the differences between the two provisions and respective applicability of radioactive noble gas concentrations correct?

Answer: Yes, assuming that it is understood that the "two provisions " in the statements preceding the question refer to the two parts of the definition (in 10 CFR 20.1003) of "airborne radioactivity area", which are separated by the word "or". There is only one "provision" that requires posting of airborne radioactivity areas, the "provision" of 10 CFR 20.1902(d). (References: 10 CFR 20.1902, 10 CFR 20.1502, 10 CFR 20.1003).

Question 460: Appendix B contains only one derived air concentration (DAC) value for each radionuclide. The DAC provided in Appendix B is derived from the more limiting of the stochastic or the non-stochastic annual limit on intake (ALD). In Regulatory Guide 8.34 (Section 3.3) the NRC provides guidance that the stochastic DAC should he used, in preference to the non-stochastic DAC, to calculate the committed effective dose equivalent (CEDE). This 
Regulatory Guide further provides a method for deriving stochastic DACs for radionuclides that only have the nonstochastic DAC listed in Appendix B. In addition, Regulatory Guide 8.7 (Section 2.2) provides guidance that if the CEDE does not exceed 1 rem, then organ doses, which utilize non-stochastic DACs for calculation, need not be calculated. Some licensees have concludied, from their prospective evaluations of potential internal dose to workers at their facility, that workers are not likely to exceed $10 \%$ of an ALI (i.e., are not likely to exceed 500 mrem CEDE). For the situation where the licensee has concluded that workers are not likely to exceed $10 \%$ of an ALI, may the licensee derive and use stochastic DACs, in liew of the nonstochastic DACs listed in Appendix B, for (a) posting and (b) exposure control purposes? Such an approach, employing the stochastic DACs, would allow licensees to more appropriately assess and control exposures commensurate with the applicable radiological conditions, than would be the case if the more conservative, non-stochastic DACs were used. For example, in evaluating the use of respirators with regard to keeping the total effective dose equivalent (TEDE) ALARA, the use of stochastic DACs, and respective calculated internal dose projections, would provide a more valid comparison with projected doses from external sources of exposure, than would be afforded through the use of non-stochastic DACs.

Answer: (a) No, with respect to posting of "airborne radioactivity areas" in accordance with the provisions of 10 CFR 20.1902(d) and the definition of "airborne radioactivity area" in 10 CFR 20.1003. The use of stochastic DACs in lieu of non-stochastic DACs listed in Appendix B would require an exemption, under the provisions of 10 CFR 20.2301 [applications for exemptions], from the posting requirements of 10 CFR 20.1902(d) [posting of airborne radioactivity areas].

(b) It is not possible to answer the general question with respect to "exposure control purposes," without having an explanation of what is meant by this term. However, in regard to the specific example given, the use of a stochastic DACs, and respective calculated internal dose projections, is acceptable in evaluating the use of respirators with regard to keeping the total effective dose equivalent (TEDE) ALARA, when this results in a more valid comparison with projected doses from external sources of exposure than would be afforded through the use of non-stochastic DACs. Note: See related Question 459 concerning the meaning of the word "applicable" in the phrase "applicable ALIs" in 10 CFR 20.1502. (References: 10 CFR 20.1902, 10 CFR 20.1502, 10 CFR 20.1003).

\section{CFR 20.1903 - Exceptions to Posting Requirements}

Question 35: Do posting requirements apply to the hospital room of a hospitalized nuclear medicine patient if the patient recrived less than $30 \mathrm{mCi}$ and the dose rate at 1 meter is grenter than $5 \mathrm{mrem} / \mathrm{hr}$ ?

Answer: No, the hospital room is nat required to be posted provided that the provision of $820.1903(\mathrm{~b})(2)$ is also met. (Note that only one of the three conditions in 820.1903 (b)(1) needs to be met and that one has been met). (Reference: 10 CFR 20.1903 (b)(1))

Question 223: Are radiographers exempt from posting at a temporary field site, under 10 CFR 20.1903(a), since they perform radiography in each area less than 8 hours, attend the material to prevent exposure of individuals in excess of the limits (i.e., have clear sight over the designeted area and are in constant attendance), and control the area (i.e., tell individuals to leave if they come too close to the source)?

Answer: The revised Part 20 requirements do not change this exemption. Radiographers continue to be exempt under 20.1903(a); however, industrial radiographers are required under 10 CFR 34.42 to conspicuously post areas where radiography is being performed. (Reference: 10 CFR $20.1903,34.42$ )

Question 224: 10 CFR 20.1903(a) gives exemptions to posting "caution signs" under certain conditions. Since 10 CFR 20.1902 specifies "danger" signs, instead of caution signs, (e.g., "grave danger, very high radiation area"), do the exemptions in 10 CFR 20.1903 apply to these "danger" areas as well?

Answer: No. The authorization to use only the term "danger" (vice "caution") for a very high radiation area provides emphasis to the potential hazards. There are no exemptions in the code for posting a very high radiation area. Since a high radiation area does not require using the term "danger," the exemption would apply to this area if the conditions of 10 CFR 20.1903(a) are met. (Reference: 10 CFR 20.1903, 10 CFR 20.1902) 


\section{CFR 20.1904 - Labeling Containers}

Question 127: 10 CFR 20.1904(a), Labeling containers, indicates in a parenthetical statement that "the radionuclides(s) present " may now be intended to be a part of the information required to be inchuded on labels. In reply to comments on this rule, the preamble (56 FR 23380, first column) provides a special interpretation for nuclear power plant licensees as to acceptable methods for compliance for labeling fission and activation product containers. Taken together, the rule and preamble can be understood to mean that nuclear power plant licensees are required by the revised Part 20 to include the words "activation products" and/or "mixed fission products" on all containers in which greater than an Appendix C quantity is present - a considerable undertaking which would not contribute appreciably to radiation protection. Do the words "such as" in the parenthetical statement mean that this interpretation is incorrect?

Answer: Yes. This interpretation of the rule and preamble is incorrect. The parenthetical statement provides examples of the types of information that may be included on the label; it is not a requirement to include all of the information in the parenthetical statement. However, 10 CFR 20.1904 does require the label to include sufficient information to permit individuals handling or using the containers, or working in the vicinity of the containers, to take precautions to avoid or minimize exposures. Simply having only "Caution, Radioactive Material" or "Danger, Radioactive Material" on the label is not sufficient. (Reference: 10 CFR 20.1904)

Question 128: If a package containing radioactive material is to be shipped, and marking the package as low specific activity (LSA) is the only U.S. Department of Transportation (DOT) warning requirement, is labeling under 10 CFR 20.1904(a) required?

Answer: No. Although the exemption of 10 CFR 20.1905(d) applies to U.S. Department of Transportation (DOT) "labeled" containers, not DOT "marked" containers, the Statement of Considerations, in discussing 10 CFR 20.1905(d) [56 FR 23380, second column], states that "Quantities and concentrations not requiring DOT labels would not warrant an NRC labeling requirement." See also the answer to Question 36 (10 CFR 20.1906), which indicates that DOT "marked" packages are not DOT "labeled" packages. (References: 10 CFR 20.1904, 10 CFR 20.1905).
Question 226: (a) Under 10 CFR 20.1904, what is a container? (b) How big can a container be? (c) Can a room be considered a container? (d) Is a transportation cask a container when it is not being transported? (e) Are vohicles (o.g., trailer of a tractor-trailer) containers?

Answer: (a) In the contoxt of 10 CFR 20.1904, and in accordance with Health Physics Position (HPPOS) 28, a container is a receptacle in which radioactive material is held or carried.

(b) There is no limit to the size of a container.

(c) Typically, a room is not considered a container; it is considered an area, and should be posted as such.

(d) A transportation cask or package in certain circumstances could be a container. If a container is in transport and packaged and labeled in accordance with Department of Transportation (DOT) regulations, it is exempt from the labelling requirements of 10 CFR 20.1904. If, however, the container/cask/package is not in transport, it is subject to the labelling requirements of 10 CFR 20.1904.

(e) Under certain circumstances, the trailer of a tractortrailer could be considered a container. (Reference: 10 CFR 20.1904, HPPOS 28)

\section{CFR 20.1906 - Procedures for Receiving and Opening Packages}

Question 36: Part 20 requires that "labelled packages" be monitored. Is it corroct to assume that only packages with White I, Yellow II, or Yellow III labels must be monitored, and that marked packages (LSA or radioactive markings) are not required to be monitored?

Answer: Yes. Based on the statement of considerations, it is correct to assume that only packages with DOT White I, Yellow II or Yellow III labels need to be monitored.

(Reference: 10 CFR 20.1906(b)(1))

Question 108: Can the surveys of radiographic exposure devices performed under 10 CFR 34.43(b) and (c) be used to show compliance with 10 CFR 20.1906(f)? If so, is it sufficient to document the survey once, to satisfy both requirements?

Answer: The survey performed to show compliance with 10 CFR 34.43(c) can be used to show compliance with 10 
CFR 20.1906(f). It is sufficient to document the survey results one time.

The survey performed to show compliance with 20 CFR 34.43(b) cannot be used to show compliance with 10 CFR 29.1906(f). The purpose of the survey performed under 10 CFR 20.1906(f) is to ensure the radioactive source is still properly lodged in its shield after transport. (Reference: 10 CFR 20.1906(f), 34.43(b), and 34.43(c)).

Question 227: (a) Must gauge licensees perform a survey of each gauge package (if the package is labeled with a DOT label) for contamination and radiation levels upon receipt of the package? (b) What surveys must a licensee perform during routine operation where portable gauges are transported daily from site to site, then returned to a storage location?

Answer: (a) As a result of amendments to Part 20 published on 8/31/92 [57 FR 39353], the licensee is not required to survey the gauge package for contamination if the source is in special form as defined in 10 CFR 71.4 and is not required to monitor radiation lovels unless the package contains quantities of radioactive material that are in excess of the Type A quantity, as defined in 10 CFR 71.4 and Appendix A to Part 71, provided there is not evidence of degradation of package integrity.

(b) If there is no evidence of degradation of package integrity, no surveys are required if the package contains less than or equal to a Type A quantity and the source is in special form. If the source is not in special form, contamination survey is required; if the source is greater than a Type A quantity, the external surface of the package must be monitored for radiation levels. (Referencrs: 10 CFR 20.1906, 71.4)

Question 228: A licensee (e.g., radiographer, moisture density gauge operator, well logger) has a source that the licensee transports to temporary job sites in a licenseeowned vehicle. 10 CFR 20.1906(f) exempts the licenses from doing contamination surveys during routine operations, but does not exempt the licensee from performing eurveys for radiation levels. (a) When must the licensee perform such surveys (i.e., when is the package "received")? Is it only after returning to the storage location at the end of the day? (b) Or is each transport from one temporary site to another considered a shipment, with a "receipt" at each job site?

Answer: (a) The source should be surveyed at the end of the work day, just prior to or immediately after storage. If the package contains quantities less than a Type A quantity, the licensee is not required to survey the surface of the package for radiation levels. If the package contains quantities of radioactive material in excess of a Type A quantity, as defined in 10 CFR 71.4 and Appendix A to 10 CFR Part 71, the licensee, in accordance with 10 CFR 20.1906(c), shall perform monitoring as soon as practicable but not later than 3 hours after the package is received at the licensee's facility if it is received during the licensee's normal working hours, or not later than 3 hours from the beginning of the next working day if it is received after working hours.

(b) No. The package "is received at the licensee facility" when it is returned to the storage location at the end of the day. It is not necessary to survey radiation levels at temporary job sites. (Reference: 10 CFR 20.1906, 71.4)

Question 229: Will the radiographers have to wipe test the sealed source upon receipt (10 CFR 20.1906(b)(1)) even if the manufacturer has performed a recent leak test on the source?

Answer: The requirements of 20.1906 refer to the external surface of package, not the source itself; the requirement to wipe test a source is usually a license condition. If the source is not a gas or not in special form, the licensee is required to monitor the labeled package (White I, Yellow II or III) for contamination regardless of whether a leak test has been performed. If the source is in special form as defined in 10 CFR 71.4, the external surface of the package does not need to be monitored for contamination.

(Reference: 10 CFR 20.1906, 71.4)

Question 230: 10 CFR 20.1906(a) gives specific requirements for packages containing radioactive material in excess of Type A quantities; it is not followed by the word "and." 10 CFR 20.1906(b) appears to apply to all packages as containing radioactive material, or labeled packages that are crushed, wet, or damaged. Is it a correct statement that 10 CFR 20.1906(b) requirements have nothing to do with Typo A quantities, and that (a) and (b) are independent requirements?

Answer: No. 10 CFR 20.1906(b)(2) correlates radiation lovel monitoring requirements with Typo A quantities; however, 10 CFR 20.1906(a) and (b) are independent requirements because 20.1906(a) delineates requirements for making arrangement for receiving radioactive material, and 10 CFR 20.1906(b) delineates the monitoring requirements once the material is received. See Question 227.

(Reference: 10 CFR 20.1906, 71.4) 


\subsection{SUBPART K - WASTE DISPOSAL}

\section{CFR 20.2001 - Waste Disposal - General}

Question 376: "Decay in storage" is one means of waste disposal authorized in the revised Part 20 [10 CFR 20.2001(a)(2)]. How can "decay in storage" be used for wastes (a) at nuclear power plants and (b) at materials facilities?

Answer: (a) The inclusion of the "decay in storage" option in revised Part 20 does not provide any new options for waste disposal at nuclear power plants. See the discussion of "decay in storage" in the preamble to revised Part 20 (56 FR 23380-23381). "Decay in storage" is a practical means of disposal only for radionuclides with short half lives. Wastes from nuclear power reactors usually inchude radionuclides whose half lives are too long for application of the "decay in storage" option. In any case, wastes that are to be released to unrestricted areas after having decayed in storage must meet the requirements of one of the other allowed forms of waste disposal in Part 20, or the requirements of \$35.92, "Decay in-storage," of 10 CFR Part 35 or the specific requirements given in the applicable NRC or Agreement State License conditions. However, the requirements of $\$ 35.92$ of Part 35 are not applicable to Part 50 licensees.

(b) As indicated in the answer to part (a) of this question, wastes that are to be released to unrestricted areas after having decayed in storage must meet the requirements of one of the other allowed forms of waste disposal in Part 20, or the requirements of $\$ 35.92$, "Decay in Storage," of 10 CFR Part 35 or the specific requirements given in the applicable NRC or Agreement State License conditions. For medical licensees (under 10 CFR Part 35), requests for specific license amendments providing exemptions from 10 CFR 35.92 may be considered by the NRC for approval based on extraordinary circumstances, in accordance with 10 CFR 35.19, provided that the licensee demonstrates a real need for the requested exemption. These exemption requests to NRC Regional Offices will bo reviewed at NRC Headquarters on a case-by-case basis under a technical assistance request from the Regional Office. See Question 389 for additional discussion of decay in storage.

(Reference: 10 CFR 20.2001).
Question 389: The revised 10 CFR 20 includes a new provision that allows disposal of licensed material "...by decay in storage..." What criteria should be used in implementing this provision? Is the NRC planning to develop generic guidance for "decay in storage"?

Answer: See the answer to Question 376 for a discussion of "decay in storage." As indicated in that answer, "decay in storage" is not a practical means of disposal of licensed material at nuclear power plants (and at some other facilities). Therefore, the NRC is providing no criteria to be used in implementing this provision at nuclear power plants and is not planning to develop (additional) generic guidance for "decay in storage" at nuclear power plants. As noted in the statement of considerations for revised Part 20 (56 FR 23380 , third column, and 23381, first column), technically, the "decay in storage" option has always been available to licensees as an allowed waste disposal option. This option was formally included in the proposed and final rules because the list of disposal options is exclusive and there had been questions as to whether this option is allowed under \$820.1-20.601 (in old Part 20). It should be noted that this option does not allow material that has "decayed in storage" to be released to an unrestricted area unless it meets the requirements of one of the other allowed forms of waste disposal in part 20 , or the requirements of $\$ 35.92$, "Decay in Storage," of 10 CFR Part 35, or the specific requirements given in any NRC or Agreement State license. (References: 10 CFR 20.2001).

Question 428: 10 CFR 20.2102(a) requires the use of the units curie, rad, rem, inchuding multiples and subdivisions, on records required by Part 20. May a licenses continue to use roentgen-based units (e.g., $R, \mathrm{mR}, \mathrm{R} / \mathrm{h}, \mathrm{mR} / \mathrm{h}$ ) in exposure control, radiation survey, and instrument and dosimeter calibration records without conversion to rad or rem, provided that assessed doses for indivicuals are recorded in units of rad or rem?

Background: The purpose in asking this question is to establish whether or not the units of measurement specified in 10 CFR 20.2101(a) -- curie, rad, rem, and multiples and subdivisions -- must appear in all records required by Part 20 or only in those records that specifically deal with activity, absorbed dose, or dose equivalent. The intent is to be scientifically correct in recording exposure rate measurements mado with radiation survey instruments and estimates of exposure obtained with direct-reading dosimeters and to avoid unnecessary changes to existing recordkeeping practices. Nuclear fuel cycle, radiography, medical, welllogging, and low-level waste licensees perform hundreds of thousands of radiation surveys each year with instruments that are calibrated for exposure rate and that read out in 
units of $\mu R / h, m R / h$, or $R / h$. Thousands of workers at nuclear power plants and licensed radiographers wear direct-reading dosimeters that are calibrated for exposure and that display $m R$ or $\mathbf{R}$. These radiation surveys and dosimeters are used to estimate exposure rates and exposures for the purpose of controlling individual doses, but they are not normally used to assess dose equivalent. Therefore, it is not normally necessary to convert roentgenbased units to rad or rem in records of surveys and dosimeter readings. Rather than change the hundreds of forms, survey maps, logs and calibration sheets that are used at a facility to record exposure control data, radiation surveys, and calibrations, each licensee would prefer to contimue recording radiation levels and exposures in roentgen-based units and to explain the relationship of these units to rem in a single program document, such as the facility's radiation protection plan. An example of such an explanation for a nuclear power plant is "exposures and exposure rates measured and recorded in roentgen-based units are numerically equal to or greater than deep-dose equivalent rates in rembased units for the $x$-ray and gamma radiation energies normally present in locations other than inside or near open reactor plant components." The use of a single program statement would permit a licensee to recond what was actually measured in the true units of measurement. This approach to recording exposures and exposure rates appears to be consistent with 10 CFR 20.2101(a), which implicitly prohibits the use of the SI units becquerel, gray, and sievert, but which does not prohibit the use of roentgen and other appropriate units when measuring and recording quantitios other than activity, absorbed dose, and dose equivalent. It is also consistent with the use of roentgen-based units in 10 CFR Part 34 (8834.21, 34.24, 34.33) and in 10 CFR Part 39 (\$839.33).

Answer: Yes, except that the "assessed doses for individuals" must be recorded and reported in terms of dose equivalent quantities in units of rem for demonstrating compliance with the limits of Part 20.

As indicated in the background to the quisstion, 10 CFR 20.2101(a) prescribes the units to be used for the quantities activity, absorbed dase, and dase equivalent on records required by Part 20. 10 CFR 20.2101(a) also requires that each licensee clearly indicate the units of all quantities on records required by Part 20. The roentgen is a unit for the quantity expasure; it is not a unit for the quantities absorbed dase or dase equivalent. Thus the use of this quantity and unit are not inconsistent with the requirements of $10 \mathrm{CFR}$ 20.2101(a). However, the quantity exposure and its unit roentgen are commonly used as surrogates for the quantity absorbed dose and the unit rad or the guantity dose equivalent and the unit rem. When this is the case for use of the quantity exposure and its unit roentgen on records required by Part 20, the quantitative relationship between exposure (roentgen) and absorbed dose (rad) or dose equivalent (rem) must be clearly documented and understood by individuals using these quantities and units in meeting the requirements of Part 20 . The documentation of this relationship may be in the licensee's "radiation protection plan" or other radiation protection program document(s), including survey procedures; it is not necessary that this relationship (e.g., conversion factor) appear on each form, map, or $\log$ used in surveys and calibrations. It may be assumed that one roentgen equals one rem, or a more accurate conversion factor may be used. The relationship between exposure (roentgen) and absorbed dose (rad) or dose equivalent (rem) should also be included in the instruction (training) of individuals who make the measurements of exposure (in roentgen units), and records of those measurements, that are required by Part 20.

Note: The answer to Question 96(a) has been revised to be consistent with the answer above. Questions and answers 116 and 117 and answers also discuss dose quantities and units to be used in records. (References: 10 CFR 20.2101, 10 CFR 20.1003; 10 CFR 34.21, 34.24, 34.33; 10 CFR 39.33).

Question 432: Questions 376 and 389 in section 10 CFR 20.2001 concern the use of the "decay in storage" option of 10 CFR 20.2001(a)(2) at nuclear power plants and at materials facilities. However, it is not clear whether or not these questions and answers also apply to non-power reactor facilities. How can this option be used at non-power reactor facilities?

Answer: As indicated in the statement of considerations for revised Part 20 (56 FR 23380, third column, and 23381, first column), and in the answers to questions 376 and to 389 , technically, the "decay in storage" option has always been available to all licensees as an allowed waste disposal option. However, this option does not allow material to be released to an unrestricted area unless it meets the requirements of one of the other allowed forms of waste disposal in 10 CFR Part 20, or the requirements of 835.92, "Decay in Storage," of 10 CFR Part 35 (for medical licensees, only), or the specific license conditions given in any NRC or Agreement State license. (Reference: 10 CFR 20.2001). 


\section{CFR 20.2003 - Disposal by Release into Sanitary Sewerage}

Question 39: Can biological material be defined better in 20.2003? For example, is all organic material biological material? Can animal fats be released to the sower?

Answer: Biological material, in its ordinary moaning, is material pertaining to living organisms (plants or animals). The statement of considerations indicates that ground-up animal carcasses are examples of such material. Animal fats are biological material and, if "dispersible," can be released to the sewer. (Reference: 10 CFR 20.2003(a)(1))

\subsection{SUBPART L - RECORDS}

\section{CFR 20.2101 - Records, General Provisions}

Question 116: 10 CFR 20.2101(b) requires the licensee to make a clear distinction among the dose quantities entered on the reconds and gives examples of the following different dose quantities: total effective dose equivalent, shallow dose equivalent, eye dose equivalent, deep dose equivalent, committed effective dose equivalent. Does this mean (for example) that the dose rates measured during surveys of external radiation fields must be recorded in terms of one of these dose quantities or (as another example) that the results of air sampling must be recorded in terms of one of these quantities?

Answer: No. The examples given refer to dose quantities used for doses to individuals, not to dose (or activity) quantities used in surveys of areas. (Reference: 10 CFR 20.2101)

Question 117: Does the requirement of 10 CFR 20.2101(a) to use the unit curie (for activity) mean that it will not be permissible to record the results of contamination surveys in units of disintegrations per minute (dpm) or mrad smearable?

Answer: No. The 10 CFR 20.2101(a) requirement as it applies to units of activity (curies) is intended to apply to records of quantities of material directly related to the explicit requirements of Part 20 (e.g., storage and control, posting and labeling, waste disposal, concentrations in air, and individual intakes of radioactive material). It is not intended to apply to surveys for contamination. Note: There are requirements in 10 CFR 35.70(h) which apply to medical licensees to record the results of surveys for removable contamination as disintegrations per minute per 100 square centimeters. (Reference: 10 CFR 20.2101)

\section{CFR 20.2104 - Determination of Prior Occupational Dose}

Question 10: Why does the rovised Part 20 still require Form 4?

Answer: Form 4 is used as a cumulative record of exposures at each licensee facility and serves as a mechanism for transmitting data from one licensee to another. Licensees must attempt to obtain the information on lifetime cumulative occupational radiation dose on Form 4, or equivalent, for all workers requiring monitoring. Licensees must obtain that information for occupational radiation doses received during the current year and prior to permitting a Planned Special Exposure. (See 10 CFR 20.2104.) Form 4 is not transmitted to the NRC. Form 5 is a summary of annual exposure and may have more frequent entries. The data on several previous Form 5's might be used to prepare a summary Form 4. The Form 5 will be provided to the NRC annually for workers in 7 classes of licensed facilities under the revised Part 20. (References: 10 CFR 20.2104, 10 CFR 20.2206)

Question 51: Do 10 CFR 20.2104(a), 10 CFR 20.2104(d) and Footnote 4 to 20.2104(d) mean that a licensee must "backfit" effective dose equivalents (EDE) for individuals who were occupationally exposed before implementation of the revised Part 20?

Answer: No. Such backfitting is not required. However, licensees may, if they so desire, make estimates of the EDE and committed EDE based on the occupational dose records available for this period. (References: 10 CFR 20.2104(a), 10 CFR 20.2104(d), 10 CFR 20.2104(d) Footnote 4)

Question 55: 10 CFR 20.2104(e)(1) prorates the 5-rem annual limit on the total effective dose equivalent at a rate of 1.25 rems per quarter for each quarter for which records were unavailable but includes no similar provisions for the other annual limits (individual organs, eye, skin, extremities). Is similar proration required for doses covered by the other limits? 
Answer: Yes. As indicated in the statement of considerations (56 FR 23383, first column), the values for the other limits should be rectuced by one quarter for each unreported quarter. (References: 10 CFR 20.1201(f), 10 CFR 20.2104(e)(1))

Question 64: The following question relates to the requirements of 10 CFR 20.2104(a)(2), 10 CFR 20.2104(c), and 20.2104(d) concerning records of lifetime cumulative occupational dose. Assuming that (1) the licensee has obtained, by electronic media, a printed report (or reports) conthining tho Form 4 information on an individual's lifetime cumulative dose, (2) the individual who recoived the dose signed Form 4, or equivalent, in accordance with 10 CFR 20.2104(d), and (3) there is no other signature attesting to the authenticity of the Form 4 record. Is the licensee in compliance with the requirements in 10 CFR 20.2104 concerning records of lifetime cumulative occupational dose?

Answer: Yes. As stated in Regulatory Guide 8.7, Section C.1.3, to demonstrate compliance with the requirement of 10 CFR 20.2104(a)(2) (to attempt to obtain the records of lifetime cumulative occupational radiation dose), the indivichual to be monitored may provide a written estimate of the cumulative lifetime dose or an up-to-date NRC Form 4 signed by the individual. This information does not need to be verified so long as the individual does not participate in a planned special exposure. However, in the unlikely event that it was the individual who provided the licensee with the report by electronic media, Regulatory Guide 8.7, Section C.1.3, also states that "Although not required by the regulations, it is considered good bealth physics practice to verify the information provided by the individual." (Reference: 10 CFR 20.2104)

Question 113: If an NRC licensee employs an individual formerly employed at a DOE lab and that individual's DOE lab dose record shows a CEDE of more then 5 rems (but within DOE limits) must the NRC licensee consider this an overexposure and reduce this individual's planned special exposure allowance accordingly?

Answer: No. The "limits" referenced in 20.2104(a)(2) and 20.1206(e) are the limits in effect and applicable to the individual at the time of the exposure. It should be noted that if the 5 rem CEDE was received during the current year, this individual would not be allowed any further exposure for the balance of the year. (References: $10 \mathrm{CFR}$ 20.2104 and 20.1206(e)).
Question 139: In-vivo measurements for an incoming worker could indicate that the worker's internal dose, as determined and recorded by the preceding licensee, was incorrect. What action would the NRC expect the current licensee to take

Answer: The NRC would expect the licensee to correct the erronecus dose, document the reasons for that correction, and inform the worker about this correction.

(Reference: 10 CFR 20.2104)

Question 142: (a) In compliance with 10 CFR

$20.2104(a)(2)$, what constitutes an acceptable attempt to obtain a record of the lifetime dose for a worker? (b) Since there are no limits for lifetimo doses (other than planned special exposures), and lifetime dose reports to workers are not required, why must licensees go to the expense of obthining and recording these doses?

Answer: (a) The licensee should request this information from the worker. Altematively, the licensee also may roquest this information from the worker's most recent employer for work involving radiation exposure or the worker's current employer if the individual is not employed by the licensee. If this request is denied, the licensee need make no further efforts to obtain the information; however, the individual will not be available for a planned special exposure.

(b) As explained in the Statement of Considerations (56 FR 23383,23384 ) the requirement to attempt to obtain the records of lifetime cumulative doses follows one of the provisions of the guidance to Federal agencies on occupational radiation protection. Also, as stated in SECY-88-315 (available in the NRC Public Document Room), the recordkeeping and reporting requirements of the revised Part 20 are consistent with implementing an NRC staff recommendation to establish a registry of radiation workers and their radiation doses. Such a registry will be of value in analyzing doses received by workers at several sites during the year, in tracking exposure trends, and will facilitate epidemiological studies of potential radiation-induced health effects. (Reference: 10 CFR 20.2104).

Question 143: 10 CFR 20.2104(c) states in three places that licensees may accept or obtain dose data from the most recent employer. The most recent employer may not be the licensee at whose facility the worker was most recently exposed. Will it be permissible to accept or obtain tho data from the most recent facility at which the worker was exposed? (Small contractors often do not have the data. 
Nuclear power plant licensees in general would much profor to continue receiving data from the most recent licenseo).

Answer: Yes. (Reference: 10 CFR 20.2104).

Question 371: 10 CFR 20.2104(c)(1) states that a licenes may accept, as a record of the occupational dose that the individual received during the current year, a written signed statement from the indivichual. If this was done and the statement is false, would a resulting exposure greater then 5 rem in the year be considered an overexposure and a violation?

Answer: The exposure would be an "overexposure" (an occupational dose in excess of the annual limit). However, os indicated in the statement of considerations for the revised Part 20 (56 FR 23384, first column) if the individual deliberately falsifies the statement, the licensee would not bo penalized for a resulting overexposure. Furthermore, the staff believes that the licensee should not be penalized for false information provided by the individual even if the falsification was not deliberate. However, as indicated in Regulatory Guide 8.7, Rev. 1, although not required by the regulations, it is considered good bealth physics practice to verify the information on prior exposure provided by the individual. Such verifications should reduce the likelihood of overexposure resulting from false information on prior exposures. If an individual deliberately provides false information on the prior dose, that individual would be in potential violation of the revised regulations covering the "deliberate misconduct" (56 FR 40664, 8/15/91) that caused the licensee to be in violation of the regulatory limit.

(Reference: 10 CFR 20.2104)

Question 390: During 1993, there may be radiation workers transiting between licensees that have, and have not, implemented the revised Part 20. (a) In the case of a worker whose dose was monitored earlier in the year at a licensee that has implemented the revised Part 20 and is now in processing at a licensee that has not implemented the revised Part 20: (1) Should "whole body dose" be taken as the "total effective dose equivalent" (TEDE) or as the "deep dose equivalent" (DDE) recorded by the previous licensee? (2) If the individual has received dose in excess of an "old" Part 20 limit for the current quarter, but less than the respective revised Part 20 limit for the year (0.8., shullow dose equivalent to an extremity of 20 reans for both the current quarter and year to date), is the individual unavailable for any further exposure in that dose category for the remainder of the quarter? (3) If the individual has received dose in excess of the "implied annual limit" of the "old" Part 20, but less than the respective annual limit in the revised Part
20 (0.8., shallow dose equivalent to the skin of 35 rems in the current quarter and year to date), is the individual unavailable for further exposure in that dose category for the remuinder of the year? (4) If the individual has received a planned special exposure (PSE) at the previous workplace in tho curreat quarter, how should the PSE dose be accounted for as prior occupational dose by the present licensee under the "old" Part 20? Should the PSE dose bo subtracted from the available current quarter dose for that dose category?

(b) In the case of a worker whose dose was monitored earlior in the your at a licensee that has not implemented the rovised Part 20 and is now inprocessing at a licensee that hes implemented the revised Part 20: if the individual has received recorded internal dose (in terms of rem) or internal exposure (in terms of MPC-hrs) or internal uptake (in terms of orgen burden), how should this data be considered with regand to revised Part 20 requirements (i.e., TEDE, CEDE, or $\mathrm{CDE})$ ?

Answer: (a) (1) DDE. (2) Yes, the individual is "unavailable for any further exposure in that dose category for the reminder of the quarter" because the individual has already exceeded the applicable dose limit for the quarter. (3) The individual is unvailable for further exposure in that dose category for the remainder of the quarter (because the individual has exceeded the applicable dose limit for the quarter), but is available for further exposure in that dose category for the remainder of the year after the end of the quarter. (4) The PSE dose should bo accounted for as occupational dose received during the quarter and should be subtracted from the available current quarter dose for the dose category.

(b) CEDE. (Reference: 10 CFR 20.2104).

\section{Question 408:}

Beclegmind

10 CFR 20.2104 states that for each individual for whom monitoring is required, the licensee must: 1.) Determine the occupational radiation dose for the current year; and 2.) Attempt to obtain the records of lifetime cumulative occupational radiation dose. "Records of lifetime cumulative occupational radiation dose" refers to occupational dose records prior to the current year. These records are only used when implementing the planned special exposure option. Some licensees may use prior year's TEDE to control an individual's lifetime dose in compliance with NCRP. 91 recommendations or average annual exposure in complinnce with ICRP-60 recommendations. However, other prior year's dose quantities such as shallow dose equivalent 
(SDE) and lens (eyo) dose equivalent (LDE) aro not useful to licensees and provide no additional protection to individuals. Therefore, it was reasonable and compliant to obtain only TEDE for prior years. Can a licenses seek only to obtain the TEDE occupational dose quantity for prior years to comply with the 20.2104(a)(2) requirement to "attempt to obtain the records of lifetime cumulative occupational radiation dose"?

Answer: Yes, provided the licensee does not intend to authorize planned special exposures for the individuals for whom the licensee attempts to obtain only the TEDE. For planned special exposures, the provisions of $10 \mathrm{CFR}$ 20.1206(e) that limit "lifetime" exposures apply to all occupational doses having annual limits in 10 CFR 20.1201(a) (TEDE, organ dose, eye dose, skin dose and extremity dose), not just the TEDE. The reasons for this requirement other than for use in cases of planned special exposures are given in the answer to Question 142(b). (Reference: 10 CFR 20.2104)

Question 420: This question refers to the answer to Question 55 in 820.2104. (a) Despite the quoted reference, $\$ 20.2104$ only refers to occupational radiation dose (why radiation when the defined term is occupational dose?), which is defined in terms of "dose." (b) The definition of dose does not inchude eye, shallow, or extremity doses. What is the regulatory basis for inchuding eye, shallow, and extremity doses within the scope of $\$ 20.2104$ where it is so explicitly not inchuded? A simple discussion in the Statement of Considerations does not seem to be an adequate basis for rewriting a regulation. (c) Are the dose histories of these three organs (eye, skin, extremity) so high as to necessitate the paperwork to track these for now employees? I suspect that for the vast majority of workers, these are negligible compared to TEDE.

Answer:

(a) "Dose" and "radiation dose" are synonymous (8e0 "Dose or radiation dose" in \$20.1003); therefore, "occupational dose" and "occupation radiation dose" are synonymous.

(b) Contrary to the statement in the question, "dose or radiation dose" is broadly defined in Part 20 as "a generic term that means absorbed dose, dose equivalent, effective dose equivalent, committed dose equivalent, committed effective dose equivalent, or total effective dose equivalent, as defined in other paragraphs of .. . [10 CFR 20.1003]." The "eye dose equivalent" and the "shallow dose equivalent" (the quantity used in the limits for the skin and for the extremities) are both "dose equivalent" quantities and, therefore, are "doses" as defined in Part 20. The occupational dose limits inchude limits for the eye, shallow, and extremity doses and the "occupational dose" in 10 CFR 20.2104(a)(1) includes the eye, shallow, and extremity doses. The recommendation in the Statement of Considerations (which is not an explicit requirement in the regulation) that, in establishing administrative controls, the licensee should reduce the value for limits other than the TEDE ty one quarter of thoir annual limit for each unroported quarter provides a method, acceptable to the NRC staff, for licensees to demonatrate compliance with those limits when records of those doses are missing for a portion of the year.

(c) A licensee is required to determine a particular occupational dose received by new omployeo ourlier in the current year only if the licenseo makes the prospective determinution that individual monitoring will be required, pursuant to 10 CFR 20.1502, for the prospective occupational dose. If the licensee determines that individual monitoring for eye or shallow or extremity dose are not required for a particular individual (because, at the licensee's facility, those doses are not likely to exceed 10 percent of the limits for those doses), the licensee is not required to determine the prior eye or shallow or extremity doses. (References: 10 CFR 20.2104, 10 CFR 20.1003).

\section{CFR 20.2105 - Records of Planned Special Exposures}

Question 112: A licensee authorizes a "planned special exposure" in accordance with 10 CFR 20.1206 and the doses to the involved indivichuals are fortuitously much lower than anticipated. In retrospect, a plannerl special exposure authorization was unnecessary. May the doses be assigned as "routine" doses on the Form 5 rather than recorded as planned special exposure doses?

Answer: No. Following a planned special exposure, the individual doses must be recorded in accordance with 10 CFR 20.2105 (no matter how small) and may not be recorded as routine doses on the Form 5. (References: 10 CFR 20.1206 and 20.2105).

\section{CFR 20.2106 - Records of Individual Monitoring Results}

Question 399: The NRC Form 5 (Item No. 8) provides for entry of multiple NRC license numbers. Some licensees may hold multiple licenses and provide common monitoring (e.g., a single set of dosimeters) for personnel working 
under any or all of the licenses. In such cases, it is proposed that only a single NRC Form 5 woukd be generated for each individual, listing all licenses under which they were monitored under 20.1502 . Is this accoptable to satisfy regulatory requirements?

Answer: Yes, in general. For one nuclear power station, it is acceptable for the licenses to provide a single NRC Form 5 for an individual who works at one or more units at the station. However, a nuclear utility that hes two or more power stations shoukd not use a single NRC Form 5 for an individual who works at two or more different stations; a separate form should bo used for each station at which the individual works. (References: 10 CFR 20.2106, 10 CFR 20.2206, Regulatory Guide 8.7).

Question 400: NRC Form 5 (Item No. 10B) inchudes the symbol "V", which is not defined in Regulatory Guide 8.7, Revision 1. (a) Does the "V" signify "vapor" as used in Federal Guidance Report No. 11? (b) If so, how is this lung clearance class to be applied in operational air sampling and internal dosimetry programs?

Answer: (a) "V" in Item 10B of Form 5 is an abbreviation for the hung clearance class "vapor" in Appendix B to 10 CFR 20.1001 - 20.2401. "Vapor" is listed as a hung clearance "class" for only two elements, sulfur and nickel. (However, the "water" inhalation class for hydrogen-3 indicates water vapor.)

(b) The "vapor" inhalation class should be used when the radionuclides are present in the form of a vapor in the air and the associated air sampling should be appropriate for sampling the radionuclides in this form. (References: 10 CFR 20.2106, 10 CFR 20.2206, Regulatory Guide 8.7).

Question 401: NRC Form 5 (Item No. 20) provides for the signature of the licensee's authorized representative responsible for the data and is not noted as "optional" as is the licensee signature block on NRC Form 4. Appendix $A$ of Regulatory Guide 8.7, Rev. 1, "Instructions for Recording and Reporting Occupational Radiation Exposure Data," provides for the licensee to sign the transmittal letter for electronic transmission of exposure data to the NRC and thereby certify the database. If a letter certifying the database is maintained on file, can the licensee 80 note NRC Form 5 's which are generated from the database, e.g., "signature on file," rather than signing each individual NRC Form?" In particular, this would facilitate the providing of individual exposure reports annually to each worker, as required by 10 CFR Part 19.
Answer: Yes, if the exposure data are reported to the NRC by electronic transmission, the Form 5 exposure report prepared from the data base and provided to the worker need not be signed ("signature on file" is acceptable). However, if the exposure data are provided to the NRC on Form 5, rather than by electronic transmission, the form must be signed. As noted in the question, the sigmeture block on Form 5 is not optional. (Reforencos: 10 CFR 20.2106, 10 CFR 20.2206, Regulatory Guide 8.7, Rev. 1).

Question 402: NRC Form 5 (Item No. 21, "Comments") implies that dose from a "hot particlo" should be added to the shallow dose equivalont, maximum extremity (SDE, MB - Block 14). However, 1\&E Notice 90-48 states that "hot particle exposure will not bo added to skin doses from sources other than hot particles." (a) Should hot particle doses be added to the shallow dose equivalent as implied? (b) If so, should this dose be subtracted from the applicable dose category with regard to remaining available shallow dose equivalent (skin or extremity) for the year? Based on our understanding of the intent of I\&E Notice $90-48$, we believe that "hot particle" doses should nat be subtracted from the remaining available shallow dose equivalent (skin or extremity) for the year.

Answer: The intent of the "hot particle" example in the instructions for Item 21 on Form 5 is simply to give one an example of how this space on the form might be used. There is no intention to imply that hot particle doses should be added to other doses. The question of adding hot particle skin doses to other skin doses was addressed in IE Information Notice 90-48, "Enforcement policy for Hot Particle Exposures," and the enforcement policy enclosed with that notice, and in Health Physics Position (HPPOS) 246 (in NUREG/CR-5569, Rev. 1). The NRC policy and staff positions in these documents have not been changed by revised Part 20 or the instructions for Form 5 in Regulatory Guide. Answers to the specific questions are as follows: (a) As indicated in HPPOS-246, licensees may choose whether or not to add a hot particle dose to other skin or extremity doses. However, in either case, the record should be clear as to the amount of the hot particle dose. In determining whether or not an overexposure has occurred, the NRC will consider the hot particle dose alone, without adding it to other doses.

(b) The hot particle dose should not be subtracted from the remaining available shallow dose equivalent (skin or extremity) for the year. (References: 10 CFR 20.2106, 10 CFR 20.2206, Regulatory Guide 8.7). 
Question 403: NRC Form 5 (Item No. 10) provides for liating of specific radionuclides in intakes that contribute to the recorded committed offectivo doss equivalent (CEDE). When determining the CEDE only significantly irradiated organs need be included in the calculations [10 CFR 20.1202(b)(3)]. An organ is considered to bo significantly irradiated if the product of tho woighting factor and committed dose equivalont, por unit intake, is greater than $10 \%$ of the maximum woighted value of committed dose equivalent (CDE), per unit intake [Footnote 1 to 20 CFR 20.1202(b)(3)]. Similarly, an isotope need not be considerad to bo in an airtorne mixture if the concentration of any radionuclide is less then $10 \%$ of its DAC, and the sum of the percentages of the disrogarded radionuclides is loss than 30\% [10 CFR 20.1204(g)]. Given these two examples of cut off lovels, can a licensee disregard the contribution a radionuclide makes to the CEDE, with regard to recording and reporting specific radionuclides, if it is less than $10 \%$ of the total CEDE rosulting from uptake of a mixture, and the sum of the disregarded radionuclides is less than $30 \%$ ? In this way insignificant doses, the addition of which imply greater precision then exists for internal dosimetry, can be disregarded without compromising sound radiological practicos.

Answer: No. The statements concerning significantly irradiated organs [in 10 CFR 20.1202(b)(3) and Footnote 1] apply to compliance with requirements for summation of extornal and internal dose and are not relevant to cutoffs of radionuclides used in intake calculations. The statement in the question concerning the provisions of 10 CFR 20.1204(g) is incorrect; it does not include the necessary condition of 10 CFR 20.1204(g)(1) concerning use of the "total activity" in demonstrating compliance. [See the answer to Question 121 for clarification of 10 CFR 20.1204(g).] There is no basis in the regulations for the proposed cutoff in the calculation of the CEDE. (References: 10 CFR 20.2106, 10 CFR 20.2206, Regulatory Guide 8.7).

Question 404: NRC Form 5 (Item No. 10) provides for reporting of indivicual radionuclides involved in an intake. How does the NRC plan on using this data (i.e., what is the NRC's purpose in collecting this data)?

Answer: NRC Form 5 (Item 10) provides for recording/ reporting of individual radionuclides involved in an intake because 10 CFR 20.2106, records of individual monitoring results, requires that the records include, when applicable, the estimated intake or body burden of radionuclides. There are several reasons for inclusion of intake information on Form 5. One reason is that if the internal dose models and weighting factors are changed at some future date, the NRC can recalculate the reported doses using the now models and weighting factors. Another reason, of benefit to licensees, is to make it possible for a licensee to determine the CDE to the maximally exposed organ for an individual who has organ doses reported from provious employers. For example, consider an individual, who, during a year, was employed by licensee $A$ and received a CDE of 20 rem to the lung, then was employed by licenseo $B$ and received a CDE of 20 rem to the bone, and finally was employed by licenseo $C$ and received a CDE of 20 rem to the thyroid. NRC Form 5 does not provide a space for recording which organ is the maximally exposed organ (unless the "Comments" space is used for this purpose). In the absence of information on which organ was maximally exposed and on the intakes of individual radionuclides, the total CDE to the maximally exposed organ in this example woukd be considered to be the total of these three 20-rem doses (to different organs), or a total of $60 \mathrm{rem}$, which would appear to be a potential violation of the organ dose limit. With the individual radionuclicle intake information, the CDE to the maximally exposed organ could be recalculated and very likely would be below the limit. The NRC will also use the intake data from some of the earlier reports to the NRC under revised Part 20 to recalculate the doses to ensure that the reported doses are reasonably consistent (within a factor of 2 or so). Finally, the recordkeoping and reporting requirements of revised Part 20 are consistent with implementing an NRC staff recommendation to establish a registry of radiation workers and their radiation doses. Such a registry will be of value for a number of reasons, one of which is to facilitate opidemiological studies of potential radiation-induced health effects. The inclusion of the radionuclide intake data in the dose records provides a better basis for these studies than records of dose alone. (References: 10 CFR 20.2106, 10 CFR 20.2206, Regulatory Guide 8.7).

\section{CFR 20.2107 - Records of Dose to Indi- vidual Members of the Public}

Question 391: (a) Are records maintained by nuclear power plants that satisfy the requirements of 10 CFR Part 50, Appondix I, and related regulatory guidance sufficient to demonstrate compliance with the requirements of 20.2107 ? (b) If not, what additional records are required?

Answer: (a) Not necessarily.

(b) For example, additional records may be noeded to domonstrate compliance with the limits for individual members of the public in controlled areas. See the answer to the 
rolated Queation 384 and anawers (References: 10 CFR 20.2107).

\section{CFR 20.2110 - Form of Records}

Quaction 141: 10 CFR 20.2110 requires adoquate safocuards againat tamporing with and loss of records. For data stored in electronic systems, what safeguards are acceptable?

Answer: The NRC does not have, and hes no plans to develop, prescriptive requirements or guidance on safoguands for electronic systems to provent tamporing with or loss of records. However, the Electric Power Research Intitute (BPRI) has published a report, "Guidelines for Quality Records in Electronic Media for Nuclear Facilities (NCIO-10)," Report No. EPRI NP-6295 (May 1989) that may be bolpful in meeting this requirement in 10 CFR 20.2110. The NRC staff has taken no position in regard to this EPRI document. The abstract of this report inchudes the atatement that the guidelines in the report "provide a consistent approach to the electronic creation, storage, retrieval, control and approval of quality records, a subject beretofore not addressed by inctuatry standards and regulations." (Reference: 10 CFR 20.2110)

\subsection{SUBPART M - REPORTS}

\section{CFR 20.2202 - Notification of Incidents}

Question 56: Would areas periodically patrolled, but not constantly manned, be considered to fall within the exception in 10 CFR 20.2202(a)(2) and 20.2202(b)(2) for "locations where personnel are not normally stationed during routine operations, such a hot-cells or process enclosures?" For examplo, would these exceptions apply "if a hallway or cubiclo in the reactor auxiliary becomes an airborne radioactivity area and auxiliary equipment operators make thoir rounds periodically during thoir shift?"

Answer: 0 , the exception would not apply to these areas that are "periodically patrolled" or otherwise normally accessible to personnol. However, for nuclear power plants at power, primary containments aro examples of "locations where personnel are not normally stationed." (References: 10 CFR 20.2202(a)(2), 10 CFR 20.2202(b)(2))

\author{
10 CFR 20.2203 - Reports of Exposures, \\ Radiation Levels, etc.
}

Question 122: The conforming amendment to 10 CFR $50.73(a)(2)$ states that reports submitted in accordance with 10 CFR 50.73(a)(2)(viii) also meet the offluent release reporting requirements of 10 CFR 20.2203(a)(3). However, 10 CFR 20.2203(a)(3) requires reporting of concentrations in an unrestricted area of 10 times any applicable limit in Part 20 while 10 CFR 50.73(a)(2)(viii) requires reports of airborne or liquid offluent roleases that exceed 20 times the appliciblo concentration limits in Table 2, Appendix B.

Why is the multiple ten in one case and twenty in the other?

Answer: The two reporting requirements are consistent in terms of public dose. The annual dose limit for a member of the public is 100 mrem. 10 CFR 20.2203(a)(3) requires reporting above a threshold of ten times this applicable limit, or 1000 mrem. The concentrations in Table 2, Appendix B, correspond to an annual dose of 50 mrem; therefore, the requirement in 10 CFR 50.73(a)(2)(viii) for reporting at 20 times these concentrations corresponds to a reporting threebold in terms of annual dose, of $20 \times 50$ mrem, or 1000 mrem, which is the same dose threshold as that in 10 CFR 20.2203(a)(3). (Reforences: 10 CFR 20.2203, 50.73)

\section{CFR 20.2206 - Reports of Individual Monitoring}

Question 383: Reports of planned special exposures (PSEs) are required by 10 CFR 20.2204 to be submitted within 30 days of the PSE to the NRC Regional Office. Complete records of PSEs are required to be maintained in accordance with 10 CFR 20.2105 and the monitoring results for PSEs should be recorded on NRC Form 5 or equivalent in accordance with the guidance in Regulatory Guide 8.7, Revision 1. (a) Are the PSE dose reports also required to be submitted to NRC annually in accordance with 20.2206 ? (b) If 80 , is only the NRC Form 5 equivalent required to be submitted, or does the other information required by 10 CFR 20.2105 also have to be included? (c) Should separate NRC Form 5s, i.e., one for routine dose and one for PSE dose, be submitted for each applicable individual?

Answer: (a) Yes.

(b) Only the information on Form 5. The information required by 10 CFR 20.2105 does not have to be included in the reports required by $10 \mathrm{CFR} 20.2206$. (c) Two separate 
forms, one for routine dose and one for PSE dose should bo aubmitted for each individual who hed both routine and PSE doses. Soparato roports are needed because completion of Item 9B on Form 5 requires indicating whether the reported occupational exposure is for routine exposure or for PSE. In other words, the design of the Form 5 does not allow both routine exposures and PSEs to be reported on the same form. (Reforences: 10 CFR 20.2206, 10 CFR 20.1206, 10 CFR 20.2204, Rogulatory Guido 8.7)

Question 392: What monitoring poriod should be used in annual individual monitoring roports submitted, in accordance with 10 CFR 20.2206, following the first yoar of rovised 10 CFR Part 20 implementation, if the poriod of implementation did not encompass the full year? For oxample, if a licenseo implements the revised 10 CFR Part 20 on July 1,1993 , is the licenseo required to provide annual individual monitoring roports early in 1994 that cover the entire year, or only for the final six months of the year during which monitoring was provided to individuals under 10 CFR 20.1502?

Answer: This annual report should cover tho entire year, preferably using the format of Regulatory Guide 8.7, Rov. 1 (Form 5) for the entire year. However, if it is impractical to use this format for the portion of the year under 10 CFR 20.1-20.601, the format previously used for reports in compliance with 10 CFR 20.403 ("termination reports") may be used for that portion of the year. (Reference: 10 CFR 20.2206).

Question 393: Is it accoptable for regulatory purposes that occupational dose data that are being provided on a voluntary basis (i.e., the results of dose monitoring provided that is not required by regulation) be recorded and reported only in part? The purpose in asking this question is to establish whether or not the revised Part 20 provides the flexibility for liconsees to record and report the results of "monitoring performed but not required" without also incurring implied requirements with regards to NRC Forms 4 and 5, or equivalents. The intent is to be able to provide useful information, that is not required by the rogulation, on a voluntary basis to the worker and/or the NRC without unduly taxing available licensee resources. The specific example outlined below is provided to illustrate the more general issue of flexibility in recording and reporting occupational dose information that is not necessary for compliance with regulatory requirements.

Some licensees intended to voluntarily record and report the calculated Committed Effective Dose Equivalent (in rem), oven when internal monitoring is not required by $10 \mathrm{CFR}$
20.1502. Howover, it is not intended that related radionuclide intake data will also be recorded and reported because of the resources which would be needed to track and transfor the specific radionuclide data to the NRC Form 5 or equivalent. For example, the licenseo may only have trackad Derived Air Concentration hours (DAC-hrs), using the appropriate most restrictive DAC, without assessing specific radionuclide intakes. Accordingly, the "Intake" section of the NRC Form 5 would be noted as "NR" for "not required, " and no specific radionuclide data would be recorded. However, the "Instructions and Additional Information Pertinent to the Completion of NRC Form 5, " items 10A-D require that intake data be recorded "...for each radionuclide that resulted in an internal exposure recorded for the individual." The issue is that these instructions should not be considered applicable for recording and reporting performed that is not required. This approach to the partial recording and reporting of occupational dose data, when dono on a voluntary basis, appears to be consistent with the floxibility that is implied in the rovised Part 20 and rolated regulatory guidanco. Note that Regulatory Guide 8.34, Section C.1.4, states "the results of monitoring provided when not required by 10 CFR 20.1502 are not subject to [the] dose recording requirements."

Answer: Yes. The instructions for Form 5 do not apply to recording and reporting that is not required by Part 20 and that is being done voluntarily. NRC encourages licensees to report CEDE voluntarily when monitoring is performed even though not required. If the intake information is omitted when reporting voluntarily, licensees should footnote the CEDE entry with a notation in the comments section that "monitoring was not required." (Reference: 10 CFR 20.2206).

Question 394: (a) Are the results of dose monitoring of minors and declared pregnant woman performed in accordance with 20.1502 required to be reported to NRC as part of the annual reporting of individual monitoring results? (b) If so, are the records of dose to the embryo/fetus, which may differ from records of dose to the declared pregnant woman, required to be submitted as part of the annual reporting of individual monitoring results? It would seem that embryo/fetus dose records are not required to be included in the annual report, because the embryo/fetus dose records are developed in accordance with 20.1208, "Dose to the Embryo/Fetus," and not 20.1502, "Conditions Requiring Individual Monitoring of External and Internal Occupational Dose," which is the base reference for the annual reporting requirement.

Answer: (a) Yes. For a declared pregnant woman, the dose to be reported in accordance with 10 CFR 20.1502 is 
the dose to the woman herself, not the dose to the embryo/ fotus.

(b) No. See Section 2.3 of Regulatory Guide 8.7, Rev. 1, concerning reporting of embryo/fetus dose. (Reference: 10 CFR 20.2206, 10 CFR 20.1502, 10 CFR 20.1208).

Question 395: If an indivichual is monitored several times during a year by the same licensee (0.8., during two monitoring periods separated in time), how should the monitoring poriod(s) be designated in the annual individual monitoring report required by 10 CFR 20.2206 (i.e., on the NRC Form 5 or equivalent)? Due to the possible limitations in the format and structure in licensee's computerized occupational dose recordkeeping systems, it seems that there should be flexibility in meeting the intent of the requirements. Alternatives might include the following:

a. Issue one NRC Form 5 or equivalent with a single monitoring period that begins on the first day of the year and ends on the last day of the year.

b. Issue one NRC Form 5 or equivalent with single monitoring period that begins on the first day of the first monitoring period and ends on the last day of the last monitoring period.

c. Issue a separate NRC Form 5 or equivalent for each individual monitoring period (i.e., issue two or more NRC Form 58 for the same individual in the same year).

Would any or all of these approaches be acceptable in meeting the intent of the regulatory requirements? Would other approaches be acceptable? If so, please describe.

Answer: All three options are acceptable (option B is preferable) provided that the separate "monitoring period(8)" in the question fall within the year used to demonstrate compliance. 10 CFR 20.2206 requires an annual report of monitoring for individuals for whom monitoring was required by 10 CFR 20.1502 during that year (emphasis added). 10 CFR 20.1502 requires monitoring sufficient to demonstrate compliance with the limits. The year as defined in 10 CFR 20.1003 is the period of time used to demonstrate compliance. Thus, the time period for reporting under 10 CFR 20.2206 must be the year as defined in 10 CFR 20.1003 that is used to demonstrate compliance. (Reference: 10 CFR 20.2206).

\subsection{CFR 20 APPENDICES}

\author{
10 CFR Part 20 Appendix A
}

Question 452: The following questions refer to the selection and use of a half-mask face piece, as described in Appendix A, "Protection Factors for Respirators":

a. Footnote " 8 " of Appendix A states that "this type of respirator is not satisfactory for use where it might bo possible (e.g., if an accident or emergency were to occur) for ambient airborne concentrations to reach instantaneous values greater than 10 times the pertinent vahues in table 1 , column 3 of Appendix B...," i.e., the derived air concentrations (DACs) for inhalation. Is this provision intended to apply to the work activity in progress for which the respirator is being used, or is it more broadly applicable to the type of facility or licensed activity? For example, is the statement intended to exchude the use of a half-mask face piece respirator at a nuclear power plant? We believe that the use of hulf-mask face piece respirators should be permitted with the same limitations as are applied to other respirator types because the use of a half-mask face piece may offer advantages over, for example, a full face piece respirator in some applications by keeping the overall total effective dose equivalent ALARA. This would appear to be in keeping with the intent of 820.1703 , Use of Individual Respiratory Protection Equipment, which states that ". . . the licensee may select respiratory protection equipment with a lower protection factor only if such a selection would result in keeping the total effective dose equivalent ALARA."

b. Footnote " $g$ " requires that ". . . the mask is to be tested for fit prior to use each time it is donned . . ." for the use of half-mask face pieces. Is a negative pressure test an acceptable method to adequately test the respirator prior to use? Such a qualitative test method would seem to be acceptable because it appears that there would be no practical method to accomplish a quantitative test in the field prior to each use.

Answer:

(a) This provision is intended to apply to situations in which the ambient airborne concentrations are likely ". . . to reach instantaneous values greater than 10 times the pertinent values in table 1, column 3 of appendix B ..." The statement is not intended to exclude the use of a half-mask face piece at a nuclear power plant or other licensee facility. 
(b) Yes. See NUREG-0041, Section 8.5.2.3, for four accoptable tosting methods for field testing of respirator operation (isoamyl acetate, irritant smoke, negative pressure test, and positive pressure test). (Reference: 10 CFR 20, Appendix A).

\section{CFR Part 20 Appendix B}

Question 13: Why was a 2-bour half-life chosen as a time of reference for noble gases or short-lived radionuclides, as used in 10 CFR Part 20, Appendix B and its footnotes?

Answer: As indicated in Footnote 2 to Appendix B, the radiomuclides that have half-lives of less than 2 hours "might inchude a significant contribution from external exposure." "Significent contribution from external exposure" in this footnote means that the contribution to the dose equivalent from external irradiation exceeds that from inhalation. Two hours is the half-life value below which the contribution to the dose equivalent from external exposure exceeds that from inhalation for virtually all radionuclides.

A more detailed explanation is provided below. For a given radionuclide, the ratio of the dose from external irradiation to that from internal irradiation (from inhalation) depends on the half-life of the radionuclide, the characteristics of the radiations emitted in the decay of the radionuclide, the physical and chemical properties of the radioactive material containing the radionuclides, and the physiological response of the body to intakes of this material. However, considering the effect of half-life alone, and in general, the value of this ratio increases as the half-life decreases. The Statement from the 1983 Meeting of the ICRP includes the following paragraph:

"In ICRP Publication 30 the values of DAC for occupational exposure to short-lived nuclides (other than isotopes of noble gases) are based on the dose equivalent to organs and tissues as the result of inhalation. The Commission wishes to draw attention to the fact that there is an additional contribution to these dose equivalents from external irradiation. In situations where short-lived materials are widely distributed in the workplace, this additional contribution may be greater than that due to inhalation by a factor that increases from about 1 to 100 as the half-life of the radiomuclide decreases from 1 day to $10 \mathrm{~min}$. Such contributions should be assessed as part of the external irradiation."

Actually, for radionuclides with half-lives of roughly 2 hours, the vahues of this factor fall within the range of about 1 to 10 . Thus, for virtually all radionuclides with half-lives less than 2 hours, the value of this factor is greater than one. Values of this factor greater than one were selected as values indicating "a significant contribution from external exposure." (References: Part 20 Appendix B Footnote 2)

Question 23: Will all of the libraries of reference data and the procedures for gamma-ray spectrometry software or appendices that contain 10 CFR Part 20 MPCs have to be changed?

Answer: Yes. (Reference: Part 20 Appendix B)

Question 71: The "Class" column of 10 CFR 20 Appendix $B$ covers inhalation, but does not refer to ingestion. When there are two ALIs for ingestion, how do these relate to the "Class," since they really were based upon the $f_{1}$ value for gut absorption? (Note: The $f_{1}$ value is the fractional uptake from the small intestine to blood).

Answer: The ALIs for ingestion do not relate to the "Class," which refers to the retention time in the pulmonary region of the hung. There are two situations for which there are two ALIs for ingestion. One is when the ALI is determined by the non-stochastic dose to an organ. In this case, the organ or tissue to which the limit applies is shown, and the ALI for the stochastic limit is shown in parentheses (for example, see ingestion ALI for beryllium-10). The other case (and the case presumably in question) is when different $f_{1}$ values were used to calculate the ingestion ALIs. For example, see the entry for cobalt -60 , for which the ingestion ALIs are 500 (on the first line) and 200 (on the second line). These ingestion ALI values have no relationship to the corresponding "Class" on the same line (W on the first line and $Y$ on the second line). Rather, as explained in Eederal Guidance Repont No. 11, these different ingestion ALIs are based on two different $f_{1}$ values: $f_{1}=0.05$ for $A L I=500$, and $f_{1}=0.3$ for $A L I=200$. As shown in Eederal Guidance Report No. 11, Table 3, $f_{1}=0.05$ for "oxides, hydroxides and trace inorganic," and $f_{1}=0.3$ for "organic complexed and other inorganics." For inbalation of cobalt$60, f_{1}=0.05$ for both "oxides, hydroxides, halides and nitrates" (class Y), and "all others" (class W).

The following information on Federal Guidance Report No. 11 is provided for those not familiar with this document: The title of this report is "Limiting Values of Radionuclide Intake and Air Concentration and Dose Conversion Factors of Inhalation, Submersion and Ingestion." The report is subtitled "Derived Guides for Control of Occupational Exposure and Exposure-to-Dose Conversion Factors for General Application, Based on 1987 Federal Radiation Protection Guidance." The report was published by the U.S. Environmental Protection Agency (EPA) as report 
number EPA-520/1-88-020 on September 1, 1988. The ALI and DAC values in this report are used in Appendix B of the revised Part 20. (References: 10 CFR 20 Appendix B, Eederal Guidence Repart No. 11).

Question 146: The term "not present," which is defined in paragraph 5 of the Note (concerning mixtures of radiomuclides) following Appendix B of the old Part 20, is not defined in the corresponding "Note" in the revised Part 20. Does this definition from the old Part 20, which indicates when a radionuclide may be considered as not present in a mixture, continue to apply in the revised Part 20?

Answer: No. Nothing in the old Part 20 (\$\$20.1-20.601) applies in the revised Part 20 (\$\$20.1001-20.2401). This definition of "not present" is not inchudod in the revised Part 20; however, 10 CFR 20.1204(g) stipulates the conditions under which licensees may disregard certain radionuclides in a mixture when determining internal dose. See the answer to the related Question 121 for clarification of 10 CFR 20.1204(g). (References: Appendix B, 10 CFR 20.1204)

Question 396: The Appendix B tables of the revised Part 20 inchude ALIs and DACs for daughter radionuclides, in contrast to the Appendix B tables in the "old" Part 20, which do not inchude these daughter radionuclides. For example, ALIs and DACs for rubidium-88 and cesium-138 are listed. Are the listed ALIs and DACs expected to be considered separately with regand to posting and other requirements in the revised Part 20 ?

Answer: Yes. However, the statements preceding the question itself may reflect misunderstandings; these possible misunderstandings are addressed in the following discussion.

The Appendix B tables of both "old" and "revised" Part 20 do inchude many "daughter radionuclides." The tables of "revised" Part 20 inchude more radionuclides, and therefore more daughter radionuclides, than the tables of "old" Part 20. Athough rubidium-88 and cesium-138 (daughters of kypton-88 and xenon-138, respectively) are not included in "old" Part 20, they do need to be "considered separately with regard to posting and other requirements..." of "old" Part 20; the relevant concentrations for rubidium-88 and cesium-138 are those listed at the end of Appendix B for "Any single radionuclide not listed above with decay mode other than alphe emission or spontaneous fission and with radioactive half-life less than two hours." The "old" Part 20 does inchude the nubidium-87 daughter of krypton-87 and the cesium-135 daughter of xenon-135, as well as many other daughters whose parent radionuclides are listed in the tables. Some very short-lived daughters of long-lived radionuclides are not included in either "old" or "revised" Part 20 (e.g., the 2.55 -min barium-137m daughter of 30-year cesium-137).

The tables in Appendix B of "old" and "revised" Part 20 are consistent with respect to treatment of daughter radionuclides in the dose modeling used to derive the ALIs and DACs listed in the tables. When a listed radionuclide has a radionuclide daughter, the value in the table for that parent radionuclide takes into account the dose from the daughter radionuclide produced in the body from the decay of the parent following intake of the parent (unless a "submersion" value is listed for the parent). However, the value in the table for a parent radionuclide does not take into account any simultaneous intake of the daughter radionuclide. Thus the ALIs and DACs for daughter radionuclides need "to be considered separately" from their parent radionuclides "with regand to the posting and other requirements of Part 20." (Reference: 10 CFR 20 Appendix B).

Question 425: It appears that some of the oral ingestion ALIs in Appendix B of 10 CFR 20 are sometimes associated with the wrong chemical forms; is this the case?

Answer: No. See the answer to Question 71 in section 10 CFR Part 20, Appendix B which indicates that the "Class" column of 10 CFR Appendix B applies to inhalation only; it does not refer to ingestion. In other words, neither the D, $W$, and $Y$ classes nor the chemical forms (compounds) in the "Class" column refer to the ingestion ALIs. (Reference: 10 CFR 20 Appendix B).

Question 426: Are the noble gas ("submersion") DACs based on a dose of 5 rem per year or 50 rem per year? Is the submersion dose calculated at a depth of $1000 \mathrm{mg} / \mathrm{cm}^{2}$ or $7 \mathrm{mg} / \mathrm{cm}^{2}$ ?

Answer: There is no one particular dose or one particular depth. The method for calculating submersion doses is explained in Federal Guidance Report No. 11 on pages 10 , 18,181 , and 182. When air concentration is limited by submersion dose, the DAC for a particular radionuclide is the maximum concentration of that radionuclide in air that, for a 2,000-hour exposure, will result in a dose that is equal to or less than each of the applicable limits ( 5 rem effective dose equivalent, 15-rem eye dose equivalent, 50-rem dose equivalent to other organs and tissues, shallow dose equivalent of 50 rem to the skin). That is, the DAC for a particular radionuclide depends on which of the applicable dose limits is the most restrictive with respect to the concentration of that particular radionuclide. The dosimetric model 
used to calculate the DACs considers shielding of organs by overlying tissues and the degradation of the photon spectrum through scatter and attenuation by air. The dose from beta particles is evaluated at a depth of $7 \mathrm{mg} / \mathrm{cm}^{2}$ for skin, and at a depth of $3 \mathrm{~mm}$ for the lens of the eye. The worker is assumed to be immersed in pure parent radionuclide, and no radiation from airborno progeny is considered. In most cases, the concentration limit for submersion is based on external irradiation of the body; it does not take into account either absorbed gas within the body or the inhalation of radioactive decay products. An exception to the preceding statement is Ar-37, for which direct exposure of the lungs by inhaled activity limits (stochastically) the concentration in air. The skin dose is limiting for Ar-39, $\mathrm{Kr}-85$, and $\mathrm{Xe-}$ $131 \mathrm{~m}$; the eye dose is limiting for $\mathrm{Kr}-83 \mathrm{~m}$. Note: There are typographical errors in the discussion of submersion doses on page 10 of Eederal Guidance Report No. 11 . In the fifth sentence of the paragraph beginning "Some airborne radionuclides...", the word "effective" should be added before the words "dose equivalent rate". In equation (8b), the subscript "E" should be the subscript "T." (Reference: 10 CFR 20 Appendix B).

Question 453: Note 2 of Appendix B provides criteria for determining the appropriate derived air concentration (DAC) for a mixture of radionuclides where "the identity of each radionuclide in the mixture is not known, but it is known that certain radionuclides are not present in the mixture." In \$20.1204, Determination of Intermal Exposure, provisions are made to disregard the concentration of any radionuclide that is less than $10 \%$ of its DAC so long as the sum of the percentages for all of the radionuclides disregarded in the mixture does not exceed $30 \%$. Can this approach of disregarding certain radionuclides be applied to the determination of the appropriate DAC, as outlined in note 2 to Appendix B; in other words, can radionuclides that are not present in the mixture in concentrations greater than or equal to $10 \%$ of its DAC be disregarded so long as the sum of the percentages for all of the radionuclides disregarded in the mixture does not exceed $30 \%$ ? This question is intended to affirm a practical approach to truncating the analysis of radionuclide mixtures by disregarding radionuclides that are not present or may only be present in insignificant concentrations relative to other radionuclides in a mixture.

Answer: No. This would be a misapplication of the provisions of 10 CFR $20.1204(\mathrm{~g})$, which applies to the determination of internal exposure under specified circumstances, not to the choice of the appropriate DAC for a mixture. See the following related questions and answers: Question \$121 and answer in section 10 CFR 20.1204 which clarifies the meaning of "total activity" in 10 CFR 20.1204(g) and provides an example of the proper use of this provision of Part 20; Question 403 and answer in section 10 CFR 20.2106 which concerns the relevance of 10 CFR 20.1202(b)(3) and 20.1204(g) to a cutoff levels for radionuclides contributing to the CEDE; and Question 146 and answer in section 10 CFR 20 Appendix B which indicates that the definition of the term "not present" in old Part 20 does not apply to the revised Part 20. (References: 10 CFR 20 Appendix B, 10 CFR 20.1202, 10 CFR 20.1204).

\subsection{CFR 19 - NOTICES, INSTRUCTIONS, AND REPORTS TO WORKERS: INSPECTION AND INVESTIGATIONS}

\section{CFR 19.12 - Instructions to Workers}

Question 95: 10 CFR 19.12 requires training (instruction) of workers who enter a restricted area. Do individuals recoiving occupational doses in controlled areas need training?

Answer: Yes. They need training, but it is not specifically required by 10 CFR 19.12 since this section addresses only individuals working in or frequenting any portion of a restricted area. The obvious intent of the training (instruction) requirement of Part 19 is that individuals who are permitted to recoive occupational doses within the occupational limits will receive appropriate training. Although not explicitly stated in 10 CFR Parts 19 or 20, individuals who are to rocoive an occupational dose in any area should receive appropriate training. (Reference: 10 CFR 19.12).

Question 411: Under 10 CFR 19.12, what is the minimum training that licensees must provide to visitors who will enter a restricted area (where the occupational dose limits apply)?

Answer: 10 CFR 19.12, "Instructions to Workers," requires that training (instruction) be provided to "all individuals working in or frequenting any portion of a restricted area." Frequenting an area means to pay frequent visits to the area or to be in the area often. Therefore, 10 CFR 19.12 does not apply to infrequent visitors who will not be working in the restricted area. However, 10 CFR 19.12 does apply to visitors or other individuals (a) who will be working in the restricted area or (b) who are expected to bo in the aren often. (Thus, 10 CFR 19.12 does require in- 
struction of anyone working in a restricted area, even if that work is infrequent.) Licensees have the responsibility to determine which individuals are frequent visitors and which are not. Although not required by 10 CFR 19.12, in accordance with good radiation protection practice, infrequent visitor(s) should be provided with a trained escort who will provide the visitor(s) with the information needed for protection from any potential radiological hazands. (Reference: 10 CFR 19.12)

Question 422: This question refers to Question 95 under 10 CFR Part 19 and Question 81 under 10 CFR 20.1502. Clearly there is a significant population of occupationally exposed persons in unrestricted areas of whom the licensee has no knowledge. Even among their own employees, the licensed operation may be a small segment of the whole organization where license management treats the rest of the organization as general public. So presumably, the general principle of educating occupationally exposed persons has a dose threshold, e.g., something like the public dose limit; is this correct?

Answer: No. There is no such threshold. It is incorrectly assumed that any dose received by an individual while working is an occupational dose. [See the discussion of this point in the answer to Question 26 (a) "Occupational Dose v8. Public Dose."] A licensee may have an organization in which most of the workers are members of the public; these workers do not need and are not required to receive the kind of training outlined in 10 CFR 19.12. Workers who do receive an occupational dose (and therefore are not members of the public) should receive such training, whether required by 10 CFR 19.12 or not. For workers who must receive such training, there is no "dose threshold"; however, the extent of the instruction of these workers should be commensurate with the potential radiological health protection problems for these workers. (Reference: 10 CFR 19.12).

\section{CFR 19.13 - Notification and Reports to Individuals}

Question 37: Is it necessary to document that employees have been advised of their annual doses? Is it sufficient to let employees see the results of the monitoring? Does posting doses on a bulletin board in a common area, each month, fulfill this requirement?

Answer: See 10 CFR 19.13(a), which has not been revised. The licensee must provide a written report to each worker. The licensee may keep a copy of the report, or other appropriate record, on file to document compliance. (Reference: 10 CFR 19.13)

Question 377: Are licensees required by 10 CFR 19.13 to report to individuals the results of monitoring performed but not required under 10 CFR 20.1502? 10 CFR 19.13 states that radiation exposure data shall be reported to the individual, and that "the information reported shall include data and results obtained pursunt to Commission repulations, onders or license conditions, as shown in records maintained by the licenses pursusnt to Commission ragulations. From this, it appears that the results of monitoring performed but not required by NRC regulations is not required to be reported to individuals.

Answer: No. The results of monitoring performed but not required by NRC regulations are not required to be reported to individuals. (References: 10 CFR 19.13, 10 CFR 20.1502).

Question 378: If a worker formerly monitored at the licensee's facility as a "declared pregnant woman," requests that her exposure records be forwarded to her current employer, should related embryo/fetus dose records also be forwarded if not specifically requested?

Answer: No. Regulatory Guide 8.7, Rev. 1, includes the following statement in Section 3.2. "Licensees should be sensitive to the issue of personal privacy with regard to embryo/fetus dose. If requested by a monitored woman, a letter report may be provided to document prior embryo/ fetus dose." Otherwise, the embryo/fetus dose records should not be provided. (Reference: 10 CFR 19.13, 10 CFR 20.1208).

Question 409: In complying with the 10 CFR 19.13(c) report request, is it acceptable to report on a Form-4 dose received in the current year as one monitoring period and dose received in prior years as another monitoring period oven if the prior years monitoring period exceeds one year?

Answer: Yes. However, it should be recognized that this report should inchude records of doses received during planned special exposures, accidents, and emergency conditions as shown in the records maintained in accordance with 10 CFR 20.2106. If there have been no planned special exposures or overexposures, a statement to that effect should be provided. (Reference: 10 CFR 19.13) 
Question 421: This question refers to the answer to Question 37 in "Conforming Changes: 10 CFR Part 19." I sincerely hope that the NRC will encourage licensees to simply file a memo to the effect that these reports were done. Otherwise, the volume of paper will be ridiculous.

Answer: A filed memorandum to the effect that each worker has been advised of his or her dose in accordance with 10 CFR 19.13(a) is an acceptable way of documenting compliance with that requirement. Another acceptable way of documenting compliance is to file copies of the reports provided to employees (as indicated in the answer to Question 37). (Reference: 10 CFR 19.13).

Question 454: What is the specific scope of the reports required to be provided to workers in accordance with the various provisions of 10 CFR Part 19.13? The provisions in question are as follows:

a. Part 19, 819.13(b) requires that licensees provide reports to workers annually of dose as shown in records maintained by the licensee. Is the monitoring period covered by this section limited to the preceding year only? This would appear to be the case based on the comments made by the NRC staff in the statements of consideration (56 FR 23386, column 2) which states, "a copy of the annual report to NRC could also be given to the individual worker to satisfy the revised reporting requirement in 819.13..." The annual report referred to is the report submitted in accordance with Part 20, 820.2206, which is limited to the monitoring period of the preceding year.

b. If the licensee provides workers with an NRC Form 5 (or equivalent), does the scope of this information fulfill the requirements of Part 19, \$19.13(a) to provide certain information to workers? The purpose in asking this question is to confirm that, although 819.13 (a) was not revised as a conforming amendment to the revised Part 20, the comments made by the NRC (as described in item "a", above) also apply, i.e., "a copy of the annual report to NRC could also be given to the individual worker to satisfy the revised reporting requirement in \$19.13. "If the NRC Form 5 (or equivalent) is not sufficient to comply with $\$ 19.13$ (a), what additional information is required to be provided to the worker?

c. Does this provision [i.e., \$19.13(b)] apply to all workers who were monitored during the preceding year by the licensee, or only to workers who continue to be monitored by the licensee at the end of the year?

d. If the workers were given a complete and final dose report at the time of termination of employment during the preceding year, is an additional, duplicative report still required to be issued in accordance with $\$ 19.13(\mathrm{~b})$ ?

e. In providing annual dose reports to workers in accordance with $\$ 19.13(\mathrm{~b})$, are reports of dose to the worker's embryo/fetus, maintained in accordance with $10 \mathrm{CFR}$ 20.2106 , also required to be provided to the worker with the report?

f. In providing dose reports to a worker in accordance with $\$ 19.13(\theta)$, at the request of the worker at the time of termination of employment, are reports of dose to the worker's embryo/fetus, maintained in accordance with 10 CFR 20.2106, also required to be provided to the worker with the report?

\section{Answer:}

(a) Yes; the monitoring period covered by $10 \mathrm{CFR}$ 19.13(b) is limited to the previous year. See related Questions 392-395, inclusive, concerning reports required by 10 CFR 20.2206 and Questions 37, 377, and 378 concerning the requirements of 10 CFR 19.13(b).

(b) Yes, the scope of the information on NRC Form 5 (or equivalent) fulfills the information requirements of $10 \mathrm{CFR}$ 19.13 (a) [and 10 CFR 19.13(b). However, in accordance with 10 CFR 19.13(a), the transmittal of the information by the licensee to the individual must contain the following statement (which is not on Form 5): This report is furnished to you under the provisions of the Nuclear Regulatory Commission regulation 10 CFR Part 19. You should preserve this report for further reference.

(c) 10 CFR 19.13(b) applies to all workers who were required to be monitored during the preceding year, not just those who continue to be monitored at the end of the year.

(d) No, an additional duplicative report need not be issued, provided that it was made clear to the worker that the report he or she was given at time of termination of employment was a "complete and final report" from the licensee for that worker for that year.

(e) No, not unless requested by the worker. See the answer to Question 378 in the section headed 10 CFR 19.13).

(f) Yes, if the worker has requested this information. (References: 10 CFR 19.13, 10 CFR 20.2106). 


\subsection{CFR 50 - DOMESTIC LICENSING OF PRODUCTION AND UTILIZATION FACILITIES}

\section{CFR Part 50}

Question 14: Are Design Basis Accident criteria (doses) changed by the revised Part 20?

Answer: No, only those conforming changes included in the Federal Register notice will be effective when the revised Part 20 is implemented. Old dose criteria used for Design Basis Accident will retain their original definitions unless they are specifically changed in a licensing action. (References: 10 CFR 50 Appendix A, 10 CFR Part 100)

Question 15: Will the reporting criteria of 10 CFR 50.72 and 50.73 have to be changed?

Answer: The necessary changes have been already been made. See "Conforming Amendments," in the May 21, 1991 Federal Register notice on 10 CFR Part 20 et al. (56 FR 23473). Licensee's procedures may have to be changed accordingly. (References: 10 CFR 50.72, 10 CFR 50.73)

Question 16: Will the Emergency Action Levels (EAL) as part of the Emergency Plans have to be changed if based on the old Part 20 methodology?

Answer: The EALs are not related to Part 20. Appendix 1 of NUREG-0654 contains the descriptions for the four emergency classifications; unusual event, alert, site area emergency, and general emergency. Example initiating conditions are also found in this appendix. No reference is made to the use or applicability of Part 20 in either the regulations pertinent to emergency classifications nor in the guidance. In the class descriptions, reference is made to EPA protective action guide (PAG) exposure levels.

EPA has revised its PAG manual. EPA recommends the use of committed effective dose equivalent to replace the whole body dose for the plume PAG. The numerical values for the plume PAG remain the same. It is therefore expected that the licensees will have to revise, if necessary, their emergency dose calculation methodology to classify an emergency and recommend protective actions in order to comply with the revised EPA PAG manual. (Reference: 50.47, EPA PAG manual)

Question 17: Will QA Category 1 requirements discussed in Regulatory Guide 1.26 have to be changed due to offsite dose requirements of 0.5 rem being changed to $0.1 \mathrm{rem}$ in the revised Part 20?

Answer: The revised Part 20 does not change the QA Category 1 requirements. The 0.5 rem bench-mark is for design.considerations; therefore, it will likely remain the same. (Reference: 10 CFR 50 Appendix B)

Question 20: Pertaining to Question 19, will 10 CFR 50 Appendix I and Technical Specifications have to be modified to reflect a total effective dose equivalent (TEDE)?

Answer: Appendix I, and the corresponding Technical Specifications, will not have to be modified as a result of the revised Part 20; however, the staff is considering whether Appendix I design objectives need to be recast as effective dose equivalent. (References: 10 CFR 50 Appendix I, Reactor Technical Specifications)

Question 456: FSARs for Part 50 power reactor licensees typically contain multiple references to current 10 CFR Part 20 concepts and terminology, primarily with regard to describing aspects of the radiation protection program. Updating of these references would be editorial in nature, without any health and safety benefit, but would nevertheless divert resources from potentially more significant matters. Additionally, these changes would be submitted to the NRC as part of the FSAR Update process, involving NRC staff review, an additional expenditure of resources. May licensees forego such editorial changes to the FSAR, that have no health and safety significance? Note that programmatic changes required to inplement the revised Part 20 will still be accomplished through new or revised procectures and training. Additional clarification of the NRC staff's expectations would be useful for Part 50 licensees to more appropriately efficiently allocate resources to their revised Part 20 implementation efforts.

Answer: Yes; power reactor licensees do not need to provide updates that are purely editoriai and have no health and safety significance. 10 CFR 50.71(e) requires each power reactor licensee to update the licensee's FSAR and to submit the changes to the NRC. The only FSAR changes (resulting from the revised Part 20) that need to be made are: (a) significant changes in commitments identified in the FSAR regarding the radiation protection program; (b) 
Questions and Answers

changes in the facility described in the FSAR; and (c) changes that involve an unreviewed safety question or technical specification change pursuant to 10 CFR 50.59. The NRC staff does not expect that implementation of revised Part 20 will result in significant changes to power reactor facilities or in unreviewed safety questions at these facilities. Changes in reactor technical specifications are not required by the revised Part 20; however, the staff does expect that some power reactor licensees will voluntarily request changes in technical specifications as a result of revised Part 20, such as changes in ESF-related process monitor alarm set points (which may have been based on the old Part 20). (Reference: 10 CFR Part 50, FSAR).

\subsection{REGULATORY GUIDES}

\section{Regulatory Guides - General}

Question 12: How will the revised Regulatory Guides be used in determining acceptability of a licenses's implementation of the revised Part 20?

Answer: In determining the acceptability of a licensee's implementation of the revised Part 20, new regulatory guides will be used in the same way existing guides have been used in determining acceptability of a licensee's implementation of the old Part 20 in cases in which there is no licensee commitment to the guide in a license application. As stated in virtually every guide, Regulatory Guides are not regulations and compliance with them is not required, unless the guide has been made a specific condition of a license (a common practice for materials licensees who are licensed by NRC's Office of Nuclear Material Safety and Safeguards). Also, as indicated in every guide, alternatives to methods described in the guide may be acceptable.

(Reference: Regulatory Guides)

\section{Regulatory Guide 1.109}

Question 21: Is it time to update Regulatory Guide 1.109 and its corresponding codes due to the updated dose conversion factors in the revised Part 20?

Answer: Perhaps, but such an update could only be a partial update at this time. The full updating could only occur if and when Appendix $I$ is recast as an effective dose equivalent. The evaluation of whether Appendix I should be changed is currently underway. (Reference: Regulatory Guides)

\section{Regulatory Guide $\mathbf{8 . 2 5}$}

Question 405: Regulatory Guide 8.25 (Section C.1.7) states that "to dotermine whether the concentration exceeds the DAC over the short term, the sample collection time should not exceed one hour. Shorter sample collection times may be used if desired, but they are not required." a.) Does this section mean to imply that the duration of a work zone air sample should not exceed one hour if it may be used to determine whether an area needs to be posted or otherwise controlled? b.) Under what circumstances does this one hour rule apply?

Answer: (a) No. The one-hour criterion applies only for sampling used "to determine whether the concentration exceeds the DAC over the short term" (emphasis added).

(b) The one-hour criterion is guidance; it is not a "nule." See answer to (a) reganding the circumstances of application. (References: Regulatory Guide 8.25, 10 CFR 20.1902).

\section{Regulatory Guide $\mathbf{8 . 3 6}$}

Question 406: Regulatory Guide 8.36, "Radiation Dose to the Embryo/Fetus," (Section C.1.3) states that "the determination of external dose should include all occupational exposures of the declared pregnant worker since the estimated date of conception. "(a) If declared pregnant worker has received occupational dose during this pregnancy while working for a previous licensee, is it intended that the dose from the previous licensee be obtained and included in estimating and limiting the embryo/fetus dose for the gestation period? (b) If this is the intention, what should be done if applicable dose records are not available because the worker had not declared pregnancy or was not monitored (i.e., was not likely to exceed $10 \%$ of a limit) at her previous workplace? In the absence of other data, should the previous dose be assumed to be zero?

Answer: (a) Yes.

(b) The licensee should make an effort to make a reasonable estimate of the dose using other information that the worker and her previous employer have concerning her exposure. Even when the worker was not monitored, a well-trained worker and her employer should be able to provide some information concerning her exposure. 
(c) No. Neither should it be assumed to be the maximum possible dose. See answer to question (b). (Reference: Regulatory Guide 8.36).

\section{Regulatory Guide 8.7, Rev. 1}

Question 451: May the codes "ND" (not detectable), "NR" (not required), and "NC" (not calculated) be used moro generally in the radiation dose data blocks on the NRC Forms 4 and 5 than is implied by the instructions on the forms? The purpose in asking this question is to clarify the guidance for filling out the forms provided in the regulatory position and in the instructions on the reverse side of the NRC Forms 4 and 5. The Form 5 instructions appear to limit the use of the "NR" and "NC" codes to the committed effective dose equivalent (CEDE) and the committed dose equivalent (CDE), "ND" is not referenced in the Form 5 instructions, and the NRC Form 4 instructions do not appear to refer to any of these codes. We believe that the references to the codes in the guidance and instructions on the forms are as examples for emphasis, and that the intent of the guidance is that "NR" and "ND" are appropriate for use, as applicable, in any of the dose blocks, and are not specifically limited for use by the manner in which referenced or described in the guidance. However, we do note that "NC" may only be applicable to the CDE (e.g., if the CEDE were less than 1 rem).

Answer: Yes. As indicated in the second paragraph of regulatory position 1.1 of the guide, "NR" should be entered in the blocks on Forms 4 and 5 to indicate the areas for which monitoring was not required and "ND" should be entered on these forms to indicate "where monitoring was provided but not measurable [detectable]". As indicated in regulatory position $\mathbf{2 . 2}$ of the guide, the use of "NC" is appropriate only for items 16 and 18 on NRC Forms 4 and 5 for cases in which the CEDE does not exceed 1 rem and there are no overexposures in any dose category within the monitoring year. (References: Regulatory Guide 8.7, Rev. 1; 10 CFR 20.2104, 10 CFR 20.2106).

\subsection{TECHNICAL SPECIFICATIONS}

\section{Reactor Technical Specifications}

Question 18: For power reactors, the Technical Specification instantaneous release rate limits are based on old Part 20 doses and concentrations (relative to an implied 500 mrem/yr limit). Will changes in the Technical Specifications and ODCMs be required as a result of the explicit 100-mrem/yr limit in the revised Part 20?

Answer: The instantanevus release rate limits for airborne releases will not be changed because they are imposed on licensees as a control to ensure that licensees meet Appendix I requirements. However, the instantaneous release rates for liquid effluents, to the extent that they directly reference Appendix B concentration values, will need to be changed. The corresponding bases and certain alarm set-points will have to be changed by license amendment. (Reference: Reactor Technical Specifications)

Question 19: Current computer codes, such as LADTAP and GASPAR, calculate individual organ doses for comparison against individual organ dose limits in 10 CFR 50 Appendix I and/or Technical Specifications. Will the codes have to be modified to convert whole body and organ doses to effective dose equivalents?

Answer: Appendix I is not changed by the revised Part 20. Therefore, until Appendix I is changed, licensees must continue to show compliance with technical specifications based on Appendix I and expressed in terms of organ and whole body doses. (Reference: Reactor Technical Specifications)

Question 52: Since the technical specification "exemptions" for nuclear power reactors already apply to locking of high radiation areas, does this "exemption" continue to apply pursuant to 10 CFR 20.1008 (d) if $45-\mathrm{cm}$ (18-inch) survey distance is specified (in technical specifications) versus the rulo's 30-cm distance (10 CFR 20.1601(a))?

Answer: The provisions of power reactor technical specifications for control of high radiation areas are not "exemptions" from the regulations. They are alternative methods of control provided in accordance with the provisions of 10 CFR 20.203(c)(5). Under the revised Part 20 these technical specifications will continue to apply to the control of high radiation areas (but not very high radiation areas) until they are changed. These technical specifications refer to a high radiation area as defined in Part 20. When revised Part 20 is implemented, the revised definition of a high radiation area, using the $30-\mathrm{cm}$ distance, will apply. Thus to determine the boundaries of the high radiation area, the 30-cm (12-in.) distance will be used. However, within the boundaries of that area the less-restrictive 45-cm (18-in.) distance specified in the technical specifications will be used to determine whether the radiation exposure is less than, equal to, or greater than $1,000 \mathrm{mR} / \mathrm{h}$, the exposure rate used 
in the technical specifications to define the degree of control required. Changes in the technical specifications to be proposed by the NRC staff will include a change from $45 \mathrm{~cm}$ to $30 \mathrm{~cm}$ for the specified distance. (References: 20.1601, 10 CFR 20.1602, Reactor Technical Specifications)

Question 61: Will the annual reports that are required by power reactor technical specifications (reports that tabulate occupational exposures greater than $100 \mathrm{mrem} / \mathrm{yr}$ acconding to work and job functions) still be required after the revised Part 20 is implemented.

Answer: Yes. There are no plans to change this requirement of the Technical Specifications. However, the reports on occupational exposures required by the old Part 20 in 10 CFR 20.407 (statistical summary reports) and 10 CFR 20.403 (termination reports), will no longer be required. These statistical summary and termination reports are being replaced by the revised "reports of individual monitoring" required by 10 CFR 20.2206. (Reference: Reactor Technical Specifications, 10 CFR 20.2206)

Question 79: Many existin reactor Technical Specifications require commercial power plant licensees to provide statistical personnel dose summary to NRC annually. The old Part 20 contained provisions for such reports, but no corresponding requirement carried over to the revised rule. Why?

Answer: The statement above confuses Technical Specification requirements with Part 20 Requirements.

Under the old Part 20, power reactor licensees (and other licensees) were required, by Part 20, to submit both annual "statistical summary" reports (in accondance with 10 CFR 20.407) and "termination" reports (in accordance with 10 CFR 20.408). In addition to these two Part 20 reporting requirements, power reactor licensees are required by their Technical Specifications to submit annual reports that inchude a tabulation of workers receiving exposures greater than $100 \mathrm{mrem} / \mathrm{y}$ and their associated collective dose according to work and job functions.

Under the revised Part 20, the statistical summary and termination reports of the old Part 20 are eliminated and replaced by a new anmual report on the results of individual monitoring of occupational exposure (10 CFR 20.2206). The revised Part 20 has no effect on the annual report roquired by Technical Specifications. There are no plans to change this reporting requirement in the Technical Specifications. (References: 10 CFR 20.2206, Reactor Technical Specifications)
Question 397: After implementation of the revised 10 CFR Part 20, shoukd nuclear power plant licensees report total effective dose equivalent (TEDE) or deep dose equivalent (DDE) as the "whole body dose" for annual reports submitted in accordance with reactor technical specifications and Regulatory Guide 1.16?

Answer: Deep dose equivalent. (Reference: Resctor Technical Specifications, Regulatory Guide 1.16).

Question 433: Question 397 concerns a reporting requirement in "renctor technical specifications." Does this question, and the answer provided, apply to non-power reactors?

Answer: No. Question 397 and its answer refer to reporting requirements contained in technical specifications for power reactors, but not in technical specifications for nonpower reactors. Question 397 also refors to Regulatory Guide 1.16, "Reporting of Operating Information Appendix A Technical Specifications," which applies only to nuclear power plants. (Reference: Reactor Technical Specifications).

Question 455: Part 50 license standard technical specifications define "Dose Equivalent I-131" as "...that concentration of I-131 (microcurie/gram) which alone would produce the same thyroid dose as the quantity and isotopic mixture of I-131, I-132, I-133, I-134, and I-135 actually present..." and "the thyroid dose conversion factors used for this calculation shall be those listed in NRC Regulatory Guide 1.109." (a) After implementation of the revised 10 CFR Part 20, should licensees continue to use the Regulatory Guide 1.109 thyroid dose conversion factors or should they use the thyroid dose conversion factors in EPA Federal Guidance Report No. 11 (b) Will this be addressed in NRC's forthcoming generic letter on changes to technical specifications related to the revised Part 20?

Answer:(a) Licensees must continue to use the thyroid dose conversion factors (DCF8) that are referenced in their technical specifications (TS). A TS amendment would be needed to allow the use of other technically acceptable values. It should be noted that in the absence of such regulatory requirements, the NRC has allowed licensees to use sources of intake-to-dose conversion factors other than Regulatory Guide 1.109.

(b) The use of Federal Guidance Report No. 11 thyroid DCFs is not planned to be included in the generic letter on changes to power reactor technical specifications to incorporate the revised Part 20 but will be addressed in a forth- 
coming hoalth physics position document (which will be mede publicly availablo). (Reforence: Reactor Technical Specifications).

\section{Power Reactor Technical Specifications and Materials Licenses}

Question 22: Alarm setpoints for many radiation monitore are based on 10 CFR 20 Appendix B concentrations. Will these now changes require numerous ODCM changes, setpoint change requests, and procecture changes?

Answer: Separate answers are provided for reactor and materials licensees because these answers are somowhat different.

Renctor Licensese: Alarm setpoints for virborne effhent monitors are not likely to change. These monitors are typically set up to detect an effluent concentration which would yield a whole body dose rate of 500 mrem/y or a thyroid dose rate of $1500 \mathrm{mrem} / \mathrm{y}$ (or fraction thereof) in an unrestricted area on an instantaneous basis, as required by the Technical Specifications. Since other limiting conditions are also contained in Technical Specifications to restrict anmual doses to the public to much smaller values than those implied above, and since short-term operational flexibility is necessary, it is unlikely that changes would noed to be mado in the alarm setpoints for airborne effluent monitors.

Alarm setpoints for waterborne effluent monitors are likely to require change, since they are based on 10 CFR 20 Appendix B concentrations, as required by the Technical Specifications. Because Appendix B concentration values differ for many radionuclides between the rovised and old versions of Part 20, liquid effluent monitor alarm setpoints may have to be changed.

For reactors, the extent of staff involvement and licensee efforts in adjusting and documenting alarm setpoints will depend on whether the licenses has implemented NRR Generic Letter 89-01. (References: 10 CFR 20 Appendix B, Reactor Technical Specifications, NRR Genoric Letter 89-01)

Mnterials Licensees: Area monitor alarm setpoints for most materials licensees that are currently required to conduct continuous air monitoring will in all likelihood require change. This is especially true for those facilities that handle significant quantities of source and special nuclear material since the now DACs for these types of material are lower or more restrictive than the old MPCs. It should be noted that for commonly occurring thorium-232 (Th-232) and uranium 238 (U-238) in the oxide (insoluble) form, the DACs are lower than the MPCs by factors of 30 and 5 , respectively. Similarly, alarm setpoints for both airborne and waterbome releases for most materials licensees would have to be modified. It should also be noted that for airborne releases, the allowable concentrations for insoluble Th-232 and U-238 have been reduced by factors of about 170 and 80, respectively. For waterbome releases, the allowable release concentrations for soluble Th-232 and U-238 have been rectuced by factors of about 70 and 130 , respectively. For these reasons, it is anticipated that numerous procedural changes will have to be made for licensees handling significant quantities of source and special nuclear material.

\subsection{OTHER QUESTIONS}

Question 87: Will the numbering sequence of the revised regulation be changed once the "old" Part 20 expires?

Answer: No. (Reference: None)

Question 88: Will each NRC region hold orientation meetings for licensees on the revised regulation? When and where might these occur?

Answer: There are no plans to hold such orientation meetings. However, the NRC is providing "orientation" information by publishing Regulatory Guides and the new ve. old Part 20 comparison in NUREG-1446, by making documented questions and answers on revised Part 20 publicly available, by publishing information in the NMSS Newsletter, and by NRC staff participation in topical meetings concerning revised Part 20. (Reference: None)

Question 89: Is it possible to obtain copies of revised NRC "inspection modules" for inspection for compliance with the revised regulation? How may these be obtained?

Answer: All "inspection modules" (inspection procedures in the NRC Inspection Manual) are available from the NRC Public Document Room, 2120 L Street N.W., Lower Level, Washington, DC 20555; Telephone (202) 634-3273. Inspection procechures have not yet been revised to reflect the revised Part 20, but will be revised during 1992.

(Reference: None)

Question 457: Some licensees have established administrative dose control levels or guidelines, below regulatory 
dose limits, as a tool to support supervisory and managemont involvement in dose minimization. Procedures commonly describe cortain roviow actions to bo taken at succossive dose lovels, with a highor lovel of management involvoment at higher dose lovels. If an administrative dose control lovel or guidelino is exceeded without all of the doscribed action boing taken, but no regulatory limit is exceoded, is the fact of exceeding the control lovel or guideline a violation of NRC regulations?

Answer: Exceoding an edministrative dose control lovel or guideline that is below the limits of 10 CFR Part 20 is not a violation of 10 CFR Part 20. This is genorally trus with respect to other parts of the NRC regulations, although it is subject to exceptions; for example, for medical licensees, 10 CFR 35.25(a)(2) specifien requiremente for a "supervised individual" inchuding following "the written radiation safoty and quality management procectures established by the licenses". Such procedures might inchude administrative dose control levels or guidelines and failure to follow such procedures could be a violation of 10 CFR 35.25(a)(2). Furthermore, exceeding an administrative dose control lovel or guideline could bo violation of procedural requirements in the plant technical specifications at a nuclear power plant or a violation of apecific licenso conditions in a material license. (Reference: Other) 


\section{APPENDIX A}

\section{NUMERICAL LIST OF QUESTIONS AND ANSWERS}

Question 1

Page 3

Q/A Set 1

Regulatory Reference: 10 CFR 20.1003, Definitions

Question 2

Page 14

Q/A Set 1

PDR-9112190258

Regulatory Reference: 10 CFR 20.1001, Purpose

Question 3

Page 15

Q/A Set 1

PDR-9112190258

Regulatory Reference: 10 CFR 20.1201, Occupational Dose

Limits for Adults

Question 4

Q/A Set 1

Page 3

Regulatory Reference: 10 CFR 20.1001, Purpose

PDR-9112190258

Question 5

Page 3

Q/A Set 1

PDR-9112190258

Regulatory Reference: 10 CFR 20.1001, Purpose

Question 6

Page 15

Q/A Set 1

PDR-9112190258

Regulatory Reference: 10 CFR 20.1201, Occupational Dose

Limits for Adults

Question 7

Page 12

Q/A Set 1

PDR-9112190258

Regulatory Reference: 10 CFR 20.1101, Radiation

Protection Programs

Question 8

Page 22

Q/A Set 1

PDR-9112190258

Regulatory Reference: 10 CFR 20.1206, Planned Special

Exposures

Question 9

Page 19

Q/A Set 1

PDR-9112190258

Regulatory Reference: 10 CFR 20.1202, Compliance with

Requirements for Summation of External and Internal Doses
Question 10

Page 54

Q/A Set 1

PDR-9112190258

Regulatory Reference: 10 CFR 20.2.104, Determination of Prior Occupational Dose

Question 11

Page 12

Q/A Set I

PDR-9112190258

Regulatory Reference: 10 CFR 20.1101, Rediation

Protection Programs

Question 12

Q/A Set 2

Page 69

Regulatory Reference: Regulatory Guides

PDR-9205010117

Question 13

Page 63

Q/A Set 1

PDR-9112190258

Regulatory Reference: 10 CFR 20 Appendix B, Annual Limits on Intake (ALls) and Derived Air Concentrations (DACs) of Radionuclides for Occupational Exposure; Effluent Concentrations; Concentrations for Release to Sewage

Question 14

Page 68

Q/A Set 1

PDR-9112190258

Regulatory Reference: 10 CFR 50 Appendix A, General Design Criteria for Nuclear Power Plants

Question 15

Page 68

Q/A Set 1

PDR-9112190258

Regulatory Reference: 10 CFR 50.72, Maintenance of

Records, Making of Reports

Question 16

Page 68

Q/A Set 1

PDR-9112190258

Regulatory Reference: 10 CFR 50.47, Permits - Emergency

Plans

Question 17

Q/A Set 1

Page 68

Regulatory Reference: 10 CFR 50 Appendix B, Quality

Asurance Criteria for Nuclear Power Plants and Fuel

Reprocessing Plants

Question 18

Q/A Set 1

Page 70

Regulatory Reference: Technical Specifications 
Appendix A

Question 19

Page 70

Q/A Set 1

PDR-9112190258

Regulatory Reference: Technical Specifications

Question 20

Page 68

Q/A Set 1

PDR-9112190258

Regulatory Reference: 10 CFR 50 Appendix I, Numerical

Guides for Design Objectives and Limiting Conditions for

Operation to Meet the Criterion "As Low as is Reasonably

Achievable" for Radioactive Material in Light-Water-Cooled

Nuclear Power Reactor Effluents

Question 21

Page 69

Q/A Set 1

PDR-9112190258

Regulatory Reference: Regulatory Guides

Question 22

Q/A Set 2

Regulatory Reference: Technical Specifications

Question 23

Page 63

Q/A Set 1

PDR-9112190258

Regulatory Reference: 10 CFR 20 Appendix B, Annual

Limits on Intake (ALIs) and Derived Air Concentrations

(DACs) of Radionuclides for Occupational Exposure;

Effluent Concentrations; Concentrations for Release to

Sewage

Question 24

Page 22

Q/A Set 1

PDR-9112190258

Regulatory Reference: 10 CFR 20.1206, Planned Special

Exposures

Question 25

Page 4

Q/A Set 1

PDR-9112190258

Regulatory Reference: 10 CFR 20.1003, Definitions

Question 26

Q/A Set 4

Page 4

Regulatory Reference: 10 CFR 20.1003, Definitions

Question 27

Q/A Set 2

Regulatory Reference: 10 CFR 20.1902, Posting

Requirements

Question 28

Page 29

Q/A Set 1

PDR-9112190258

Regulatory Reference: 10 CFR 20.1302, Compliance with

Dose Limits for Individual Members of the Public
Question 29

Q/A Set 1

Page 29

Regulatory Reference: 10 CFR 20.1302, Compliance with

Dose Limits for Individual Members of the Public

Question 30

Page 11

Q/A Set 1

PDR-9112190258

Regulatory Reference: 10 CFR 20.1008, Implementation

Question 31

Page 15

Q/A Set 2

PDR-9205010117

Regulatory Reference: 10 CFR 20.1201, Occupational Dose Limits for Adults

Question 33

Page 15

Q/A Set 1

PDR-9112190258

Regulatory Reference: 10 CFR 20.1201, Occupational Dose Limits for Adults

Question 34

Page 15

Q/A Set 1

PDR-9112190258

Regulatory Reference: 10 CFR 20.1201, Occupational Dose

Limits for Adults

Question 35

Q/A Set 1

Page 49

PDR-9112190258

Regulatory Reference: 10 CFR 20.1903, Exceptions to

Posting Requirements

Question 36

Page 50

Q/A Set 1

PDR-9112190258

Regulatory Reference: 10 CFR 20.1906, Procedures for

Receiving and Opening Packages

Question 37

Page 66

Q/A Set 1

PDR-9112190258

Regulatory Reference: 10 CFR 19.13, Notifications and

Reports to Individuals

Question 38

Page 19

Q/A Set 1

PDR-9112190258

Regulatory Reference: 10 CFR 20.1202, Compliance with

Requirements for Summation of External and Internal Doses

Question 39

Page 54

Q/A Set 1

PDR-9112190258

Regulatory Reference: 10 CFR 20.2003, Disposal by

Release into Sanitary Sewerage

Question 40

Page 7

Q/A Set 1

PDR-9112190258

Regulatory Reference: 10 CFR 20.1003, Definitions 
Question 41

Page 15

Q/A Set 1

PDR-9112190258

Regulatory Reference: 10 CFR 20.1201, Occupational Dose

Limits for Adults

Question 42

Q/A Set 1

Page 26

PDR-9112190258

Regulatory Reference: 10 CFR 20.1301, Dose Limits for

Individual Members of the Public

Question 43

Page 32

Q/A Set 1

Regulatory Reference: 10 CFR 20.1502, Conditions

Requiring Individual Monitoring of External and Internal

Occupational Dose

Question 44

Q/A Set 1

Page 33

PDR-9112190258

Regulatory Reference: 10 CFR 20.1502, Conditions

Requiring Individual Monitoring of External and Internal

Occupational Dose

Question 45

Q/A Set 1

Page 16

PDR-9112190258

Regulatory Reference: 10 CFR 20.1201, Occupational Dose Limits for Adults

Question 46

Q/A Set 1

Page 16

Regulatory Reference: 10 CFR 20.1201, Occupational Dose

Limits for Adults

Question 47

Q/A Set 1

Page 20

PDR-9112190258

Regulatory Reference: 10 CFR 20.1204, Determination of

Internal Exposure

Question 48

Page 26

Q/A Set 1

PDR-9112190258

Regulatory Reference: 10 CFR 20.1301, Dose Limits for Individual Members of the Public

Question 49

Page 40

Q/A Set 1

PDR-9112190258

Regulatory Reference: 10 CFR 20.1602, Control Access to

Very High Radiation Areas

Question 50

Page 20

Q/A Set 1

PDR-9112190258

Regulatory Reference: 10 CFR 20.1203, Determination of

External Dose From Airborne Radioactive Material
Question 51

Page 54

Q/A Set 1

PDR-9112190258

Regulatory Reference: 10 CFR 20.2104, Determination of Prior Occupational Dase

Question 52

Page 70

Q/A Set 1

PDR-9112190258

Regulatory Reference: Technical Specifications

Question 53

Page 47

Q/A Set 2

PDR-9205010117

Regulatory Reference: 10 CFR 20.1902, Posting

Requirements

Question 54

Page 33

Q/A Set 1

PDR-9112190258

Regulatory Reference: 10 CFR 20.1502, Conditions

Requiring Individual Monitoring of External and Internal

Occupational Dose

Question 55

Page 54

Q/A Set 1

PDR-9112190258

Regulatory Reference: 10 CFR 20.2104, Determination of

Prior Occupational Dose

Question 56

Page 60

Q/A Set 1

PDR-9112190258

Regulatory Reference: 10 CFR 20.2202, Notification of Incidents

Question 57

Page 7

Q/A Set 1

PDR-9112190258

Regulatory Reference: 10 CFR 20.1003, Definitions

Question 58

Page 11

Q/A Set 1

PDR-9112190258

Regulatory Reference: 10 CFR 20.1008, Implementation

Question 59

Page 24

Q/A Set 1

PDR-9112190258

Regulatory Reference: 10 CFR 20.1208, Dose to an

Embryo/Fetus

Question 60

Page 44

Q/A Set 1

PDR-9112190258

Regulatory Reference: 10 CFR 20.1703, Use of Individual

Respiratory Protection Equipment

Question 61

Page 71

Q/A Set 1

Regulatory Reference: Technical Specifications 
Appendix A

Question 62

Q/A Set 1

Regulatory Refereno

Protection Programs

Question 63

Q/A Set 2

Regulatory Reference: 10 CFR 20.1206, Planned Special

Exposures

Question 64

Page 55

Q/A Set 5

PDR-9306110303

Regulatory Reference: 10 CFR 20.2104, Determination of

Prior Occupational Dose

Question 65

Q/A Set 2

Page 11

Regulatory Reference: 10 CFR 20.1008, Implementation

Question 66

Q/A Set 2

Page 7

Regulatory Reference: 10 CFR 20.1003, Definitions

Question 67

Q/A Set 2

Regulatory Reference: 10 CFR 20.1003, Definitions

Question 68

Q/A Set 2

PDR-9205010

Page 8

PDR-9205010117

Regulatory Reference: 10 CFR 20.1302, Compliance with

Dose Limits for Individual Members of the Public

Question 69

Page 30

Q/A Set 2

PDR-9205010117

Regulatory Reference: 10 CFR 20.1302, Compliance with

Dose Limits for Individual Members of the Public

Question 71

Q/A Set 2

Page 63

Regulatory Reference: 10 CFR 20 Appendix B, Annual Limits on Intake (ALIs) and Derived Air Concentrations (DACs) of Radionuclides for Occupational Exposure;

Effluent Concentrations; Concentrations for Release to

Sewage

Question 72

Page 30

Q/A Set 2

PDR-9205010117

Regulatory Reference: 10 CFR 20.1302, Compliance with

Dose Limits for Individual Members of the Public

Question 73

Q/A Set 2

Page 11

Regulatory Reference: 10 CFR 20.1004, Units of Radiation

Dose
Question 74

Page 8

Q/A Set 2

PDR-9205010117

Regulatory Reference: 10 CFR 20.1003, Definitions

Question 75

Page 33

Q/A Set 2

PDR-9205010117

Regulatory Reference: 10 CFR 20.1502, Conditions

Requiring Individual Monitoring of External and Internal

Occupational Dose

Question 76

Page 20

Q/A Set 2

PDR-9205010117

Regulatory Reference: 10 CFR 20.1204, Determination of Internal Exposure

Question 77

Page 16

Q/A Set 2

PDR-9205010117

Regulatory Reference: 10 CFR 20.1201, Occupational Dose Limits for Adults

Question 78

Page 44

Q/A Set 2

PDR-9205010117

Regulatory Reference: 10 CFR 20.1703, Use of Individual

Respiratory Protection Equipment

Question 79

Page 71

Q/A Set 2

PDR-9205010117

Regulatory Reference: Technical Specifications

Question 80

Page 8

Q/A Set 5

PDR-9306110303

Regulatory Reference: 10 CFR 20.1003, Definitions

Question 81

Page 34

Q/A Set 2

PDR-9205010117

Regulatory Reference: 10 CFR 20.1502, Conditions

Requiring Individual Monitoring of External and Internal

Occupational Dose

Question 82

Page 34

Q/A Set 2

PDR-9205010117

Regulatory Reference: 10 CFR 20.1502, Conditions

Requiring Individual Monitoring of External and Internal

Occupational Dose

Question 83

Page 21

Q/A Sat 2

PDR-9205010117

Regulatory Reference: 10 CFR 20.1204, Determination of

Internal Exposure

Question 84

Page 24

Q/A Set 2

PDR-9205010117

Regulatory Reference: 10 CFR 20.1208, Dose to an

Embryo/Fetus 
Question 85

Q/A Set 2

Regulatory Reference: 10 CFR 20.1902, Posting

Requirements

Question 86

Page 19

Q/A Set 2

PDR-9205010117

Regulatory Reference: 10 CFR 20.1202, Compliance with

Requirements for Summation of External and Internal Doses

Question 87

Q/A Set 2

Regulatory Reference: None

Question 88

Q/A Set 2

Page 72

Regulatory Reference: None

Question 89

Q/A Set 2

Regulatory Reference: None

Question 90

Q/A Set 2

Page 42

PDR-9205010117

Regulatory Reference: 10 CFR 20.1701, Use of Process or

Other Engineering Controls

Question 91

Page 44

Q/A Set 3

PDR-9207300261

Regulatory Reference: 10 CFR 20.1703, Use of Individual

Respiratory Protection Equipment

Question 92

Q/A Set 3

Page 40

PDR-9207300261

Regulatory Reference: 10 CFR 20.1602, Control Access to

Very High Radiation Areas

Question 93

Q/A Set 3

Page 8

Regulatory Reference: 10 CFR 20.1003, Definitions

Question 94

Page 8

Q/A Set 3

PDR-9207300261

Regulatory Reference: 10 CFR 20.1003, Definitions

Question 95

Q/A Set 3

Page 65

Regulatory Reference: 10 CFR 19.12, Instructions to

Workers

Question 96

Q/A Set 3

Page 8

Regulatory Reference: 10 CFR 20.1003, Definitions
Question 97

Q/A Set 3

Page 16

PDR-9207300261

Regulatory Reference: 10 CFR 20.1201, Occupational Dose Limits for Adults

Question 98

Page 34

Q/A Set 3

PDR-9207300261

Regulatory Reference: 10 CFR 20.1502, Conditions

Requiring Individual Monitoring of External and Internal

Occupational Dose

Question 99

Page 12

Q/A Set 3

PDR-9207300261

Regulatory Reference: 10 CFR 20.1101, Radiation

Protection Programs

Question 100

Page 16

Q/A Set 3

PDR-9207300261

Regulatory Reference: 10 CFR 20.1201, Occupational Dose

Limits for Adults

Question 101

Page 19

Q/A Set 3

PDR-9207300261

Regulatory Reference: 10 CFR 20.1202, Compliance with

Requirements for Summation of External and Internal Doses

Question 102

Q/A Set 3

Page 30

(0) 20.1203 , Determination of

External Dose From Airborne Radioactive Material

Question 103

Page 30

Q/A Set 3

PDR-9207300261

Regulatory Reference: 10 CFR 20.1302, Compliance with

Dose Limits for Individual Members of the Public

Question 104

Q/A Set 3

Page 30

Regulatory Reference: 10 CFR 20.1302, Compliance with

Dose Limits for Individual Members of the Public

Question 105

Page 27

Q/A Set 3

PDR-9207300261

Regulatory Reference: 10 CFR 20.1301, Dose Limits for Individual Members of the Public

Question 106

Page 27

Q/A Set 3

PDR-9207300261

Regulatory Reference: 10 CFR 20.1301, Dose Limits for

Individual Members of the Public 
Question 108

Page 50

Q/A Set 2

PDR-9205010117

Regulatory Reference: 10 CFR 20.1906, Procedures for

Receiving and Opening Packages

Question 109

Q/A Set 2

Page 22

Regulatory Reference: 10 CFR 20.1206, Planned Special

Exposures

Question 110

Q/A Set 2

Page 23

Regulatory Reference: 10 CFR 20.1206, Planned Special

Exposures

Question 111

Q/A Set 3

Page 27

Regulatory Reference: 10 CFR 20.1301, Dose Limits for

Individual Members of the Public

Question 112

Q/A Set 3

Page 57

Q

Special Exposures

Question 113

Page 55

Q/A Set 3

PDR-9207300261

Regulatory Reference: 10 CFR 20.2104, Determination of

Prior Occupational Dose

Question 114

Page 34

Q/A Set 3

PDR-9207300261

Regulatory Reference: 10 CFR 20.1502, Cunditions

Requiring Individual Monitoring of External and Internal

Occupational Dose

Question 115

Q/A Set 3

Page 42

Regulatory Reference: 10 CFR 20.1701, Use of Process or

Other Engineering Controls

Question 116

Page 54

Q/A Set 3

PDR-9207300261

Regulatory Reference: 10 CFR 20.2101, Records - General

Provisions

Question 117

Page 54

Q/A Set 3

PDR-9207300261

Regulatory Reference: 10 CFR 20.2101, Records - General Provisions
Question 118

Q/A Set 3

Page 13

PDR-9207300261

Regulatory Reference: 10 CFR 20.1101, Radiation

Protection Programs

Question 119

Page 9

Q/A Set 5

PDR-9306110303

Regulatory Reference: 10 CFR 20.1003, Definitions

Question 120

Page 24

Q/A Set 3

PDR-9207300261

Regulatory Reference: 10 CFR 20.1208, Dose to an

Embryo/Fetus

Question 121

Page 21

Q/A Set 3

PDR-9207300261

Regulatory Reference: 10 CFR 20.1204, Determination of Internal Exposure

Question 122

Page 60

Q/A Set 3

PDR-9207300261

Regulatory Reference: 10 CFR 20.2203, Reports of

Exposures, Radiation Levels, and Concentrations of

Radioactive Material Exceeding the Limits

Question 123

Page 16

Q/A Set 3

PDR-9207300261

Regulatory Reference: 10 CFR 20.1201, Occupational Dose Limits for Adults

Question 124

Page 45

Q/A Set 3

PDR-9207300261

Regulatory Reference: 10 CFR 20.1703, Use of Individual

Respiratory Protection Equipment

Question 125

Page 27

Q/A Set 3

PDR-9207300261

Regulatory Reference: 10 CFR 20.1301, Dose Limits for Individual Members of the Public

Question 126

Page 35

Q'A Set 5

PDR-9306110303

Regulatory Reference: 10 CFR 20.1502, Conditions

Requiring Individual Monitoring of External and Internal

Occupational Dose

Question 127

Page 50

Q/A Set 4

PDR-9209230012

Regulatory Reference: 10 CFR 20.1904, Labeling

Containers 
Question 128

Page 50

Q/A Set 4

PDR-9209230012

Regulatory Reference: 10 CFR 20.1904, Labeling

Containers

Question 129

Q/A Set 4

Page 46

PDR-9209230012

Regulatory Reference: 10 CFR 20.1801, Security of Stored

Material

Question 130

Page 41

Q/A Set 4

PDR-9209230012

Regulatory Reference: 10 CFR 20.1603, Control Access to

Very High Radiation Areas - Irradiators

Question 131

Q/A Set 4

Page 45

Q

Respiratory Protection Equipment

Question 132

Page 45

Q/A Set 4

PDR-9209230012

Regulatory Reference: 10 CFR 20.1703, Use of Individual

Respiratory Protection Equipment

Question 133

Q/A Set 5

Regulatory Reference: 10 CFR 20.1101, Radiation

Protection Programs

Question 134

Q/A Set 4

Page 13

Page 13

PDR-9306110303

Regulatory Reference: 10 CFR 20.1101, Radiation

Protection Programs

Question 135

Page 23

Q/A Set 4

PDR-9209230012

Regulatory Reference: 10 CFR 20.1206, Planned Special

Exposures

Question 136

Page 23

Q/A Set 4 PDR-9209230012

Regulatory Reference: 10 CFR 20.1206, Planned Special

Exposures

Question 137

Page 23

Q/A Set 4

PDR-9209230012

Regulatory Reference: 10 CFR 20.1206, Planned Special

Exposures

Question 138

Q/A Set 4

Page 24

Regulatory

PDR-9209230012
Question 139

Page 55

Q/A Set 4

PDR-9209230012

Regulatory Reference: 10 CFR 20.2104, Determination of

Prior Occupational Dose

Question 141

Q/A Set 4

Page 60

Regulatory Reference: 10 CFR 20.2110, Form of Records

Question 142

Page 55

Q/A Set 4

PDR-9209230012

Regulatory Reference: 10 CFR 20.2104, Determination of

Prior Occupational Dose

Question 143

Page 55

Q/A Set 4

PDR-9209230012

Regulatory Reference: 10 CFR 20.2104, Determination of

Prior Occupational Dose

Question 144

Page 9

Q/A Set 4

PDR-9209230012

Regulatory Reference: 10 CFR 20.1003, Definitions

Question 145

Q/A Set 4

Page 42

Regulatory Reference: 10 CFR 20.1702, Use of Other

Controls

Question 146

Page 64

Q/A Set 4

PDR-9209230012

Regulatory Reference: 10 CFR 20 Appendix B, Annual

Limits on Intake (ALIs) and Derived Air Concentrations

(DACs) of Radionuclides for Occupational Exposure;

Effluent Concentrations; Concentrations for Release to

Sewage

Question 147

Page 32

Q/A Set 4

PDR-9209230012

Regulatory Reference: 10 CFR 20.1501, Surveys and

Monitoring - General

Question 148

Q/A Set 4

Page 9

Regulatory Reference: 10 CFR 20.1003, Definitions

Question 149

Page 9

Q/A Set 5

PDR-9306110303

Regulatory Reference: 10 CFR 20.1003, Definitions

Question 150

Page 10

Q/A Set 5

PDR-9306110303

Regulatory Reference: 10 CFR 20.1003, Definitions

Embryo/Fetus 
Appendix A

Question 172

Q/A Set 6

Page 17

PDR-9310070005

Regulatory Reference: 10 CFR 20.1201, Occupational Dose

Limits for Adults

Question 175

Page 17

Q/A Set 6

PDR-9310070005

Regulatory Reference: 10 CFR 20.1201, Occupational Dose

Limits for Adults

Question 176

Q/A Set 6

Page 17

A

Limits for Adults

Question 177

Q/A Set 6

Page 17

Regulatory Reference: 10 CFR 20.1201, Occupational Dose

Limits for Adults

Question 179

Q/A Set 6

Page 19

Regulatory Reference: 10 CFR 20.1202, Compliance with

Requirements for Summation of External and Internal Doses

Question 180

Page 20

Q/A Set 6

PDR-9310070005

Regulatory Reference: 10 CFR 20.1202, Compliance with

Requirements for Summation of External and Internal Doses

Question 183

Page 21

Q/A Set 6

PDR-9310070005

Regulatory Reference: 10 CFR 20.1204, Determination of Internal Exposure

Question 191

Page 24

Q/A Set 6

PDR-9310070005

Regulatory Reference: 10 CFR 20.1206, Planned Special

Exposures

Question 192

Page 24

Q/A Set 6

PDR-9310070005

Regulatory Reference: 10 CFR 20.1206, Planned Special

Exposures

Question 201

Page 27

Q/A Set 6

PDR-9310070005

Regulatory Reference: 10 CFR 20.1301, Dose Limits for

Individual Members of the Public

Question 203

Page 28

Q/A Set 6 PDR-9310070005

Regulatory Reference: 10 CFR 20.1301, Dose Limits for

Individual Members of the Public
Question 204

Page 28

Q/A Set 6

PDR-9310070005

Regulatory Reference: 10 CFR 20.1301, Dose Limits for Individual Members of the Public

Question 205

Page 28

Q/A Set 6

PDR-9310070005

Regulatory Reference: 10 CFR 20.1301, Dose Limits for Individual Members of the Public

Question 206

Page 28

Q/A Set 6

PDR-9310070005

Regulatory Reference: 10 CFR 20.1301, Dose Limits for

Individual Members of the Public

Question 207

Page 31

Q/A Set 6

PDR-9310070005

Regulatory Reference: 10 CFR 20.1302, Compliance with

Dose Limits for Individual Members of the Public

Question 208

Page 31

Q/A Set 6

PDR-9310070005,

Regulatory Reference: 10 CFR 20.1302, Compliance with

Dose Limits for Individual Members of the Public

Question 209

Page 32

Q/A Set 6

PDR-9310070005

Regulatory Reference: 10 CFR 20.1501, Surveys and

Monitoring - General

Question 210

Page 32

Q/A Set 6

PDR-9310070005

Regulatory Reference: 10 CFR 20.1501, Surveys and

Monitoring - General

Question 211

Page 35

Q/A Set 6

PDR-9310070005

Regulatory Reference: 10 CFR 20.1502, Conditions

Requiring Individual Monitoring of External and Internal

Occupational Dose

Question 212

Page 35

Q/A Set 6

PDR-9310070005

Regulatory Reference: 10 CFR 20.1502, Conditions

Requiring Individual Monitoring of External and Internal

Occupational Dose

Question 213

Page 36

Q/A Set 6

PDR-9310070005

Regulatory Reference: 10 CFR 20.1502, Conditions

Requiring Individual Monitoring of External and Internal

Occupational Dose 
Question 214

Q/A Set 6

Page 36

PDR-9310070005

Regulatory Reference: 10 CFR 20.1502, Conditions

Requiring Individual Monitoring of External and Internal

Occupational Dose

Question 215

Page 36

Q/A Set 6

Regulatory Reference: 10 CFR 20.1502, Conditions

Requiring Individual Monitoring of External and Internal

Occupational Dose

Question 216

Q/A Set 6

Regulatory Reference: 10 CFR 20.1502, Conditions

Requiring Individual Monitoring of External and Internal

Occupational Dose

Question 217

Q/A Set 6

Page 18

Regulatory Reference: 10 CFR 20.1502, Conditions

Requiring Individual Monitoring of External and Internal

Occupational Dose

Question 218

Page 38

Q/A Set 6

PDR-9310070005

Regulatory Reference: 10 CFR 20.1601, Control Access to

High Radiation Areas

Question 219

Page 39

Q/A Set 6

PDR-9310070005

Regulatory Reference: 10 CFR 20.1601, Control Access to

High Radiation Areas

Question 220

Q/A Set 6

Page 40

Q

Very High Radiation Areas

Question 221

Page 47

Q/A Set 6

PDR-9310070005

Regulatory Reference: 10 CFR 20.1902, Posting

Requirements

Question 223

Q/A Set 6

Page 49

Regulatory Reference: 10 CFR 20.1903, Exceptions to

Posting Requirements

Question 224

Q/A Set 6

Page 49

PDR-9310070005
Question 226

Q/A Set 6

Regulatory Reference: 10 CFR 20.1904, Labeling

Containers

Question 227

Page 51

Q/A Set 6

PDR-9310070005

Regulatory Reference: 10 CFR 20.1906, Procedures for

Receiving and Opening Packages

Question 228

Page 51

Q/A Set 6

PDR-9310070005

Regulatory Reference: 10 CFR 20.1906, Procedures for

Receiving and Opening Packages

Question 229

Page 51

Q/A Set 6

PDR-9310070005

Regulatory Reference: 10 CFR 20.1906, Procedures for

Receiving and Opening Packages

Question 230

Page 51

Q/A Set 6

PDR-9310070005

Regulatory Reference: 10 CFR 20.1906, Procedures for

Receiving and Opening Packages

Question 371

Q/A Set 5

Page 56

Regulatory Reference: 10 CFR 20.2104, Determination of

Prior Occupational Dose

Question 372

Page 21

Q/A Set 5

PDR-9306110303

Regulatory Reference: 10 CFR 20.1204, Determination of

Internal Exposure

Question 373

Q/A Set 5

Page 39

Regulatory Reference: 10 CFR 20.1601, Control Access to

High Radiation Areas

Question 374

Page 45

Q/A Set 5

PDR-9306110303

Regulatory Reference: 10 CFK 20.1703 , Use of Individual

Respiratory Protection Equipment

Question 375

Page 36

Q/A Set 5

PDR-9306110303

Regulatory Reference: 10 CFR 20.1502, Conditions

Requiring Individual Monitoring of External and Internal

Occupational Dose

Regulatory Reference: 10 CFR 20.1903, Exceptions to

Posting Requirements 
Appendix A

Question 376

Q/A Set 5

Page 52

PDR-9306110303

Regulatory Reference: 10 CFR 20.2001, Waste Disposal -

General Requirements

Question 377

Page 66

Q/A Set 5

PDR-9306110303

Regulatory Reference: 10 CFR 19.13, Notifications and

Reports to Individuals

Question 378

Q/A Set 5

Page 66

Regulatory Reference: 10 CFR 19.13, Notifications and

Reports to Individuals

Question 379

Q/A Set 5

Regulatory Reference: 10 CFR 20.1902, Posting

Requirements

Question 380

Q/A Set 5

Page 14

Regulatory Reference: 10 CFR 20.1101, Radiation

Protection Programs

Question 381

Page 14

Q/A Set 5

PDR-9306110303

Regulatory Reference: 10 CFR 20.1101, Radiation

Protection Programs

Question 382

Q/A Set 5

Page 25

PDR-9306110303

Regulatory Reference: 10 CFR 20.1208, Dose to an

Embryo/Fetus

Question 383

Page 60

Q/A Set 5

PDR-9306110303

Regulatory Reference: 10 CFR 20.2206, Reports of

Individual Monitoring

Question 384

Page 28

Q/A Set 5

PDR-9306110303

Regulatory Reference: 10 CFR 20.1301, Dose Limits for

Individual Members of the Public

Question 385

Q/A Set 5

Page 39

Regulatory Reference: 10 CFR 20.1601, Control Access to

High Radiation Areas

Question 386

Q/A Set 5

Page 43

Regulatory Reference: 10 CFR 20.1702, Use of Other

Controls
Question 387

Q/A Set 5

Page 43

Regulatory Reference: 10 CFR 20.1702, Use of Other

Controls

Question 388

Page 43

Q/A Set 5

PDR-9306110303

Regulatory Reference: 10 CFR 20.1702, Use of Other

Controls

Question 389

Q/A Set 5

Page 52

Regulatory Reference: 10 CFR 20.2001, Waste Disposal -

General Requirements

Question 390

Q/A Set 5

Page 56

PDR-9306110303

Regulatory Reference: 10 CFR 20.2104, Determination of

Prior Occupational Dose

Question 391

Page 59

Q/A Set 5

PDR-9306110303

Regulatory Reference: 10 CFR 20.2107, Records of Dose to Individual Members of the Public

Question 392

Page 61

Q/A Set 5

PDR-9306110303

Regulatory Reference: 10 CFR 20.2206, Reports of

Individual Monitoring

Question 393

Page 61

Q/A Set 5

PDR-9306110303

Regulatory Reference: 10 CFR 20.2206, Reports of

Individual Monitoring

Question 394

Page 61

Q/A Set 5

PDR-9306110303

Regulatory Reference: 10 CFR 20.2206, Reports of

Individual Monitoring

Question 395

Page 62

Q/A Set 5

PDR-9306110303

Regulatory Reference: 10 CFR 20.2206, Reports of Individual Monitoring

Question 396

Q/A Set 5

Page 64

PDR-9306110303

Regulatory Reference: 10 CFR 20 Appendix B, Annual

Limits on Intake (ALIs) and Derived Air Concentrations

(DACs) of Radionuclides for Occupational Exposure;

Effluent Concentrations; Concentrations for Release to

Sewage 
Question 397

Q/A Set 5

Regulatory Reference: Technical Specifications

Question 398

Q/A Set 5

Regulatory Reference: 10 CFR 20.1502, Conditions

Requiring Individual Monitoring of External and Internal

Occupational Dose

Question 399

Q/A Set 5

Page 57

PDR-9306110303

Regulatory Reference: 10 CFR 20.2106, Records of

Individual Monitoring Results

Question 400

Q/A Set 5

Page 58

PDR-9306110303

Regulatory Reference: 10 CFR 20.2106, Records of

Individual Monitoring Results

Question 401

Q/A Set 5

Page 58

Regulatory Reference: 10 CFR 20.2106, Records of

Individual Monitoring Results

Question 402

Q/A Set 5

Regulatory Reference: 10 CFR 20.2106, Records of

Individual Monitoring Results

Question 403

Q/A Set 5

Regulatory Reference: 10 CFR 20.2106, Records of

Individual Monitoring Results

Question 404

Q/A Set 5

Regulatory Reference: 10 CFR 20.2106, Records of

Individual Monitoring Results

Question 405

Q/A Set 5

Page 69

Regulatory Reference: Regulatory Guide 8.25, Air Sampling

in the Workplace

Question 406

Q/A Set 5

Page 69

Regulatory Reference: Regulatory Guide 8.36, Radiation

Dose to the Embryo/Feths

Question 407

Q/A Set 5

Regulatory Reference: 10 CFR 20.1001, Purpose

Page 3
Question 408

Q/A Set 5

Page 56

Regulatory Reference: 10 CFR 20.2104, Determination of

Prior Occupational Dose

Question 409

Q/A Set 5

Page 66

PDR-9306110303

Regulatory Reference: 10 CFR 19.13, Notifications and

Reports to Individuals

Question 411

Page 65

Q/A Set 5

PDR-9306110303

Regulatory Reference: 10 CFR 19.12, Instructions to

Workers

Question 412

Page 10

Q/A Set 7

PDR-93! 1050284

Regulatory Reference: 10 CFR 20.1003, Definitions

Question 413

Page 10

Q/A Set 7

PDR-9311050284

Regulatory Reference: 10 CFR 20.1003, Definitions

Question 414

Page 18

Q/A Set 7

PDR-9311050284

Regulatory Reference: 10 CFR 20.1201, Occupational Dose

Limits for Adults

Question 415

Page 18

Q/A Set 7

PDR-9311050284

Regulatory Reference: 10 CFR 20.1201, Occupational Dose

Limits for Adults

Question 416

Page 25

Q/A Set 7

PDR-9311050284

Regulatory Reference: 10 CFR 20.1208, Dose to an

Embryo/Fetus

Question 417

Q/A Set 7

Page 31

Regulatory Reference: 10 CFR 20.1302, Compliance with

Dose Limits for Individual Members of the Public

Question 418

Page 45

Q/A Set 7

PDR-9311050284

Regulatory Reference: 10 CFR 20.1703, Use of Individual

Respiratory Protection Equipment

Question 419

Page 46

Q/A Set 7

PDR-9311050284

Regulatory Reference: 10 CFR 20.1801, Security of Stored

Material 
Question 420

Page 57

PDR-9311050284

Q/A Set 7

Determination of

Prior Occupational Dose

Question 421

Q/A Set 7

Page 67

PDR-9311050284

Regulatory Reference: 10 CFR 19.13, Notifications and

Reports to Individuals

Question 422

Q/A Set 7

Page 66

PDR-9311050284

Regulatory Reference: 10 CFR 19.12, Instructions to

Workers

Question 423

Page 40

Q/A Set 7

PDR-9311050284

Regulatory Reference: 10 CFR 20.1602, Control Access to

Very High Radiation Areas

Question 425

Q/A Set 7

Page 64

PDR-9311050284

Regulatory Reference: 10 CFR 20 Appendix B, Annual

Limits on Intake (ALIs) and Derived Air Concentrations

(DACs) of Radionuclides for Occupational Exposure;

Effluent Concentrations; Concentrations for Release to

Sewage

Question 426

Page 64

Q/A Set 7

PDR-9311050284

Regulatory Reference: 10 CFR 20 Appendix B, Annual

Limits on Intake (ALIs) and Derived Air Concentrations

(DACs) of Radionuclides for Occupational Exposure;

Effluent Concentrations; Concentrations for Release to

Sewage

Question 427

Q/A Set 7

Page 31

PDR-9311050284

Regulatory Reference: 10 CFR 20.1302, Compliance with

Dose Limits for Individual Members of the Public

Question 428

Page 52

Q/A Set 7

PDR-9311050284

Regulatory Reference: 10 CFR 20.2103, Records of Surveys

Question 429

Page 37

Q/A Set 7

PDR-9311050284

Regulatory Reference: 10 CFR 20.1502, Conditions

Requiring Individual Monitoring of External and Internal

Occupational Dose
Question 430

Page 39

Q/A Set 7

PDR-9311050284

Regulatory Reference: 10 CFR 20.1601, Control Access to

High Radiation Areas

Question 431

Page 39

Q/A Set 7

PDR-9311050284

Regulatory Reference: 10 CFR 20.1601, Control Access to

High Radiation Areas

Question 432

Page 53

Q/A Set 7

PDR-9311050284

Regulatory Reference: 10 CFR 20.2001, Waste Disposal -

General Requirements

Question 433

Page 71

Q/A Set 7

PDR-9311050284

Regulatory Reference: Technical Specifications

Question 434

Q/A Set 7

Page 11

Regulatory Reference: 10 CFR 20.1003, Definitions

Question 435

Page 18

Q/A Set 7

PDR-9311050284

Regulatory Reference: 10 CFR 20.1201, Occupational Dose

Limits for Adults

Question 436

Page 18

Q/A Set 7

PDR-9311050284

Regulatory Reference: 10 CFR 20.1201, Occupational Dose

Limits for Adults

Question 437

Page 21

Q/A Set 7

PDR-9311050284

Regulatory Reference: 10 CFR 20.1204, Determination of

Internal Exposure

Question 438

Page 20

Q/A Set 7

PDR-9311050284

Regulatory Reference: 10 CFR 20.1207, Occupational Dose

Limits for Minors

Question 439

Page 25

Q/A Set 7

PDR-9311050284

Regulatory Reference: 10 CFR 20.1208, Dose to an

Embryo/Fetus

Question 440

Page 25

Q/A Set 7

PDR-9311050284

Regulatory Reference: 10 CFR 20.1208, Dose to an

Embryo/Fetus 
Question 441

Page 25

Q/A Set 7

PDR-9311050284

Regulatory Reference: 10 CFR 20.1208, Dose to an

Embryo/Fetus

Question 442

Page 26

Q/A Set 7

PDR-9311050284

Regulatory Reference: 10 CFR 20.1208, Dose to an

Embryo/Fetus

Question 443

Q/A Set 7

Regulatory Reference: 10 CFR 20.1208, Dose to an

Embryo/Fetus

Question 444

Q/A Set 7

Page 37

Regulatory Reference: 10 CFR 20.1502, Conditions

Requiring Individual Monitoring of External and Internal

Occupational Dose

Question 445

Q/A Set 7

Regulatory Reference: 10 CFR 20.1502, Conditions

Requiring Individual Monitoring of External and Internal

Occupational Dose

Question 446

Page 38

Q/A Set 7

PDR-9311050284

Regulatory Reference: 10 CFR 20.1502, Conditions

Requiring Individual Monitoring of External and Internal

Occupational Dose

Question 447

Page 41

Q/A Set 7

PDR-9311050284

Regulatory Reference: 10 CFR 20.1602, Control Access to

Very High Radiation Areas

Question 448

Q/A Set 7

Page 41

Regulatory Reference: 10 CFR 20.1602, Control Access to

Very High Radiation Areas

Question 449

Q/A Set 7

Page 43

PDR-9311050284

Regulatory Reference: 10 CFR 20.1702, Use of Other

Controls

Question 450

Q/A Set 7

Regulatory Reference: 10 CFR 20.1801, Security of Stored

Material
Question 451

Page 70

Q/A Set 7

PDR-9311050284

Regulatory Reference: Regulatory Guide 8.7, Rev. 1,

Instructions for Recording and Reporting Occupational

Exposure Data

Question 452

Page 62

Q/A Set 7

PDR-9311050284

Regulatory Reference: 10 CFR 20 Appendix A, Protection

Factors for Respirators

Question 453

Page 65

Q/A Set 7

PDR-9311050284

Regulatory Reference: 10 CFR 20 Appendix B, Annual

Limits on Intake (ALIs) and Derived Air Concentrations

(DACs) of Radionuclides for Occupational Exposure;

Effluent Concentrations; Concentrations for Release to

Sewage

Question 454

Page 67

Q/A Set 7

PDR-9311050284

Regulatory Reference: 10 CFR 19.13, Notifications and

Reports to Individuals

Question 455

Page 71

Q/A Set 7

PDR-9311050284

Regulatory Reference: Technical Specifications

Question 456

Page 68

Q/A Set 7

PDR-9311050284

Regulatory Reference: Technical Specifications

Question 457

Page 72

Q/A Set 7

PDR-9311050284

Regulatory Reference: FSAR

Question 458

Page 32

Q/A Set 7

PDR-9311050284

Regulatory Reference: 10 CFR 20.1501, Surveys and

Monitoring - General

Question 459

Page 48

Q/A Set 7

PDR-9311050284

Regulatory Reference: 10 CFR 20.1902, Posting

Requirements

Question 460

Page 48

Q/A Set 7

PDR-9311050284

Regulatory Reference: 10 CFR 20.1902, Posting

Requirements 


\section{Appendix A}

Question 461

Q/A Set 7

Page 38

Regulatory Reference: 10 CFR 20.1502, Conditions

Requiring Individual Monitoring of External and Internal

Occupational Dose 


\section{APPENDIX B}

\section{REGULATORY REFERENCES CITED IN TEXT}

10 CFR 19.12, Instructions to Workers

10 CFR 19.13, Notifications and Reports to Individuals

10 CFR 20, Standards for Protection Against Radiation

10 CFR 20.1001, Purpose

10 CFR 20.1002, Scope

10 CFR 20.1003, Definitions

10 CFR 20.1004, Units of Radiation Dose

10 CFR 20.1008, Implementation

10 CFR 20.1009, Reporting, Recording, and Application Requirements: OMP Approval

10 CFR 20.1101, Radiation Protection Programs

10 CFR 20.1201, Occupational Dose Limits for Adults

10 CFR 20.1202, Compliance with Requirements for Summation of External and Internal Doses

10 CFR 20.1203, Determination of External Dose From Airborne Radioactive Material

10 CFR 20.1204, Determination of Internal Exposure

10 CFR 20.1206, Planned Special Exposures

10 CFR 20.1207, Occupational Dose Limits for Minors

10 CFR 20.1208, Dose to an Embryo/Fetus

10 CFR 20.1301, Dose Limits for Individual Members of the Public

10 CFR 20.1302, Compliance with Dose Limits for Individual Members of the Public

10 CFR 20.1501, Surveys and Monitoring - General
10 CFR 20.1502, Conditions Requiring Individual Monitoring of External and Internal Occupational Dose

10 CFR 20.1601, Control Access to High Radiation Areas

10 CFR 20.1602, Control Access to Very High Radiation Areas

10 CFR 20.1603, Control Access to Very High Radiation Areas - Irradiators

10 CFR 20.1701, Use of Process or Other Engineering Controls

10 CFR 20.1702, Use of Other Controls

10 CFR 20.1703, Use of Individual Respiratory Protection Equipment

10 CFR 20.1704, Further Restrictions on the Use of Respiratory Protection Equipment

10 CFR 20.1801, Security of Stored Material

10 CFR 20.1802, Control of Material not in Storage

10 CFR 20.1901, Caution Signs

10 CFR 20.1902, Posting Requirements

10 CFR 20.1903, Exceptions to Posting Requirements

10 CFR 20.1904, Labeling Containers

10 CFR 20.1905, Exemptions to Labeling Requirements

10 CFR 20.1906, Procedures for Receiving and Opening Peckages

10 CFR 20.2001, Waste Disposal - General Requirements

10 CFR 20.2003, Disposal by Release into Sanitary

Sewerage

10 CFR 20.2101, Records - General Provisions

10 CFR 20.2102, Records of Rediation Protection Programs 
10 CFR 20.2103, Records of Surveys

10 CFR 20.2104, Determination of "rior Occupational Dose

10 CFR 20.2105, Records of Planned Special Exposures

10 CFR 20.2106, Records of Individual Monitoring Results

10 CFR 20.2107, Records of Dose to Individual Members of the Public

10 CFR 20.2110, Form of Records

10 CFR 20.2202, Notification of Incidents

10 CFR 20.2203, Reports of Exposures, Radiation Levels, and Concentrations of Radioactive Material Exceeding the Limits

10 CFR 20.2204, Reports of Planned Special Exposures

10 CFR 20.2206, Reports of Individual Monitoring

10 CFR 20 Appendix A, Protection Factors for Respirators

10 CFR 20 Appendix B, Annual Limits on Intake (ALIs) and Derived Air Concentrations (DACs) of Radionuclides for Occupational Exposure; Effluent Concentrations;

Concentrations for Release to Sewage

10 CFR 34.21, LImits on Levels of Radiation for Radiographic Exposure Devices and Storage Containers

10 CFR 34.24, Radiation Survey Instruments

10 CFR 34.33, Personnel Monitoring

10 CFR 34.42, Posting

10 CFR 34.43, Radiation Surveys

10 CFR 39.33, Radiation Deiection Instruments

10 CFR Part 50, Domestic Licensing of Production and Utilization Facilities

10 CFR 50.47, Permits - Emergency Plans

10 CFR 50.72, Maintenance of Records, Making of Reports

10 CFR 50.73, License Event Report System
10 CFR 50 Appendix A, General Design Criteria for Nuclear Power Plants

10 CFR 50 Appendix B. Quality Assurance Criteria for Nuclear Power Plants and Fuel Reprocessing Plants

10 CFR 50 Appendix I, Numerical Guides for Design Objectives and Limiting Conditions for Operation to Meet the Criterion "As Low as is Reasonably Achievable" for Radioactive Material in Light-Water-Cooled Nuclear Power Reactor Effluents

10 CFR 71.4, Packaging and Transportation of Radioactive Material - Definitions

10 CFR Part 100, Reactor Site Criteria

Byproduct Material licenses (medical)

DOE Order 5480.11, Radiation Protection for Occupational Workers

EPA PAG Manual

FSAR, Final Safety Anaiysis Report

Foderal Guidance Report No. 11

HPPOS-028, Further Guidance on Labeling Requirements" in Health Physics Positions Data Base, NUREG/CR-5569, Rev. 1

NRR Generic Letter 89-01

NUREG-1301, Offsite Dose Calculation Manual Guidance. Standard Radiological Effluent Control for Pressurized Water Reactors

NUREG-1302, Offsite Dose Calculation Manual Guidance. Standard Radiological Effluent Control for Boiling Water Reactors

Regulatory Guide 1.16, Reporting of Operating Information, Appendix A - Technical Specification, Rev. 4

Regulatory Guide 8.13, Instruction Concerning Prenatal Radiation Exposure, Rev. 2

Regulatory Guide 8.25, Air Sampling in the Workplace

Regulatory Guide 8.34, Monitoring Criteria and Methods to Calculate Occupational Radiation Exposure

Regulatory Guide 8.35, Planned Special Exposures 
Regulatory Guide 8.36, Radiation Dose to the Embryo/Fetus

Regulatory Guide 8.7, Rev. 1, Instructions for Recording and Reporting Occupational Exposure Data

Regulatory Guide 8.9, Interpretation of Bioassay

Measurements

Regulatory Guide 10.8 Appendix X, Guidance on

Complying with New Part 20 Requirements (for medical use programs)

Regulatory Guides

Technical Specifications

U.S. NRC Enforcement Policy 

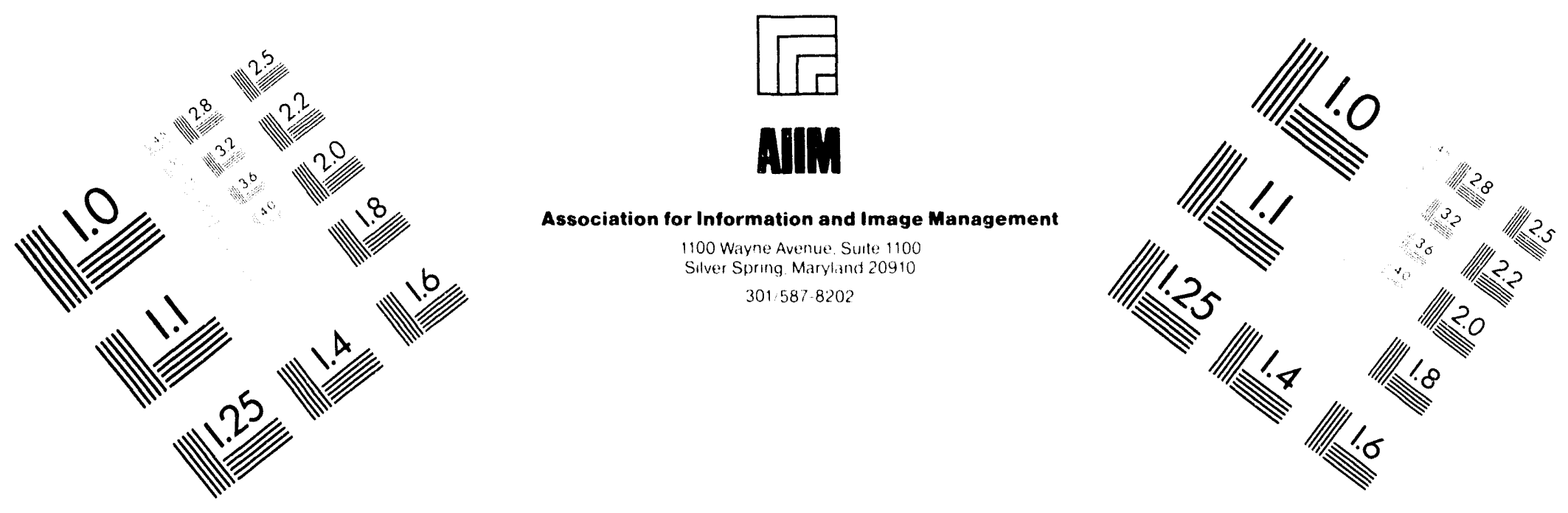

\section{Centimeter}

1
$\mid$

Inches
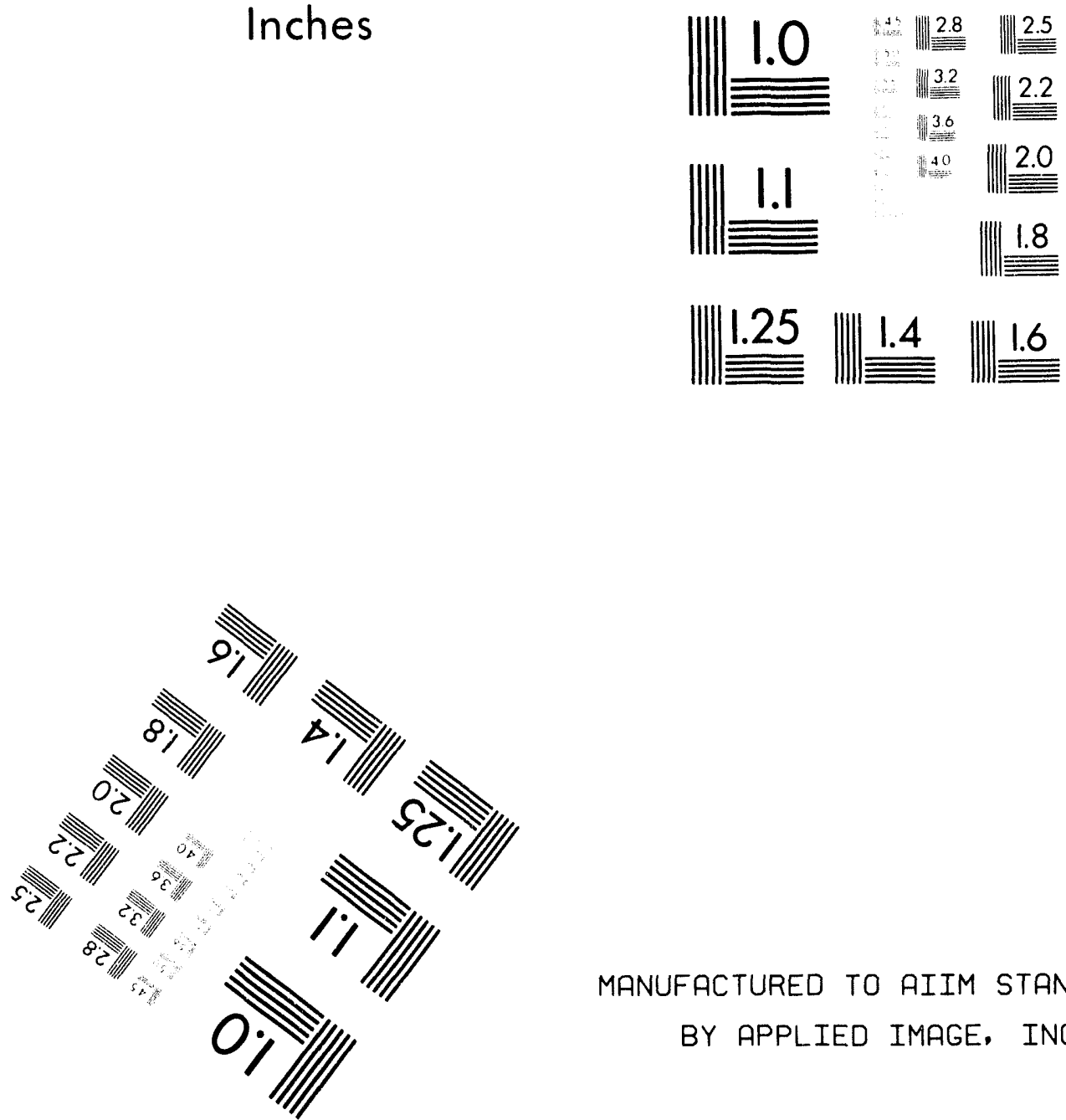

MANUFACTURED TO AIIM STANDARDS

BY APPLIED IMAGE, INC.

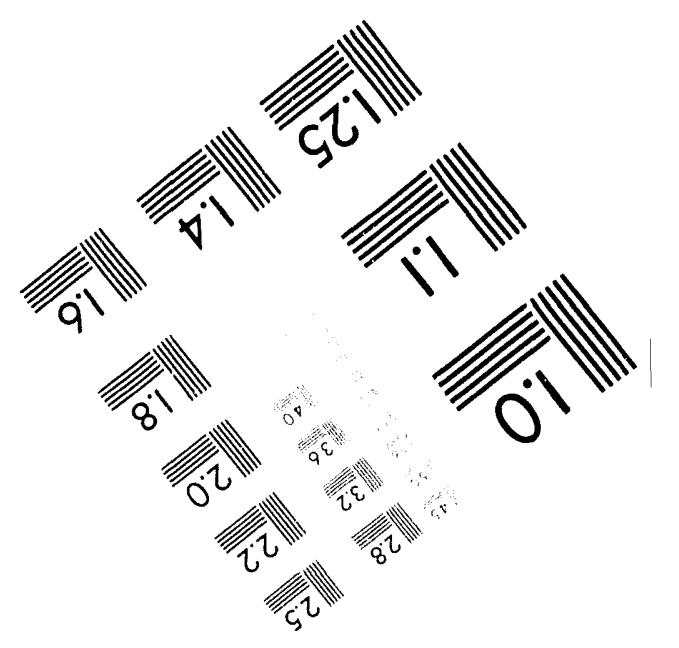



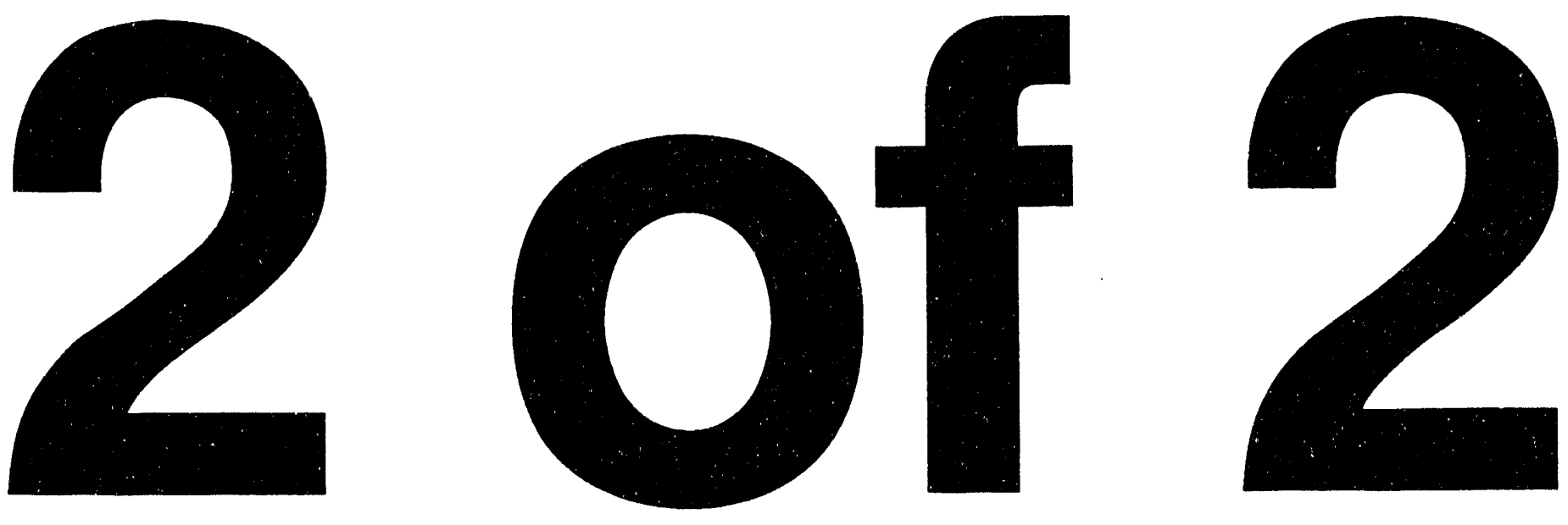


\section{APPENDIX C}

\section{QUESTIONS AND ANSWERS BY REGULATORY REFERENCE}

\author{
10 CFR 19.12, Instructions to Workers \\ Question 66 \\ Question 95 \\ Question 411 \\ Question 422
}

Y

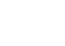

10 CFR 19.13, Notifications and Reports to Individuals

Question 37

Question 377

Question 378

Question 409

Question 421

Question 454

\section{Page 66 \\ Page 66 \\ Page 66 \\ Page 66 \\ Page 67 \\ Page 67}

\section{CFR 20, Standards for Protection Against Radiation}

Question 452

Page 62

\section{CFR 20.1001, Purpose}

Question 2

Question 4

Question 5

Question 99

Question 192

Question 407

\section{CFR 20.1002, Scope}

Question 2

Question 4

Question 5

Page 14

Page 3

Page 3

Page 12

Page 24

Page 3

10 CFR 20.1003, Definitions

Question 1

Question 2

Question 4

Question 5

Question 24

Question 25

Question 26

Question 27

Question 31

Question 34

Question 40

Question 57

Question 66

Question 67

Page 14

Page 3

Page 3

Page 3

Page 14

Page 3

Page 3

Page 22

Page 4

Page 4

Page 15

Page 15
10 CFR 20.1003, Definitions (continued)

Question 74

Question 77

Question 80

Question 82

Question 84

Question 85

Question 92

Question 93

Question 94

Question 96

Question 100

Question 104

Question 109

Question 119

Question 123

Question 125

Question 144

Question 148

Question 149

Question 150

Question 176

Question 206

Question 211

Question 220

Question 379

Question 412

Question 413

Question 416

Question 417

Page 47

Question 420

Question 428

Question 434

Question 439

Question 440

Question 444

Question 447

Question 448

Question 450

Question 459

Question 460

Page 8

Page 16

Page 8

Page 34

Page 24

Page 47

Page 40

Page 8

Page 8

Page 8

Page 16

Page 30

Page 22

Page 9

Page 16

Page 27

Page 9

Page 9

Page 9

Page 10

Page 17

Page 28

Page 35

Page 40

Page 48

Page 10

Page 10

Page 25

Page 31

Page 57

Page 52

Page 11

Page 25

Page 25

Page 37

Page 41

Page 41

Page 46

Pago 48

Page 48

10 CFR 20.1004, Units of Radiation Dose

Question 73

Page 11 
10 CFR 20.1008, Implementation

Question 30

Question 58

Question 65

Question 111
Page 11

Page 11

Page 11

Page 27

10 CFR 20.1009, Reporting, Recording, and Application Requirements: OMB Approval Question 65

Page 11

10 CFR 20.1101, Radiation Protection Programs

Question 7

Question 11

Question 26

Question 60

Question 62

Question 99

Question 118

Question 133

Question 134

Question 380

Question 381

10 CFR 20.1201, Occupational Dose Limits for Adults

Question 2

Question 3

Question 6

Question 26

Question 31

Question 33

Question 34

Question 41

Question 42

Question 45

Question 46

Question 55

Question 63

Question 66

Question 77

Question 97

Question 100

Question 106

Question 123

Question 172

Question 175

Question 176

Question 177

Question 217

Question 413

Question 414

Question 415

Question 435

Question 436

Page 13

Page 13

Page 14

Page 15

Page 15
10 CFR 20.1202, Compliance with Requirements for

Summation of External and Internal Doses

Question 9

Question 38

Page 19

Page 19

Page 19

Page 19

Question 101

Page 19

Page 20

Page 36

Page 20

Page 65

Page 12

Page 12

Page 4

Page 44

Page 12

Page 12

Page 13

Page 14

Page 14

Page 4

Page 15

Page 15

Page 15

Page 15

Page 26

Page 16

Page 16

Page 54

Page 22

Page 7

Page 16

Page 16

Page 16

Page 27

Page 16

Page 17

Page 17

Page 17

Page 17

Page 18

Page 10

Page 18

Page 18

Page 18

Page 18
Question 179

Question 375

Question 453
Question 180
10 CFR 20.1203, Determination of External Dose From

Airborne Radioactive Material

Question 50

Question 458

Page 20

Page 32

10 CFR 20.1204, Determination of Internal Exposure

Question 47

Question 76

Page 20

Page 20

Question 83

Page 21

Question 121

Question 146

Page 64

Question 183

Question 372

Question 437

Question 453

Question 458

Page 21

Page 21

Page 21

Page 65

Page 32

10 CFR 20.1206, Planned Special Exposures

Question 8

Question 24

Question 63

Question 66

Question 109

Question 110

Question 112

Question 113

Question 135

Question 136

Question 137

Question 191

Question 192

Question 383

Page 22

Page 22

Page 22

Page 7

Page 22

Page 23

Page 57

Page 55

Page 23

Page 23

Page 23

Page 24

Page 24

Page 60

10 CFR 20.1207, Occupational Dose Limits for Minors

Question 26

Question 66

Page 4

Page 7

10 CFR 20.1208, Dose to an Embryo/Fetus

Question 26

Question 58

Question 59

Question 66
Page 4

Page 11

Page 24

Page 7
Page 21 
Appendix C

10 CFR 20.1208, Dose to an Embryo/Fetus (continued)

Question 84

Question 120

Page 24

Page 24

Question 138

Question 378

Question 382

Question 394

Question 416

Question 439

Question 440

Question 441

Question 442

Question 443

Page 24

Page 66

Page 25

Page 61

Page 25

Page 25

Page 25

Page 25

Page 26

Page 26
10 CFR 20.1301, Dose Limits for Individual Members of the Public

Question 26

Question 42

Question 48

Question 105

Question 106

Question 111

Question 125

Question 201

Question 203

Question 204

Question 205

Question 206

Question 207

Question 384

Question 427

Page 4

Page 26

Page 26

Page 27

Page 27

Page 27

Page 27

Page 27

Page 28

Page 28

Page 28

Page 28

Page 31

Page 28

Page 31
10 CFR 20.1302, Compliance with Dose Limits for Individual Members of the Public

Question 28

Question 29

Question 68

Question 69

Question 72

Question 102

Question 103

Question 104

Question 207

Question 208

Question 384

Question 417

Question 427

10 CFR 20.1501, Surveys and Monitoring - General

Question 147

Question 205

Question 209

Question 210

Question 458
Page 29

Page 29

Page 29

Page 30

Page 30

Page 30

Page 30

Page 30

Page 31

Page 31

Page 28

Page 31

Page 31

Page 32

Page 28

Page 32

Page 32

Page 32

10 CFR 20.1502, Conditions Requiring Individual Monitoring of External and Internal Occupational Dose Question 9

Question 43

Page 19

Question 44

Page 32

Page 33

Question 54

Question 75

Question 81

Question 82

Page 33

Page 33

Page 34

Page 34

Page 34

Page 16

Page 34

Page 35

Page 35

Page 35

Page 36

Page 36

Page 36

Page 36

Page 21

Page 45

Page 36

Page 66

Page 61

Page 37

Page 37

Page 37

Page 38

Page 38

Page 32

Page 48

Page 48

Question 460

Page 38

Question 461

10 CFR 20.1601, Control Access to High Radiation Areas Question 52 Question 74

Page 70

Page 8

Question 218

Question 219

Question 373

Question 385

Question 423

Question 430

Question 431

Question 448

Page 38

Page 39

Page 39

Page 39

Page 40

Page 39

Page 39

Page 41

10 CFR 20.1602, Control Access to Very High Radiation Areas

Question 49

Question 52

Question 57

Question 92

Question 220

Question 373
Page 40

Page 70

Page 7

Page 40

Page 40

Page 39 
10 CFR 20.1602, Control Access to Very High Radiation Areas (Continued)

Question 423

Question 430

Question 447

Question 448

10 CFR 20.1603, Control Access to Very High Radiation

Areas - Irradiators

Question 130

Page 41

10 CFR 20.1701, Use of Process or Other Engineering

Controls

Question 90

Question 115

Page 42

Page 42

10 CFR 20.1702, Use of Other Controls

Question 145

Question 386

Question 387

Question 388

Question 449

10 CFR 20.1703, Use of Individual Respiratory

Protection Equipment

Question 54

Question 60

Question 78

Question 124

Question 132

Question 374

Question 375

Question 386

Question 387

Question 388

Question 418

Page 39

Page 41

Page 41

Page 42

Page 43

Page 43

Page 43

Page 43

Page 33

Page 44

Page 44

Page 45

Page 45

Page 45

Page 45

Page 36

Page 43

Page 43

Page 43

Page 45
Question 91

Question 131

10 CFR 20.1901, Caution Signs

Question 221

Page 47

10 CFR 20.1902, Posting Requirements

Question 27

Question 53

Question 85

Page 47

Page 47

Page 47

Page 47

Page 49

Question 224

Page 48

Question 379

Page 39

Question 385

Question 405

Question 447

Question 458

Question 459

Question 460

Page 69

Page 41

Page 32

Page 48

Page 48

10 CFR 20.1903, Exceptions to Posting Requirements

Question 35

Question 53

Question 223

Question 224

Page 49

Page 47

Page 49

Page 49

10 CFR 20.1904, Labeling Containers

Question 53

Page 47

Question 127

Page 50

Page 44

10 CFR 20.1704, Further Restrictions on the Use of Respiratory Protection Equipment

Question 374

Page 45

10 CFR 20.1801, Security of Stored Material

Question 129

Question 419

Page 46

Page 46

Question 450

Page 46

10 CFR 20.1802, Control of Material not in Storage

Question 129

Question 450

Page 46

Page 46
Question 128

Question 226

Question 450

Page 50

Page 50

Page 46

10 CFR 20.1905, Exemptions to Labeling Requirements

Question 53

Question 128

Page 47

Page 50

Question 129

Page 46

10 CFR 20.1906, Procedures for Receiving and Opening Packages

Question 36

Page 50

Question $108 \quad$ Page 50

Question $227 \quad$ Page 51

Question $228 \quad$ Page 51

Question $229 \quad$ Page 51

Question $230 \quad$ Page 51

10 CFR 20.2001, Waste Disposal - General Requirements

Question 376

Question 389

Question 432

Page 52

Page 52

Page 53

10 CFR 20.2003, Disposal by Release into Sanitary

Sewerage

Question 39

Page 54 
10 CFR 20.2101, Records - General Provisions Question 96

Question 116

Question 117

Question 428

10 CFR 20.2102, Records of Radiation Protection Programs

Question 134

10 CFR 20.2104, Determination of Prior Occupational Dose

Question 6

Question 10

Question 51

Question 55

Question 63

Question 64

Question 83

Question 113

Question 139

Question 142

Question 143

Question 179

Question 192

Question 214

Question 371

Question 390

Question 408

Question 414

Question 420

Question 436

Question 441

Question 451

10 CFR 20.2105, Records of Planned Special Exposures

Question 112

Question 191

10 CFR 20.2106, Records of Individual Monitoring

Results

Question 75

Question 212

Question 213

Question 217

Question 399

Question 400

Question 401

Question 402

Question 403

Question 404

Question 451

Question 454

Page 8

Page 54

Page 52
Page 54

Page 13

Page 15

Page 54

Page 54

Page 54

Page 22

Page 55

Page 21

Page 55

Page 55

Page 55

Page 55

Page 19

Page 24

Page 36

Page 56

Page 56

Page 56

Page 18

Page 57

Page 18

Page 25

Page 70

Page 57

Page 24

10 CFR 20.2107, Records of Dose to Individual Members of the Public

Question $391 \quad$ Page 59

10 CFR 20.2110, Form of Records

Question 141

Page 60

10 CFR 20.2202, Notification of Incidents

Question 56

Page 60

10 CFR 20.2203, Reports of Exposures, Radiation Levels, and Concentrations of Radioactive Material Exceeding the Limits

Question 122

Page 60

10 CFR 20.2204, Reports of Planned Special Exposures

Question 191

Page 24

Question 383

Page 60

10 CFR 20.2206, Reports of Individual Monitoring

Question 10

Question 61

Page 54

Question 79

Question 383

Question 392

Question 39'3

Question 394

Question 395

Question 399

Question 400

Question 401

Question 402

Question 403

Question 404

Question 446

Page 71

Page 71

Page 60

Page 61

Page 61

Page 61

Page 62

Page 57

Page 58

Page 58

Page 58

Page 58

Page 59

Page 38

10 CFR 20 Appendix A, Protection Factors for

Respirators

Question 452

Page 62

10 CFR 20 Appendix B, Annual Limits on Intake (ALIs) and Derived Air Concentrations (DACs) of Radionuclides for Occupational Exposure; Effluent Concentrations;

Page 35

Page 36

Page 18

Page 57

Page 58

Page 58

Page 58

Page 58

Page 59

Page 70

Page 67
Concentrations for Release to Sewage

Question 13

Question 22

Question 23

Question 71

Question 146

Question 425

Question 426

Question 453

Question 458
Page 63

Page 72

Page 63

Page 63

Page 64

Page 64

Page 64

Page 65

Page 32 
Appendix C

10 CFR 34.21, Limits on Levels of Raciation for Radiographic Exposure Devices and Storage Containers Question 428

Page 52

10 CFR 34.24, Radiation Survey Instruments

Question 428

Page 52

10 CFR 34.33, Personnel Monitoring

Question 428

10 CFR 34.42, Posting

Question 223

Page 49

10 CFR 34.43, Radiation Surveys

Question 108

Page 50

10 CFR 39.33, Radiation Detection Instruments

Question 428

Page 52

10 CFR Part 50, Domestic Licensing of Production and Utilization Facilities

Question 456

Page 68

10 CFR 50.47, Permits - Emergency Plans

Question 16

Page 68

10 CFR 50.72, Maintenance of Records, Making of Reports

Question 15

Page 68

10 CFR 50.73, License Event Report System

Question 15

Question 122

Page 68

Page 60

10 CFR 50 Appendix A, General Design Criteria for Nuclear Power Plants

Question 14

Page 68

10 CFR 50 Appendix B, Quality Assurance Criteria for Nuclear Power Plants and Fuel Reprocessing Plants

Question 17

Question 396

Page 68

Page 64

10 CFR 50 Appendix I, Numerical Guides for Design Objectives and Limiting Conditions for Operation to Meet the Criterion "As Low as is Reasonably Achievable" for Radioactive Material in Light-WaterCooled Nuclear Power Reactor Effluents Question 20

\section{Page 68}

10 CFR 71.4, Packaging and Transportation of

Radioactive Material - Definitions

Question 227

Question 228

Question 229

Question 230

Page 51

Page 51

Page 51

Page 51

10 CFR Part 100, Reactor Site Criteria

Question 14

Page 68

Byproduct Material Licenses (Medical)

Question 7\%

Page 30

DOE Order 5480.11, Radiation Protection for

Occupational Workers

Question 76

Page 20

Question 83

Page 21

EPA PAG Manual

Question 16

Page 68

FSAR, Final Safety Analysis Report

Question 456

Page 68

Federal Guidance Report No. 11

Question 71

Page 63

HPPOS-028, "Further Guidance on Labeling

Requirements" in Health Physics Positions Data Base, NUREG/CR-5569, Rev. 1

Question 226

Page 50

NRR Generic Letter 89-01

Question 22

Page 72

NUREG-1301, Offsite Dose Calculation Manual Guidance. Standard Radiological Effluent Control for Pressurized Water Reactors

Question 80

Page 8

NUREG-1302, Offsite Dose Calculation Manual

Guidance. Standard Radiological Efnuent Control for Boiling Water Reactors

Question 80

Page 8

None

Question 87

Page 72

Question 88

Page 72

Question 89

Page 72

Other

Question 457

Page 72 
Regulatory Guide 1.16, Reporting of Operating Information, Appendix A - Technical Specification, Rev. 4 Question 397 Page 71

Regulatory Guide 8.13, Instruction Concerning Prenatal Radiation Exposure, Rev. 2 Question 59

Page 24

Regulatory Guide 8.25, Air Sampling in the Workplace Question 405 Page 69

Regulatory Guide 8.34, Monitoring Criteria and Methods to Calculate Occupational Radiation Exposure

Question 176

Question 180

Question 214

Page 17

Page 20

Page 36

Regulatory Guide 8.35, Planned Special Exposures Question 192

Page 24

Regulatory Guide 8.36, Radiation Dose to the Embryo/Fetus

Question 406

Page 69

Regulatory Guide 8.7, Rev. 1, Instructions for Recording and Reporting Occupational Exposure Data

Question 383

Question 398

Question 399

Question 400

Question 401

Question 402

Question 403

Question 404

Question 436

Question 451
Regulatory Guide 8.9, Interpretation of Bioassay Measurements

Question 375

Page 36

Regulatory Guide 10.8 Appendix X, Guidance on Complying with New Part 20 Requirements (for medical use programs)

Question 219

Page 39

Regulatory Guides

Question 12

Page 69

Question 21

Page 69

Technical Specifications

Question 18

Question 19

Question 20

Question 22

Question 52

Question 61

Question 63

Question 79

Question 397

Question 423

Question 433

Question 455

Page 70

Page 70

Page 68

Page 72

Page 70

Page 71

Page 22

Page 71

Page 71

Page 40

Page 71

Page 71

U.S. NRC Enforcement Policy

Question 3

Page 15 
NUREG/CR-6204

ORNL/TM-12690

Dist. Category AN

\title{
INTERNAL DISTRIBUTION
}

\author{
1-34. Tim Borges \\ 35. Dan Carter \\ 36. Po-Yung Lu \\ 37. R.S. Stafford \\ 38. Dan O'Connor \\ $39 . \quad$ C.E. Pugh \\ 40. ORNL Patent Office \\ 41. Central Research Library \\ 42. Document Research Section \\ 43-44. Laboratory Records Department \\ 45. Laboratory Records (RC)
}

\section{EXTERNAL DISTRIBUTION}

46-47. DOE Office of Scientific and Technical Information, P.O. Box 62, Oak Ridge, TN 37831

48. Office of Assistant Manager for Energy Research and Development, DOE-OR, P.O. Box 2001, Oak Ridge, TN 37831-6269

49-149. Given distribution as shown in category AN (NTIS-10) 

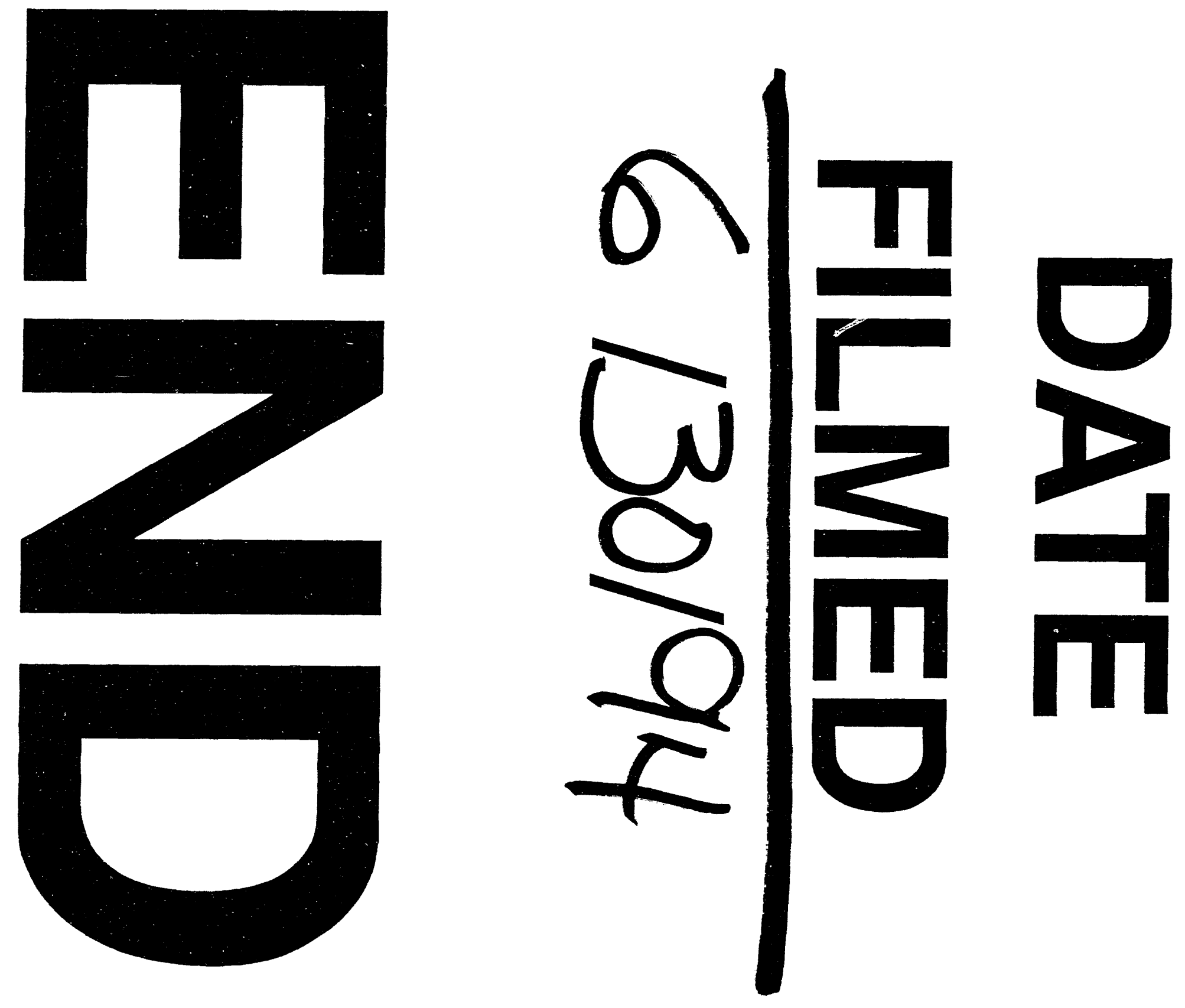
